\title{
I. IBILANDIUNGEN.
}

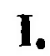

Die getraideverwaltung in der römischen kaiserzeit.

Unter den institutionen des römischen altertlıumes, die demselben specifisch eigenthümlich sind und daher ein besonderes interesse beanspruclien, nimmt die grossartige fiirsorge des stantes für den unterhalt der bevölkerung Rom's eine hervorragende stelle ein. Seit Lipsius hat dieselbe daher die aufuerksamkeit der gelehrten in hohem maasse auf sich gezogen und wir besitzen zahlreiche und scharfsinnige forschungen über diese materie ${ }^{1}$ ); weniger beachtung hat bis jetzt die art ihrer verwaltung gefunden, der hauptsächlich unsere untersuchung gewidmet sein soll. Wenn dieselbe auch im

1) Lipsitts Electa I, cap. 8 und-admiranda II, cap. 10: Contareni de frumentaria Romanorum largitione. Venetiis $1609 ;$ ich citire nach dieser ausgabe: Schaghen de re frumentaria. Traiecti ad Rhenum 1709: Burmann de vectigalibus cap. 2-3: Mazocchi comment. ad tabulas Heracleenses p. 306-323: B e seke de frumentaria largitione. Mitaviae 1775, eine schlechte compilation aus Contareni und den commentarien des Gothofredus: Dirksen civilistische abhandlungen II, p. 163-201: Naudet des secours publics chez les Romains in den Memoires de l'Acad. des inser. et belles lettres 1838 p. $12-23$ und p. 42-66: Mommsen Tribus p. 177-201: Kuhn über die korneinfuhr in Rom in der Zeitschrift für alterthumsw. 1845 n. 125-126 und n. 135136: Nasse meletemata de publica cura annonae apud Romanos. Bonnae 1851: Rein in Pauly's R. E. b. I, p. 1031 ff.: Marquardt handbuch III', p. 88-108. - Im grösseren zusammenhange handeln darüber: Hoeck röm. gesch. $I^{2}$, p. 1031 ff.: Walter röm. rechtsgesch. I, p. $355 \mathrm{ff}$. (2te aufl.). Für die spätere zeit des römischen kaiserreiches hat Gothofredus in seinem commentar zum Cod. Theodosianus ein ausserordentlich reiches material gesammelt.

Philologus. XXIX. bd. 1 . 
wesentlichen erst durch Augustus und seine nachfolger ilıre feste organisation erlaalten hat, so steht sie doch mit den einrichtungen der republikanisclıen zeit in so engem zusammenlıange, dass es nöthig erscheint, einen kurzen abriss der geschichte der Annona und der Frumentationes vorauszuschicken, um so melır, als mannigfache his jetzt unerledigte fragen zu einer noclımaligen prüfung auffordern.

Schon seit den ersten zeiten der römischen republik war das bestreben des staates darauf gerichtet dem volke billiges und zum unterlalte linreichendes getraide $d$. l. weizen, denn dieser bildete das hauptnalırungsmittel der Römer, zu versclıaffen. Den bedarf brachite in der regel der römische ackerbau auf und nur ausnahmsweise wurden aufkaufe in Italien und Sicilien nötlig; grössere dimensionen nalım dieser bedarf erst nach dem zweiten punischen kriege an, hauptsächlich in folge des zusiummenströmens des italischen proletariates nach Rom, das durch die abnahme des ackerhaues in Italien ausser nahrung gesetzt war. Herrorgerufen war dieselbe vorzüglich durch den import von getraide aus den fruclitbaren, erst seit kurzem den Römern unterworfenen provinzen Sicilien und Sardinien, mit denen der italische boden die concurrenz nicht aushalten konnte (vgl. Monmsen R. G. I, p. 849 ff.). Diesem besitzlosen pöbel war mit der aufrechterhaltung massiger kornpreise, die übrigens weder in der späteren zeit der republik, noch in der kaiserzeit besonders niedrig waren (Marquardt RA. III, 2, p. $90 \mathrm{anm}$. 424), wenig gedient, denn es fehlten ilım die mittel denselben zu bezalılen. Schon in frülıer zeit hatten daher die ädilen zuweilen auf eigene oder nuf rechnung des stantes getraide an das volk zu einem sehr niedrigen preise vertheilt (vrgl. Marquardt RA. V, 2 p. 5 -6); ähnliche volksfreundliche masssegeln fülirte die sage sogar auf den könig Servius Tullius zurück (Mommsen Clıronograph p. 645, 24 und p. 650 anm. 19, Aur. Victor de viris illustr. c. 7). Berühmt ist die getraidevertheilung des Sp. Maelius in der lungersnoth vom j. 314-315, die ilm verderblich wurde; aber sein beispiel hatte gezeigt, wie grosser eiufluss durch solche freigebigkeit auf das hungernde volk zu gewinnen war. Das erkannte in vollem masse melır als dreihundert jahre später der grösste demagog,' den Rom je besessen hat, C. Gracchus, und zu den ersten populären gesetzen, die er einbrachte, gelıörte eine Lox frumentaria, nach der dem römischen volke monatlich, wahrscheinlich fünf modii für jeden 
biirger, der modius zu $6^{\frac{1}{3}}$ as, zugemessen werden sollte, während der durchsclinittspreis etwa das doppelte betrug ${ }^{2}$ ). Durclı dieses gesetz wurden die regelmässigen getraidespenden (frumentationes) eingefülırt, die sich, zum theil in veränderter form, his in die spätesten zeiten des römischen reiches erhalten hahen. Es folgten in dem bewegten letzten jalırhundert der römischen republik eine reihe von gesetzen, theils in demselben, theils im entgegengesetzten sinne, bis endlich, nachdem die frumentationen von Sulla, freilich nur für kurze zeit, aufgehoben waren, Clodius im j. $696=58$ ein gesetz durchbraclite, dass das getraide dem volke ganz umsonst vertlueilt werden sollte ${ }^{3}$ ). Pompeius, ,dem im j. $697=57$ durch die Lex Cornelia Caecilia die cura amonac übertragen wurde, wollte ein verzeiclıniss der neubïrger mit rïcksicht auf die getraidevertheilungen anlegen, scheint jedoch diese absicht nicht ausgefülırt zu haben (Dio 39, 24, 1). Wie gross die zahl der empfänger damals war, wissen wir nicht; aus einer angabe bei Cicero (Verr. III, 30, 72) haben Contareni (a. o. c. 7, p. 59) und nach ilim Kuhn (a. o. p. 1003) dieselbe für jene zeit, d. h. nach der Lex Terentia Cassia $(681=73)$ auf 60,000 veranschlagt; Marquardt a. o. p. 94 anm. 449 hält diese zahl mit vollem rechte für zu niedrig gegriffen. Sicher ist, dass im jahr $708=46$ Caesār 320,000 empfanger vorfand und diese zahl, da sowohl die last für die staatskasse zu drückend war, als auch die ansammlung des pöbels in Rom, der durch die frumentationen herbeigelockt wurde, ihm gefälırliclı scheinen mochte, auf 150,000 reducirte, indem er durch einen vicatim gehaltenen recensus - die niclitberechtigten ausschloss $\therefore$

2) Nicht zu $8 / 8$ as, wie Mommsen a. o. 179 a. 4 nachgewiesen hat, der überhaupt zum ersten male den zusammenhang der Leges frumencariae richtig erkannt und gewürdigt hat.

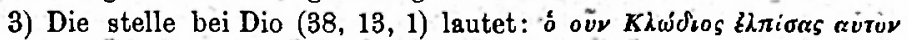

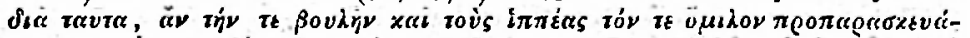

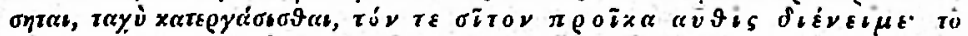

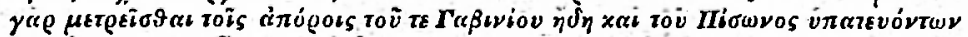

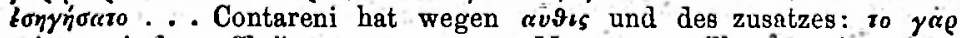
$x \pi \lambda$. zwei leges Clodiae angenommen; Mommsen will aivis in avtixa ändern, Nasse hält die ganze stelle für corrupt. Auch ich bin der ansicht, dass cevษ vs verdorben ist; schreibt man dafür mit einer ganz kleinen änderung $\alpha$ vं o is, so ist die stelle leicht zu erklären. Clodius

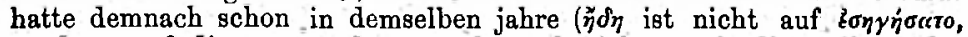
sondern auf die namen der consuln zu beziehen, wie die stellung des wortes zeigt) beantragt, dass die armen das getraide umsonst erhalten sollten, jetzt führte er diese volksfreundliche masssregel wirklich aus. 
und 80000 römische bürger in überseeische kolonieen vertlıeilte: vgl. Mommsen p. 188 ff. Nasse p. 21 ff. Zugle ich fiugte er die wichtige bestimmung hinzu, Sueton. Cacsar c. 41: ac ne qui novi coctus recensionis causa moveri quandoque possent, instituit, quotainis in demortuorum locum ex eis, qui recensi non essent, subsortitio a practore fieret $\left.{ }^{4}\right)$. Es sollte demnach diese zahl von 150,000 empfängern für die folgezeit unverändert bleiben und nur die vacanten stellen neu besetzt werden. Die biirgerkriege nach Casar's tode verlinderten die ausfülırung dieser maassregel; die zall der getraideempfanger war in diesen unruhigen zeiten allmïhlich wieder so gestiegen, dass Augustus im j. 752 sich genöthigt sab, nach dem beispiele Cäsar's einen recensus populi vicutim abzuhalten (Sueton. August. c. 40) und dabei, wie Dio 55, 10, 1 sagt: $\delta \delta$

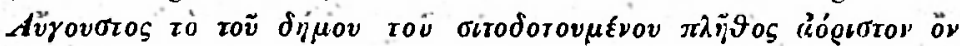

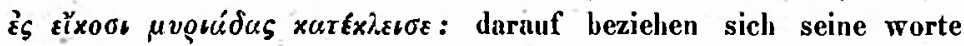
im Monum. Ancyranum III, z. 20-21: consul tertium decimum scxagenos denarios plebei, quae tum frumentum publicum accipiebat, dedi, ea millia hominum paulo plura quam ducenta fuernot ${ }^{5}$ ). Ob Augustus, wie Cäsar, die bestimmung traf', dass diese zalhl niclit vergrössert werden solle und nur vacante platze wieder zu besetzen seien, wissen wir nicht: jedenfalls muss dies zu Trajans zeit sitte gewesen sein: vgl. Plin. Paneg. c. 25: dutum est iis qui post edictum tuum in locum erasorum subditi fuerant. Unter Septimius Severus nalmen 160,000 römische bürger und 40,000 prätorianer an den frumentationen theil: Dio epit. 76, 1, 1: vgl. Mommsen Tribus p. 182.

4) Deber die bestimmungen in der Lex Iulia municipalis vgl. den anhang.

5) In den vorhergehenden zeilen (III, 7-16) zählt Augustus die von ihm vertheilten congiarien auf: die fünf ersten erhielt die plebs lomana $=250,000$ menschen; das sechste die plebs urbana - 320,000 menschen; dazu bemerkt Mommsen (R. g. d. A. p. 37): datae sunt liberalilates sex primae plebi Romanae sive urbanae, guod idem esl und p. 38: etiam plebem frumentariam ab urbana Romanave patet minime differre. Dass Augustus in diesem officiellen documente ohne grund in den ausdrücken variirt haben sollte, ist mir nicht wahrscheinlich, wenn ich auch kein gewicht darauf lege, dass der griechische übersetzer plebs $\boldsymbol{R}_{0}$ -

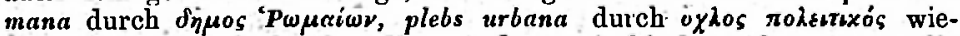
dergegeben hat (vgl. über die art der griechischen übersetzung die vorrede von Mommsen p. 27): gewiss wollte Augustus bezeichnen, dass bei dem sechsten congiarium, das übrigens kleiner als die vorhergehenden war, auch viele, die nicht das volle römische bürgerrecht besassen, mit oder ohne scine absicht: participirten. 
Sıreton berichtet Aug. c. 42: magna vero quondam sterilitate ac difficili remedio, cum venalicias et lanistarum familias peregrinosque omnes, exceptis medicis et praeceptoribus, partimque servitiorum "trbe expulisset; ut tandem annona convaluit, impetum se cepisse scribit frumentationes publicas in perpeturm abolendi, quod carum fiducia cultura agrorum cessaret: neque tamen perscverasse, quia certum haberet post se per ambitionem quandorue restitai. Gremeint ist die hungersnoth vom j. 759 , wie deutlich hervorgeht aus dem berichte des Dio. 55, 20, 1 ; in demselben jalıre stiftete Augustus das Aerariam mililare zur versorgung der veteranen: bedenkt man nun, wie eifrig bemüht er war, für diese neue kasse hinreichende einnahmequellen zu schaffen, so liegt schon an und für sich der gedanke nahe, dass er die absicht gehabt, die fonds, welche durch abschaffung der frumentationen disponibel wurden, für das Aerarium militare zu verwenden. Fast zur gewisslıeit wird das jedoch für mich durch den rath, der bei PseudoSallust. de rep. ord. I, 8, 6 dem Cäsar ertheilt wird: et frumentum id, quod antea praemium ignaviae fuit, per muicipia et colonias illis dare conveniet, qui stipendiis emeritis domos reverterint. Alle die vorschlage in diesen-suasorien beziehen sich,-wie H. Jordan (de suasor. ad Caes. senem de RP. inscr.) nachgewiesen hat auf wirklich ausgeführte, oder projectirte reformen, daher ist es mir sehr wahrscheinlich, dass wir in den angeführten worten eine anspielung auf die von Augustus beabsichtigte aufhebung der frumentationen und die verwendung dieser gelder für die veteranen zu erkennen haben; darnach müsste dann freilich dieses rhetorische machwerk nicht, wie Jordan annimmt, in das ende, sondern in den anfing des ersten jahrhunderts fallen, wofür mir auch andere gründe zu sprechen scheinen. - Von verfügungen späterer kaiser bezüglich der frumentationen. erfaliren wir wenig. Von Nero be-

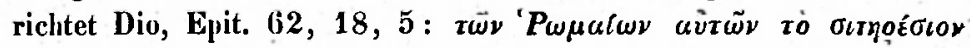
$\pi u \rho \varepsilon \sigma \pi \varkappa ́ \sigma \alpha r o$, jedenfalls nur auf, kurze zeit; den prätoriauern gab er umsonst monatliclı getraide: Sueton. Ner. c. 10. Tacit. Ann. 15, 72. Dass Titus sich um die frumentationen verdient gemacht, bezeugt die inschrift bei Mommsen I. N. 6786: Imp. T. Caesari Divi f. Vespasiano Aug. pleps urbana quae frumentum publioum accipit et tribus .. . Die münzen Nerra's: plebei urbanae frumento constituto (Eckhel DN. II, p. 406 f.) deuten wahrschein- 
lich, wie Mommseu (Tribus p. 193) annimmt, auf eine zeitweilige aufhelung derselben durch Nerva selbst in anfange seiner regierung. Ueber die pueri und puellae alimentariae, so wie über die veränderungen, welche die frumentatiouen- im dritten jahrhundert erfuhren, werden wir später sprechen.

Wer istzudengetraidevertlueilungen als empfänger berechtigt? Das erste notlwendige postulat war seit beginn der frumentationen der besitz des vollen römisclıen bürgerrechtes 6): es war dies um so natürlicher als die Leges frumentariae wesentlich politische zwecke hattên, nämliclí die suffragia des volkes zu gewinnen, dalıer auch nur die stimmbereclitigten bürger berücksichtigen konnten. Diese waren aber in der republikanischen zeit olıne ausnahme zum empfange bereclitigt, wie das bekannte beispiel des Piso Frugi bei Cicero, 'T'usc. III, 20,48 , beweist ${ }^{7}$ ); dass factisch nur die ärmeren von diesem vorreclit gebrauch gemacht liaben, liegt in der natur der sache. Cäsar war der erste, der die zalıl der empfanger gesetzlich fixirte; in die listen, die er aufstellte, wurden vielleiclit nur die wirklich bedürftigen (Mommsen R. G. 3, p. 491), gewiss niclit ritter und senatoren aufgenommen; ob jedoch eine gesetzliche ausschliessung dieser stände stattgefunden lat, ist selır fraglichı ${ }^{8}$ ).

6) Vgl. die beweisstellen bei Mommsen Tribus p. $187 \mathrm{f}$; auch die Vigiles erhalten in der späteren kaiserzeit nach dreijährigem dienste zugleich das ius Quiritium und frumentum publicum: vgl. Mommsen im Bull. d. J. 1845, p. 193 ff. Dasselbe gilt natürlich für die congiarien: vgl. Dositheus Adriani sententiae n. 14 (bei Schulting iurispr. Anteiust. p. 873); auch den panis gradilis erbalten nur arme bürger: s. Gothofr. zu Cod. Th. 14, 17.

7) Ganz verkehrt ist die ansicht von Naudet a. o. p. $20:$, la famille des Pisons elait pleteienne: c'etait sur ce titre sans doute, "que se fondait le droit, dont le consulaire " aurait pas plus fait usage" ete.

8) Mommsen schliesst dies aus der stelle des Scaevola in den Digg. 32 1. 35 pr.: patronus liberto statim tribum emi petieral; libertus diu moram ab herede patroni passus est et decedens heredem reliquit cla rissi mum virum; quasitum est, an tribus a estimatio heredi eius debeatur. Respondit deberi. Idemquaesiit, an et commoda, et principales liberalitates, quas libertus ex eadem tribu usque in diem mortis suae consecuturus fuisset, si ei ea tribus secundum ooluntatem putroni sui tune comparata esset, an veso ustrae aestimationis heredi eius debeantur. Respondi, quidquid ipse conseculurus esset, id ad heredem sutm transmittere. Vorausgesetzt wird dabei, dass tribum emere und tesseram emere ganz identisch sei, was ich besonders für die zeit des Scaevola (M. Aurel) noch kcineswegs für erwiesen halte: dass ferner betont wird, der erbe sei senatorischen standes, zeigt allerdings, dass senatoren an den kaiserlichen geschenken nicht zu participiren pflegten, doch konnte in diesem falle uberhaupt nur auf eine aestimatio, nicht auf einen kauf der tribus 
Dasselbe gilt von. der reform des Augustus und es ist chitracteristisch, dass nicht von vornherein eine runde zahl der getraideempfanger festgesetzt wurde, sondern, wie er selbst angielit (Monum. Aucyr. III, v. 21): ea milia hominum paulo plura quam ducentu fuerunt ${ }^{9}$ ). Auch die freigelassenen, die volles römisches bürgerrecht erbalten hatten, waren zu den frumentationen berechtigt: schon für die zeit des Pompeius wird dies von Dio $(39,24,1)$ ausdrücklich bezeugt; auch Cäsar und Augustus haben darin nichts geändert (Dionys. Hal. AR. 4, 24. Philon. Leg. ad Caium 2. 23); darauf gehen die bekannten worte des Persius Sat. 5, 73:

libertate opus est: non hac, ut, quisque Velina

Publius emequit, scabiosum tesserula far ${ }^{10}$ )

possidet,

die gewiss nicbt mit Mommsen (a. o, p. 185) auf die honesta missio der soldaten zu beziehen sind, wie das folgende deutlich zeigt:

heu steriles veri, quibus una Quiritem vertigo facit,

wozu vgl. 0. Jalın p. 193.

Die zweite bedingung, um zu den frumentationen zugelassen zu werden, war die ansässigkeit in Rom; dass diese gefordert wurde, lig in der natur der ganzen institution und die worte des

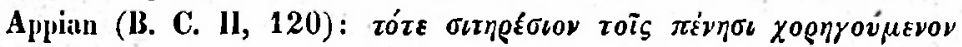

angetragen werden, ganz analog dem usus bei den tesserae: vgl. Digg. 31, 49, §. 1: si Titio frumentaria tessera legata sit, et is decesserit, quidum pulant, extingui legalum, sed hoc non est vernm, nam cui lessera vel militia legatur, aestimatio ridetur legata. Vgl. Digg. $31,87 \mathrm{pr}$.

9) Die angabe des Dio $(55,10,1)$ : to tov Śjuov toũ ouzodorov-

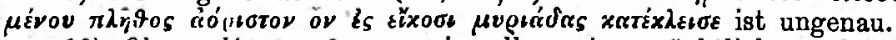

10) Ob seabiosum far nur in allgemein verächtlichem sinne gesagt ist (vgl. Juven. 7, 174: vilis frumenti tessera) oder wie die scholien erklären: corruptum et pulre frumentum, ist zweifelhaft. Wahrscheinlich ist jedoch darin eine anspielung auf gleichzeitige verhältnisse $\mathrm{zu}$ erkennen, wie solche bei Persius sich nicht selten finden (vgl. Lehmann im Philologus VI, p. 431-445 und in der Zeitschr. f. alterthwiss. 1852. h. 3, n. 25 f.); Persius starb am 24. november des jahres 62 nach Chr.; zu demselben jahre berichtet aber Tacitus A. 15, 18: Nero frumentum plebis vetustate corruptum in Tiberim iecit; dass die fünfte satire wenigstens zum theil in die letzte zeit von Persius' leben fallt. ist auch aus anderen gründen wahrscheinlich (Lelimaun de $A$. Persii Flacci satira quinta. Greifswald. Pr. 1855). Uebrigens scheint dieses getraide auch in späterer zeit öfters verdorben gewesen zu seiu, wurde aber nicht immer in den Tiber geworfen: vgl. die bestimmung im Cod. Th. 11, 14, 1 . 


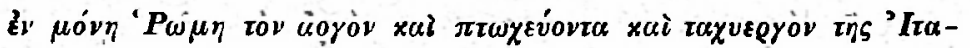

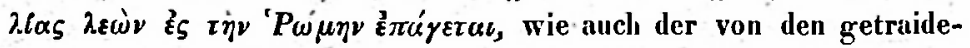
empfängern öfters gebrauchte ausdruck: plebs urbana (vgl. Mómmsen a. o. p. 184) bestätigen dies.

Von anderen postulaten ist nirgends die rede; vor allem lag die rücksiclit auf die moralische berecbtigung der empfänger und iliren lebenswandel, die in moderner zeit in erster reilıe stelit, den Römern ganz fern, wie Seneca, Benef. IV, 28, 2, dies entschieden hervorhebt: rex houores dignis dat, congiarium et indignis: frumentum publicum tam fur quam periurus et adulter accipiunt oi sine delectu morum quisquis incisus est. quicquid alind est, quod tamquam civi, non tamguam bono datur, ex aequo boni ac mali ferunt. Es bleibt hier noch die frage zu erledigen, ob und seit welcher zeit kinder an den frumentationen theilgenommen haben: Marquardt a. o. p. 98 f. meint, dass "nicht die armen allein, sondern die in den listen der tribus verzeichneten sämmtlichen bürger, in der ka iserzeit auch di e unmündigen knaben unter der zahl der empfangsberechtigten zu verstelien sei"; Nasse a. o. p. 24 delint das sogar mit rücksicht auf die Lex Inlia municipalis (s. den anhang) auf die mädchen aus; Mommsen (a. o. p. 193 a. 46) besclıränkt dies auf die waisenkinder. Erinnert man sich des politischen ursprunges der frumentationen, so wird man die zulassung von kindern, die kein stimmreclit besassen, schon an und für sich für nicht sehr walırscheinlich halten; es müsste denn eine neuerung des Cäsar oder des Augustus sein, von der aber in den uns erlacltenen-berichten keine spur sich findet, vielmehr wird immer nur die besclıränkung der zahl, niclıt die zulassung neuer getraideempfänger darin betont; ferner ist es scliwer glaublich, dass ein waisenkind (denn von hauskindern kann gewiss nicht die rede sein vgl. Mommsen a. o.) ebensoviel erhalten haben sollte, als ein familienvater; die in den listen stelienden getraideempfanger sclıeinen aber alle gleiche portionen bekommen zu liaben ${ }^{11}$ ). Diese ganze

11) Anders war dies, wenigstens zuweilen, bei den congiarien, wie Mommsen a. o. p. 193 hervorgehoben hat: er glaubt, dass das ius irium liberorum hier besonders berücksichtigt worden sei und fülırt als beleg den bericht des Dio $(60,25,7)$ über ein congiarium des Claudius

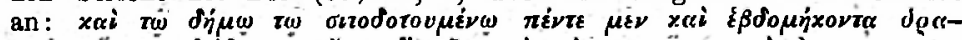

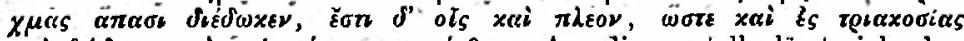

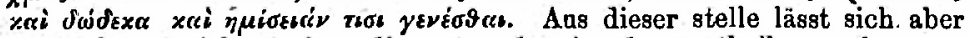
zugleich, wie ich glaube, die art und weise der vertheilung erkennen; 
amalıme stïtzt sich nun im wesentliclıen nur auf eine notiz bei Sueton. Octav. 41: ac ne minores quidem pucros praeterivit, quamvis non nisi ab undecimo aetatis anmo accipere consuessent, vgl.

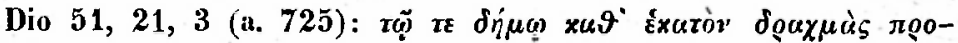

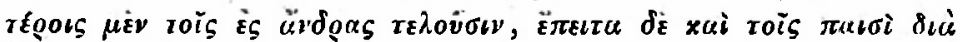

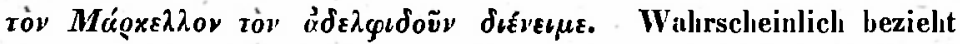
sich die allgemein gehaltene angabe des Sueton auf diesen bestimmten fall, wo eine besondere veranlassung, die kinder zu besclienken, vorlag; aus der art, wie Dio darüber bericlitet, dass zuerst die manner, dann die knaben (von mädchen ist gar nicht die rede und aucl in der späteren kaiserzeit sclıeinen frauen von den congiarien ausgeschlossen gewesen zu sein, vgl. Dositheus Adriani sententiac u. 14) besclıenkt wurden, gelit hervor, dass dies uiberlıupt eine ausnahıne war. Aber es scheint mir überhaupt nicht riclitig, aus der sitte (consuessent), bei congiarien knaben vom eilften jalıre an zu bedenken, olıne weiteres zu schliessen, dass dieselben deslıalb auch in den listen der getraideempfanger stelıen mussten; denn wenn auch Mommseu (a. o. p. 195) überzeugend nacligewiesen lat, dass die congiarien "nur ausserordentliche zulagen zu den getraidevertheilungen waren", so ist das doch nur so zu verstehen, dass die getraideempfanger in erster linie und notlıwendig die congiarien erlielten, dass es aber im belieben der kaiser stand, auch andere, besonders kinder dabei zu bedenken: dafür spreclien die eben angeführten worte des Sueton und Dio und noch melır die schilderung eines solchen congiarium, die Plinins in seinem Panegyricus (c. 26) giebt. Es kann daher immerlin zugegeben werden, dass bei den congiarien iu der regel die knaben, und zwar alle, nicht nur waisenknaben (pueri, wieSueton a. o. sigt, niclıt pupilli) vom eilften jahre ab beriicksiclitigt wurden, ohne dass man deshalb berechtigt ist, ilıre aufnalıme unter die getraideempfanger vorauszusetzen und es giebt, ausser den angefuilırten stellen, meines wissens kein einziges zeugniss aus dem ersten jalırlıudert, dis zu einer solclien annalime

die minimalsumme ist 300 sesterzen, einige (oder vielleicht nur einer, denn das tuvis ist wohl nicht so genau zu nehmen) bekommen 1250 sesterzen, also nicht etwa das vierfache, sondern 950 sesterzen mehr. Dies ist sicher nur so zu erklären, dass dem empfanger für jedes kind 50 sesterzen extra gezahlt wurden und dass in diesem falle, den Dio als maximum hervorhebt, der betrefiende.mit 19 kindern gesegnet war und daher 950 scsterzen ausser den normalen 300 erhielt. 
nothigt. Trajan war der erste, der hierin eine bedeutungsvolle ändernng traf: er sorgte im anschlusse an das von Nerva begründete grossartige alimentationssystem bedürftiger freigeborner kinder in Italien, ebenfalls für den unterhalt der kinder in Rom. Ueber diese einrichtungen Trajan's und seiner nachfolger hat Henzen ausführlich gehandelt in Tabula alim. Baeb. p. 19-24 (Ann. d. 1. bd. XVI); wir heben daher hier nur einige für uns wichtige punkte hervor:

1) Trajan scheint nach dem ausführlichen berichte des Plinius (Paueg. c. 26-28) nur knaben, nicht mädcheu zu dieser perceptıo frumentaria in Rom zugelassen zu haben: s. besonders c. 28: hi subsidium bellorum, ornamentum pacis publicis sumptibus aluntur .... ex his castra, ex his tribus replebuntur ${ }^{12}$ ). Dagegen würde nicht die erwähnung der pueri puellaeque Ulpiani in einer inschrift aus Ameria (Gruter 1084, $7=$ Murat. 230, 5) sprechen, selbst wenn sie nicht, wie Monmsen (Ber. d. s. G. d. W. 1849, p. 270) annimmt, gefalscht, sein -sollte, da dieselbe sich auf alimentationen in Italien; wo von anfang an, wie die worte des Aurelius Victor (epit. c. 12, 2. 4) und die erhaltenen urkunden zeigen, auch die mädcheu berücksichtigt wurden, bezieht, ebenso wie nach meiner ansicht die notiz in der V. Hadrian. 'c. 7 : pueris ac pucllis, quibus etiam Traianus alimenta detulerat, incremenlum liberalitatis adiecit. Erst Antoninus Pius (vit. c. 8): puellas alimentarias in honorem Faustinac Faustinianas constituit (vgl. die münze bei Eckhel VII, 40), und Marc Aurel folgte seinem beispiele und setzte pueros et puellas novorum nominum (vit. c. 7) und novas puellas Fauslinianas in honorem uxoris mortuce (vit. c. 26) ein ${ }^{13}$ ); die verheissung

12) Auch Henzen a. o. p. 24 ist dieser ansicht: „cum vero ita Romae alimenta instituta essent, ut frumentariae plebi i. e. tribubus qui ea accipiebant, adscripti cssent, puellis inter eos locum non fuisse dixerim; der von ihm angegebene grund ist jedoch, wie wir sehen werden, unrichtig und dasselbe bedenken hätte ja dann auch die späteren kaiser von der alimentirung der mädchen abhalten müssen.

13) Hierauf bezieht sich die inschrift bei Orelli $3365: d . m$. Sextiae Saturninae C. Sexti Daphni et Sextiaes Saturninae fil. q. vix. an. VI. m. VII. dieb, XIIII. ing. fr. publ. dio. Faust. iunior; jedoch ist die lesart ing. nur eine nachlässigkeit Muratori's, da sowohl Ligorio, von dem er abhängt, als zwei andere bandschriften (Torrent. Brux. 4347 f. 7 und Manut. Vat. 5253 f. 359) dafür inc. lesen d. h. incisae (nicht ingenuae, wie Henzen a. o. p. 24 erklärt) frumento publico Divae Faustinae innioris. Ich verdanko diese notiz, wie viele andere, meinem freunde Eugen Bormaun in Rom, der meine fragen betreffs. der 
des Macrinus in bezug auf Diadumenianus (vit. c. 2): incideret praeterea et pueros Antoninianos et puellas Antoninianas ist wohl schwerlich zur ausfïhrung gekommen; Alexander Severus endlich (vit. c. 57): puellas et pueros quemadmodum Antoninus Faustinianas instituerat, Mammaeanas et Mammaeanos instituit. - 2) Ein nothwendiges postulat scheint die ingennität gewesen zu sein: Plin. Paneg. c. 28: paulo minus, patres conscripti, quingue milia ingenuorum fucrunt .... : vgl. Murat. 1161, 11 : incisus ingenuusque; auch in Italien scheinen freigelassene von den alimentationen ausgeschlossen gewesen zu sein, vgl. Henzen a. o. p. 32. - 3) Wie die übrigen getraideempfänger wurden auch diese kinder in listen eingetragen: dafür ist incidere der technische ausdruck: vgl. Plin. Paneg. c. 26 : omnes .... recipi incidi iussisti, und Vit. Diadumen. c. 2, s. ob., und darauf gelit die von Henzen (Bull. d. I. 1859, p. 232) ohne zweifel richtig erklärte iuschrift: M Bacbius Asclepiades Iustinus qui vixit annis IIII mens. III. dieb. XIIII trib. Offentina e collegio aeniatorum frumento publico, wozu Henzen (p. 233) bemerkt: ,siccome da Plinio conosciamo che anche i fanciulli donati della percesione delle pubbliche largizioni si incidevano, cosi non saro forse troppo ardilo, se a questi suppongo essersi dato il nome di aeneati frumenlo publico. Nuovo, ì vero, sarebbe in tal caso puranche il nome di collegio dato a quel numero di benificati .... v vgl. Henzen 6662: frumentum [publ]icum et aeneatorum. Jedoch kann ich Henzens behauptung in Tab. alim. p. 22: nihil aliud imperatori agendum erat, nisi ut tabulis corum, qui frumentum publicum gratis accipiebant, puerorum nomina incidi iuberel ss nicht beipflichten; vielmelir ist es mir unzweifelhaft, dass für diese kinder besondere listen geführt wurden. Es sprechen für solche absondernng eine reihe gewichtiger gründe, so schon der name Funstinianae, novae Faustinianae, Mammaeanae, der ausdruck incisa frumento pu-

überlieferung und der ächtheit mehrerer in dieser abhandlung benutzten inschriften, soweit dieselben sich aus den scheden für das Corp. IL. feststellen liess, in bereitwilligster und gründlichster weise beantwortet bat. Ich kann übrigens auch diese gelegenheit nicht vorübergehen lassen, ohne den herren $\mathrm{Nommsen}$, Henzen und Huebner für dic liberalität zu danken, mit der sie mir in Berlin und Rom die unbeschränkte benutzung der grossartigen vorarbeiten für das Corpus IL. gestattet haben; nur auf diese weise war es vor der vollendung des Corpus insor, möglich, ein gesichertes und vollständiges epigraphisches material für dieso und andere untersuchungen zu gewinnen. 
blico Divae Faustinae innioris, und vor allem die collegieubildung dieser aeneati frumento publico; ausserdem wird ausdrücklich bezeugt (Henzen 6663), dass dieselben an verschiedenen tagen im monate ilır getraide erhielten ${ }^{14}$ ), wälırend die grossen frumentationen nur an einem einzigen tage stattfanden (s. unten); ferner war zu Trajan's zeit noch, wie wir gesehen haben, die liste der empfanger geschlossen und nur bei racanzen traten neue empfänger ein (subditi in locum erasomim) und schliesslich ist es nicht wahrscheinlich, dass diese kinder so viel erhalten haben sollten als die übrigen getraideempfänger, um so melrr als auch bei den alimentationen in Italien knaben vor den mädchen bevorzugt waren (Henzen a. o. p. 29); wir laben- aber schon oben darauf aufinerksam gemacht, dass bei den frumentationeu derartige unterschiede nicht stattgefunden zu haben scheinen: alle diese thatsachen zwingen zu der annahme, dass neben den grossen listen für die plebs frumentaria noch besondere für die pueri et puellae alimentarii in Rom geführt worden sind; dass sie aber auch wahrscheinlich an eiuem verschiedenen orte und von anderen beamten das getraide empfingen, werden wir später zu erweisen suchen. - 4) Wenn schliesslich Henzen a. o. p. 22 behauptet: „ qui incisus crat, simul tribui cnidam adscriptus esse debebat und dafür anfülırt die inschrift (Henzen 6662): reluqui tri[bu]m ingenuam frumentum [publ]icum et aeneatorum ${ }^{15}$ ), so kann ich das für die zeit 'Trajan's nicht gelten lassen (die kinderinschriften fallen sclıwerlich vor das ende des zweiten jahrhunderts), da Plinius (Paneg. 28) sonst nicht hätte sagen können: ex his castra, ex his tribus replebuntur; überhaupt ist es meines wissens noch nicht erwiesen, dass so lange die tribus noch einige corporative bedeutung hatten, kleine kinder darin aufgenommen worden sind.

Die art dervertheilung bei den frumentationen. Es ist jetzt woll allgemein anerkannt, dass das vertheilte getraide seit Clodius und in der ganzen kaiserzeit dem volke gratis gege-

14) Dasselbe gilt von den Vigiles, vgl. Kellermann Vigil. p. 29 n. 12.

15) Vgl. auch die oben angeführte inschrift; trib. Offentina e collegio aeniatorum frumento publico; dass übrigens bei Henzen 6662 unter frumentum publicum et aeneatorum nicht zwei verschiedene dinge zu verstehen sind, sondern et durch, ,und $\mathrm{zwar}$ " zu übersetzen ist, scheint mir nach der von Henzen gegebenen erklärung der Aeneati sicher. 
ben wurde ${ }^{16}$ ); es spricht dafür, ausser. anderen gründen, die Kuln p. 1079. Nasse p. 25 f. Marquardt a. o. p. 103 angeben, besonders die notiz bei Tacit. A. 15, 72: quibus perpetratis Nero et contione militum habita bina nummum milia viritim manipalaribus divisit addiditque sine pretio frumentum, quo ante ex modo annonae utebantur, vgl. Sueton. Nero c. 10 : constituit item praetorianis cohortibus fir umentum menstruum gratuitum; sie erlielten demnach seit Nero das getraide umsonst und zwar monatlich: da nun aber auch die frumeutationeu monatlich waren, da ferner Septimius Severus (Dio 76, 1) dasselbe congiarium den getraideempfängern und den prätorianern giebt, (nach anderen beispielen würde man eine grosse bevorzugung der letzteren erwarten), da endlich dieselben stets in oder bei Rom stationirt waren, so kann kein zweifel sein, dass sie von Nero in die listen der gètraideempfänger eingetragen wurden, dass also das frumentum menstrum gratuitum auch unf die plebs frumenturia zu beziehen ist. Diese stelle, wenn sie auch an und für sich nicht entscheidend ist, passt selır wohl zu den übrigen nachrichten, wo nur sorgfaltig der unterschied zwischen den frumentutiones und der cura amnonue zu beachten ist; die worte Iuvenal's, VII, 174 summula ne pereat qui vilis tessera venit Frumenti deuten nur daranf hin, dass schon dimals es erlaubt und gebräuchlich war, die tessera frumentaria fiir einzelne frumentationen an nichtberechtigte zu verkaufen ${ }^{17}$ ). Bezüglich der art und weise der vertheilung hat Momusen (Tribus p. 194) naclizuweisen gesucht, dass dieselbe nach den tribus geschah, ilım liaben Nasse p. 27. Marquardt a. o. p. 105 beigestimmt: hauptsächlich folgert or das aus dem usus bei den congiarien. Nun lässt sich allerdings nicht leugnen, dass geldgeschenke der kaiser zuweilen den curatores tribuum zur vertheilung übermacht

16) Auch Mommsen, der früher (Tribus p. 186) einen billigen verkauf des getraides annahm, scheint jetzt dieser ansicht zu sein, wenigstens fasst er in den R. g. D. A. p. 50 die tesserae uummariae (Sueton. Ang. c. 41), abweichend von seiner früheren ansicht, einfach als tesserce frumentaviae, ebenso wie Nasse p. 29; irrig hält Marquardt (a. o. p. $105 \mathrm{anm}$. 504) dieselben für ,bezahlte tesserne, gegen welche man das getraide in empfang nahm, welches man kaufte".

17) Die gewōhnlichen rhetoren, von denen hier die rede ist, waren meist peregrinen und nicht im besitz des vollen bürgerrechtes, daher auch nicht zu den frumentationen berechtigt; dieser umstand scheint mir für die erklärung dieser stelle beachtenswerth. 
wurden, vgl, die von Mommsen citirten stellen: Appian. B. C. 3, 23 und Julian. orat. 3 encomium imperatricis Eusebiae; dass dies regelmässig bei den congiarien geschehen sei, muss ich bestreiteu. Von dem testamente des Augustus bericltet Sueton, Aug. c. 101: legavit populo R. quadringenties $t r i b u b u s$ tricies quinquies sestertium, practorianis militibus singula milia nummortm, cohortibus urbanis quingenos, legionaris trecenos nummos. Tacitus (A. I, 8) sagt von demselben legate: legata non ultra civilem modum nisi guod populo et plebi quadringenties tricies quintuies.... Mommsen a. o., wie auch Nipperdey im commentar beziehen dieses legat an den populus auf eine zalılung an das aerarium, obgleich Mommsen selbst annimmt, dass Tiber, da nach Dio's bericht (57, 14, 2) jeder bïrger etwa 65 denare erhielt, schliesslich die ganze summe vertheilt habe. Ist es schon an und für sich unwahırscheinlich, dass der nicht selır freigebige Tiber melır vertheilt haben sollte, als August legirte, da er sich doch erst nach längerem zögern entschloss, diese bestimmungen des testamentes auszufülıren (Dio 57, 14, 1-2), so scheint es mir geradezu undenkbar, dass August nur 3,500,000 HS. zur vertheilung an die biirger auszusetzen beabsichtigt liaben sollte, d. l., wenn wir nur 200,000 bürger rechnen, für jeden $171 / 2$ HS., wälırend die prätorianer 1000 HS. und selbst die gemeinen legionarier 300 HS. erhielten und die congiarien, die August bei lebzeiten dem volke gab, sich auf 300--400 HS. für jeden bürger beliefen. Daher halte ich es für unzweifelhaft, dass August 40,000,000 HS. zur vertheilung viritim an das rolk vermaclit habe und ausserdem noch für jede tribus extra 100,000 HS., die allerdings auch wohl sofort zur vertheilung an die mitglieder derselben kamen (vgl. Mommsen a. o. p. 202). Ganz entsprechend ist die stelle des Plinius (Paneg. c. 25): locupletatac tribus datumque congiarium populo, ot datum totum, cum donativi partem milites accepissent, wo aus der entgegensetzung des populus und der tribus mir ebenfalls evident hervorzugehen scheint, dass die vertheilung der congiarien nicht tribusweise geschah ${ }^{18}$ ).

18) Bei Martial. 8, 15: dat populus, dat gratus eques, dat tura senatits et ditant Latias tertia dona tribus, wie auch bei Statius Silv. 3, 10, steht tribus gewiss nur in dem sinne: ",arme bürger in Rom", eine bedeutung, welche die tribus, wie Mommsen nachgewiesen hat, in der saiserzeit allmählich erhält. 
Was August zu dieser doppelten vertheilung bewogen habe, bei der wesentlich dieselben empfänger waren ${ }^{19}$ ), ist nicht mit sicherheit zu sagen; vielleicht geschah es, um die corporative bedeutung der tribus nicht ganz schwinden zu lassen; übrigens ist das legat an dieselben verhältnissmässig sehr gering.

Können wir demnach aus der vertheilung der congiarien nicht den schluss ziehen, dass die frumentationen tributim stattfanden, so fehlen fïr diese selbst die beweise vollständig. Wenn eine dedication an Titus vollzogen wird von der pleps urbana que frumentum publicum accipit et tribus ... (Mommsen 1. N. 6786), so ist das für mich nur ein beweis, dass beide kategorieen sich nicht vollständig decken, wie das besonders bei beschränkter empfängerzall (s. ob.) ganz natürlich ist; die inschrift bei Orelli 3214 endlich, die einen hor(v)eurius ple(bis) et trib(us) Pal(atinas) nennt, ist eine Ligorianische fälschung ${ }^{20}$ ). Es kommt ferner in betracht, dass nach notizen aus der republikanischen zeit, als die tribus noch eine weit höhere bedeutung hatten, als in der kaiserzeit, ausserordentliche geschenke oder billige verkäıfe von getraide und öl nicht tributim, sondern vicutim geschehen (vgl. Liv. 30, 26 und 25, 2); auch die getraidevertheilung des C. Gracchus scheint von ilım persönlich geleitet worden zu sein und geschalí in contione, Cic. Tuscul. 3, 20, 48; da endlich bei den frumentationen der kaiserzeit genaue listen der empfanger gefiilirt wurden (incisi frumento publico) und, wie wir sehen werden, besondere beante für dieselben ernannt waren, so ist nicht abzusehen, warum diese vertheilungen hätten tributim geschehen sollen. Wir können demnach als gewiss an nehmen, dass weder die monatlichen frumentationen noch die regelmässigen congiarien nach den tribus vertheilt worden sind: dass dies zuweilen bei geschenken, die den tribus als solchen gemacht

19) Ygl. Suet. Tiber. 76: dedit et legata. . . plebei Romanae viritim, atque eliam separatim vicorum magistris.

20) Anstössig sind, ausser dem titel selbst, die abkürzungen qui . ple ., obgleich sich ähnliches auch sonst findet, ferner dio beiden gentilnamen der frau, deren erstes mit dem namen des mannes übereinstimmt; sodann das cognomen des mannes Capitius und schliesslich die ingenuität des horrearius (s. unt.). Malvusia, aus dem Muratori 964, 8 (vgl. 722, 2: ex Ligorio) sie genommen, hat, wie mir Bormann schreibt, die inschrift aus den schedae Valicanae; sie steht bei Ligorio Neap. lib. 39 p. 134 und in den schedae Barberinae (jetzt Vaticanne), an erster stelle mit der ortsangabe: in via Latina nella terra di S. Giovanni a Laterano, an der zweiten: nella via Latina. 
wurden, der fall war. verstelit sich von selbst und spricht nicht gegen unsere behauptung. Daher können wir auch nicht Mommsen heistimmen, wenn er sagt (a. o. p. 196): "nachdem die tesserac frumentariae in concione, vielleicht in der porticus Minucia frumentaria vertheilt waren, oline dass hier wohl die tribus gesondert waren, meldete sich der empfanger mit der tessera hei dem magazinverwalter, zu dem seine tribus gehörte" (älınlich Nasse p. 28 f.). Auch diese ansicht stützt sich hauptsảchlich auf die oben erwähnte falsche insclrift; aber, wie schon der titel: pracfecti-frumento dando andeutet, liegt der schwerpunkt nicht in der ausiheilung der tesserae, sondern des getraides selbst, und gerade diese vertheilung fand vor dem versummelten volke, d. h. der plebs frumentaria in contione statt. Daher heisst es in der Lex Iulia muicipalis $v$. $15 \mathrm{f}$ : et quom frumentum populo dabitur ibei ubei frumentum populo dabitur ... ., und bei Philo (leg. ad Caiun e.. 23): ov̀

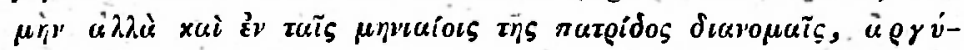

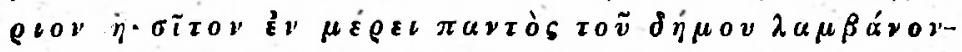
ros... Es liegt übrigens die annahme nahe, dass diese tesserae frumentariae nicht vor jeder vertheilung ausgegeben wurden, sondern der empfangsberechtigte bei der aufnalume in die listen ein für allemal eine tessera empfing, die er so lange behielt, als er diese berechtigung nicht verlor. Die oben citirten worte des Iuvenal, VII, 174: qua vilis tessera venit frumenti, sprechen nicht gerade dagegen, da trotzdem eine solche tessera für einzelne frumentationen verkauft werden konnte; dafür spricht wenigstens in der späteren zeit, der kauf und das legat der tessera in den Pandecten (vgl. Mommsen 'Tribus p. $197 \mathrm{f}$ ), obgleich sich dies auch mit monatlicher vertheilung der tesserac vereinigen liesse; vor alJem aber die unwahrscheinlichkeit, dass man, obgleich fast ganz dieselben empfänger blieben, sich die mühe gemacht haben sollte, jeden monat etwa 200,000 dieser marken auszugeben. Bedenklich könnten gegen diese annahme machen die worte des Sueton, Aug: c. 40 ; populi recensum vicatim egit, ac ne plebs frumentationum causa frequentius ab negotiis, avocarelur, ter in anmum quaternim mensum tesseras dare destinavit; sed desideranti consuetudinem veterem concessit mrsus, ut sui cui usque mensis acciperet; doch ist es sehr wahrscheinlich, dass tessera hier nicht in dem sinne von ,marke sondern , portio $\mathrm{n}^{\prime \prime}$ zu verstelien ist, obgleich 
allerdings die lexica meines wissens diese bedeutung nicht aufweisen. Auf einer wasserleitungsrölıre des Prätorianerlagers in Rom nänlich, die Henzen in den Ann. dell' Inst. 1864 p. 6 veröffentlicht hat, findet sich folgende inschrift: Pisone et Iuliano Cos || tessera castre(n)sis, und schion Henzen bemerkt dazu: "tessera tutti sanno significare un marchio ossia biglietto, per mezzo del quale $s$ ' assegnava una qualunquesiasi cosa al latore di esso, ma non conosco alcun.esempio dell' esserne stata indicata puranche quella cosa medesima che si assegnava. Nondimeno non vedo alcuna spiegazione possibile nel caso nostro, fuorche quest' vltima, credendo accennata mediante la voce, "tesserac la stessa porzione d' acqua assegnata al castro pretorio". Ja auch în der vielbesprochenen stelle des Sueton, Aug. c. 41: frumentum quoque in annonae difficultatibus saepe levissimo, interdum nullo pretio viritim admensus est tesserasque nummarias duplicavit, scheint mir tessera diese bedeutung zu haben, da sonst nach meiner ansicht nothwendig eine verdoppelung der zahl der empfänger angenommen werden muss, während nach dem Monum. Ancyr. III, 11-12, vgl. Dio 55, 26 und Marquardt a. o. p. 103 anm. 491 dieselbeu empfänger nur doppelte portionen erhielten.

Von diesen tesserae frumentariae ist uns leider nur ein einziges exemplar erhalten, das Marini (Atti II, p. $695=$ Orelli 3360) mittheilt; die insclırift steht auf einer ,laminetta di metallo con lettere d'argentos" und lautet:
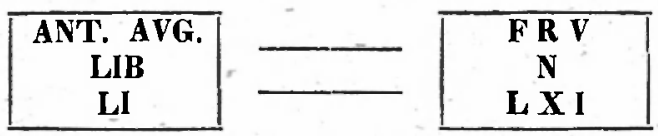

„videla il P. Lesleo Gesuita ${ }^{21}$ ) che vi lesse: Antonini Aug. liberalitas II., frumentum numero sexagesimo primo"; zweifelhaft ist natürlich II, doch ist LI keineswegs richtig und II wohl das wahrscheinlichste; statt frumentum dürfte fru(mentatio) vorzuziehen sein; auch sind die letzten worte gewiss nicht mit Forcellini (s. v. tessera) zu erklären : numero (scilicet ostio) sexagesimo primo, sondern: fru(nentatio) n(umero) sexagesima prima d. h. die 61ste frumen-

21) Die tessera scheint leider verloren zu sein, auch sind mir keine anderen abschriften bekannt; doch ist an der echtheit gewiss nicht zu zweifeln.

Philologus. XXIX. Bd. 1.: 
tation, ohne zweifel von der thronbesteigung des betreffenden kaisers - welcher von den Antoninen gemeint ist; lasst sich nicht feststellen - an gerechnet. Dass die tessera zugleich auf ein congiarium (liberalitas wird sehr läufig dafür, besonders auf münzen gebraucht) und eine frumentation lautet, ist bezeichnend für den engen zusammenhang beider, auf den besonders Mommsen (a. o. p. 195) aufmerksam gemacht hat; zugleich aber ist dies ein beweis, dass wir hier keine gewöhnliche tessera frumentaria vor uns haben, da congiarien natürlich nicht jeden monat ausgetheilt wurden, sondern eine bei einer besonderen, festlichen gelegenheit geprägte marke; auch der umstand, dass dieselbe aus metall mit silbernen buchstaben besteht, deutet darauf hin. Erwägt man nun, dass es die 61ste frumentation, d. h. die erste im sechsten jahre seit der thronbesteigung des kaisers ist, so wird man sich der vermuthung nicht entziehen können, dass dieses congiarium bei gelegenheit der von den kaisern bekanntlich festlich begangenen Quinquonnalia ausgetheilt worden ist ${ }^{22}$ ) und die marke zu diesem speciellen zwecke geprägt wurde; wenn daher auch dieselbe auf eine bestimmte frumentation lautet, so spricht dies nicht gegen unsere oben ausgeführte ansicht ${ }^{23}$ ). Uebrigens sei hier bemerkt, dass es nicht erlaubt gewesen zu sein scheint, zwei tesserae zur selben zeit zu besitzen, vgl. Digg. 31, 87 pr.: Titia Seio tesseram frumentariam comparari voluit post diem trigesimum a morte ipsius; quaero, quum Seius viva testatrice tesseram frumentariam ex causa lucrativa habere coeperit, nec possit id, quod habet, petere, an ei actio competat. Paulus respondit, ei, de quo quaeritur, pretiım tesserae praestandum.

Diese frumentationen fanden jeden monat statt (vgl. z. b. Dio-

22) Das geschenk des Septimius Severus an die plebs frumentaria und die Prätorianer (Dio 76, 1, 1) wurde im j. 202 an seinen decennalien gegeben. Ueber die Vota quinquennalia, die, wie einige ohne grund behaupten, erst nach Alexander Severus vorkommen sollen, vgl. Eckhel, D. N. VIII, $476 \mathrm{ff}$. und die von ihm citirte inschrift einer lampe: VOT. V. ANTON. A. N.

23) Vgl. Sueton. Nero 11: sparsa el populo missilia omnium serum per omnes dies: singula cotidie milia avium cuiusque generis, multiplex peuus, tes sera e f ume ularia e, vestis, aurum, argentum etc. Diese tesserae frumentariae lauteten schwerlich auf eine monatliche frumentation, sondern wurden ohne zweifel, wie die anderen dinge, yon den damit beauftragten kaiserlichen dispensatoren eingelöst: vgl. Dio. Epit. 66, 25, $\breve{5}$. 
nys. 4, 24 u. a.) und dauerten nur einen tag ${ }^{24}$ ) (Philo leg. ad Caium 8. 23); letzteres gilt dalser auch von den congiarien: vgl. Plinius Paueg. 26: advenlante congiarii die. Dass auf den kinderinschriften verschiedene tage im monate als empfangstage angegeben werden, spricht, wie gesagt, nur dafür, dass die pueri et puellae alimentarii gesondert von der plebs frumentaria ihr getraide empfingen. Augustus beabsichtigte statt der monatlichen vertheilung drei im jahre abhalten zu lassen, gab aber diesen plan wieder auf (Sueton. Aug. c. 40).

\section{Oel-, fleisch - und brod - vertheilungen.}

Schon in der zeit der republik und der frühen kaiserzeit war öl zuweilen an das volk vertheilt worden (vgl. z. b. Liv. 25, 2. Dio 49, 43, 2. Suet. Iul. c. 38 u. a. m.) ; regelmässig wurden diese spenden erst seit Septimius Severus und fanden seitdem täglich statt, vgl. Vit. Severi c. 18 : populo Romano diarnum oleum gratuitum et facundissimum (f e c u $n$ dis $i m u m$ Casaubonus; ei i ucundis s i$m u m$ Monmsen; man erwartet etwa: abundantissimum) in aeternum donavit ${ }^{25}$ ). Von Alexander Severus heisst es (vita c. 22): oleum quod Severus populo dederat quodque Heliogabalus inminuerat, turpissimis hominibus praefecturam annonae tribuendo, integrum restituit. Diese ölspenden erhielten sich bis in die späte kaiserzeit (vgl. Symmachus Epp. $\mathbf{X}, 48$; Cod. Th. de mensis oleariis : $\mathbf{X I V}$, 24 mit dem commentar von Gothofred.; ferner Gothofr. zu Cod. Th. 14, 15, 3 und 14, 17, 15); Aurelian fuigte vertheilungen von schweinefleisch dazu, die noch zur zeit des Vopiscus üblich waren (vita Aureliani c. 35. Gothofr. zu Cod. Th. 14, 4, 1); ausserdem beabsichtigte Aurelian, auch wein dem volke umsonst zu vertheilen, stand jedoch auf rath seines praefectus praetorio davon ab und begnügte sich damit, wein auf rechnung des fiscus zu billigen preisen zu verkaufen ${ }^{26}$ ).

24) Gewiss richtig erklärt Dirksen (a. o. p. 198) collidie in v. 16 der iabula Heracleenies durch: quolo die.

25) Vgl. den brief des Septimius Severus in der Vita Albini c. 12: ego populo Romano tanlum olei deluli quantum rerum nalura vix habuit: Vgl. auch vila Severi c. 23.

26) Dieser verkauf fand in dem von Aurelian erbauten templum So- 
Wichtiger sind die brodvertheilungen, da dieselben die frumentationen verdrängt und ersetzt haben. Die ansicht von Lipsius (Elect. I c. 8), dass diese brodvertheilungen schon unter Traian begonnen haben, ist mit recht von Contareni (p. 43 ff.) und neueren schriftstellern verworfen worden: denn bis in die zeit von Alexander Severus finden sich deutliche spuren von getraidevertheilungen (vgl. Contareni a. o. p. 48 ff.). Der erste kaiser, von dem eine tägliche brodvertheilung berichtet wird, ist Aurelian (vita c. 35): non praetereundum videtur quod et populus memoria tenet et fides historica frequentavit, Aurelianum eo tempore, quo profciscebatur ad orientem, bilibres coronas populo promisisse, si victor rediret et cum aureas populus speraret neque Aurelianus aut posset aut vellet, coronas eum fecisse de panibus, qui nunc siliginei vocantur et singulis quibusque donasse, ita ut siligineum-sum cotidie toto aevo suo et unus quisque acciperet et posteris suis dimitteret. Diese brodvertheilungen erhielten sich, wenn auch nicht in dieser form, selır lange und häufig geschieht erwähnung des sogenannten panis gradilis im cod. Th. und anderen späten quellen (vgl. Salmas. zu Vopisc. Aurelian. c. 35 : besser Gothofred. zu Cod. Th. XIV, 17: de annonis civicis et pane gradili, besonders t. V, p. 267-275); von getraidevertheilungen findet sich dagegen seit dieser zeit nur noch die notiz in den Excerpta Valesiana ê..67 von Theoderich: donavitque populo Romano et pauperibus annonas singulis annis, centum viginti milia modios: doch sieht man deutlich die verschiedenheit dieses jährlichen geschenkes, das übrigens sehr unbedeutend war, von den alten monatlichen frumentationen. Dass aber erst unter Aurelian die getraidevertheilungen, wie allgemein angenommen wird, aufgelört haben, ist mir nicht walırscheinlich; die art, wie Vopiscus über die austheilung der panes bilibres berichtet, spricht dafür, dass dieselben nicht etwa als ersatz für die dadurch aufgehobenen frumentationen gegeben wurden; zielt man ferner in betracht, dass seit Alexander Severus sich keine erwäl-

lis statt (vita c. 48); darauf beziehe ich die merkwürdige inschrift bei Mommsen I. N. 6830 จ. 4-5: falancariis qui de ciconiis ad templum cupas referre consuerunt, die demnach nicht vor Aurelian gesetzt sein kann; erläutert ist sie von Mommsen in den Ber. d. sächs. G. d. W. 1851 p. $76 \mathrm{f}$. 
nung der tesserac frumentarice mehr findet ${ }^{27}$ ), dass ferner, wie wir selieu werden, die inschriften, welche Praefecti frumento dando nennen, mit Alexander Severus aufhören, so wird es sehr wahırscheinlich, dass schon vor Aurelian die frumentationen illr ende erreichten. ob aber sofort brodvertheilungen an ihre stelle traten, die Aurelian nur qualitativ und quantitativ verbesserte ${ }^{28}$, , oder ob in der unruhigen zeit nach Alexander Severus die naturalspenden an das volk zeitweilig überhaupt nicht stattgefunden haben ${ }^{29}$ ), ist fraglich: dass aber etwa die monatlichen frumentationen noch neben den täglichen brodvertheilungen bestanden haben sollten, ist, abgesehen von dem stillschweigen der quellen, der zu grossen kostspieligkeit wegen undenkbar. Ueber die pistores und illr verhältniss zum Praefectus annonae werden wir in dem zweiten theile unserer abhaudlung sprechen.

\section{Die cura annonae.}

Schon lange bevor durch die Leges frumentariae regelmässige getraidevertheilungeu eingefülırt wurdeh, war es die sorge des römischen staates gewesen, einen massigen und ziemlich stabilen marktpreis für das getraide in Rom herzustellen (vgl. Mommsen $\mathbf{R}$. G. I, p. 268). Natürlich konnte der staat auf den getraidemarkt nur nachdrücklich einwirken, wenn er selbst bedeutende massen von getraide auf den markt brachte: dass dies, besonders nach der eroberung von Sicilien und Sardinien, in grossem umfange geschehen und auch nach einfuilirung der frumentationen beibehalten ist, hat Kuhn in der angeführten abhandlung gründlich und scharfsinnig nachgewiesen. Nur in seltenen fällen wird dieses getraide unter dem selbstkostenpreise abgegeben sein, sowohl in der früheren zeit der republik, als besonders, seitdem das aerarium die bedeutenden kosten für die frumentationen zu tragen hatte. Die bedenkliche vermehrung eines besitzlosen, leicht aufrülırerischen pöbels in der

27) Die Yỹ̄or (tesserae) in Iustinian. Novell. 88 c. 2 beziehen sich natürlich auf brodvertheilungen.

28) Doch scheinen die worte des Aurelian in seinem briefe an den Praefeclus annonae Flavius Arabianus (vita c. 47): additamento unciae omne annonarum urbicarum genus iuvi nicht auf diese vertheilungen, sondern auf den brodverkauf zu gehen.

29) Congiarien von Maximinus, Pupienus, Gordianus u. s. w. werden erwähnt vgl. Marquardt a. o. p. 111. 
hauptstadt, die schon seit dem zweiten punischen kriege begonnen hatte und in der kaiserzeit ihren löhepunkt erreichte, zwang die kaiser, auf die erhaltung mässiger kornpreise ein wachsames auge zu haben, denn das in den frumentationen gespendete getraide reichte für den bedarf bei weitem nicht aus, da meistens gewiss von den monatlichen fünf modii eine ganze familie leben sollte. Fon Augustus an bis in die späteste zeit haben, wie zahlreiche erwähnungen bei scbriftstellern und auf münzen ${ }^{30}$ ) zeigen, nur wenige unter den kaisern die bedeutung dieser aufgabe unterschätzt ${ }^{31}$ ); vorzïglich werden in dieser hinsicht August, Claudius, Traian, Antoninus Pius, Pertinax, Septimius und Alexander Severus und Aurelian wegen ilıres eifers gerühmt. Sehr erleichtert wurden den kaisern diese bemühungen durch die eroberung der fruchtbarsten länder, besonders Aegypten's, das zu August's zeit allein 20,000,000 modii waizen jährlich nach Rom lieferte (Aurel. Victor epit. c. 1); trotzdem konnte ein bedeutendes schwanken der kornpreise und damit verbundene noth selbst unter den besten kaisern nicht ganz vermieden werden (Kuhn a. o. p. 1075 a. 75), so dass man zu ausserordentlichen getraidevertheilungen oder verkaufen unter dem werthe nicht selten sich verstehen musste (vgl. z. b. Sueton, Aug. c. 41. Mommsen R. G. D. A. p. 50. Vita Antonini Pii c. 8 u. a. m.).

Onter diesen umständen war es unvermeidlich, dass allmählich der getraideverkauf in Rom fast ausschliesslich dem staate zufiel, denn es war für den privathandel unmöglich, die concurrenz mit dem fiscus auszulalten, da dieser das getraide zum grössten theil aus den provinzen als abgabe geliefert erhielt und zuweilen unter dem reellen werthe verkaufte. Doch finden sich auch in der kaiserzeit ${ }^{32}$ ) noch deutliche spuren von privatkornhandel in

30) Vgl. Eckhel D. N. VI, 268. VII, 62. 111. 176. 303. 239. 418 und Brunn in den Annali d. J. 1849 p. $135 \mathrm{ff}$.: eine dedication an die Annona sancta von Aelius Vilalio mensor perpetuus dignissimi corporis pistorum siliginariorum findet sich in einer stadtrömischen inschrift des zweiten jahrhunderts bei Orelli 1810 .

31) Vgl. Tacit. A. 15, 36: haec atque talia plebi volentia fuere, voluptatum cupidine, el quae praecipua cura est, rei frumentariae angustias, si abesset (scil. imperator), metuenti.

32) Ueber die kornhändler in republikanischer zeit vgl. Kuhn a. o. p. $993 \mathrm{ff}$. Marquardt Handbuch $\mathrm{V}^{2}$ p. 33. Auch der vicus frumentarius in der 13ten region, ohne zweifel in der nähe des emporium, wo die 
Rom ${ }^{33}$ ) und die kaiser seit Claudius liessen es sich angelegen sein, durch auszeichnungen und privilegien diese art von speculation zu ermuthigen (vgl. Sueton. Claudius c. 18. Gaius I, 32c bei Studemund verhandlungen der würzburger philologenvers. 1868 separatabdruck p. 9. Ulpian. frgm. 3, 6. Digg. 50, 6, 5 \&. 3 und 6 . Vita Alex. Sever. c. 22. Marquardt Handbuch $V^{2}$ p. 33); aber gerade diese privilegien zeigen deutlich, dass der private getraideimport unbedeutend war und künstlich gehoben werden musste; ohne zweifel war der absatz nach den übrigen theilen Italiens und anderen kornarmen provinzen weit einträglicher, da dort nicht der staat selbst als concurrent auftrat.

'Da das getraide vorzugsweise aus weit entfernten überseeischen provinzen kam ${ }^{31}$ ), so konnte leicht durch schiffbruch oder

grossen getraidespeicher lagen, hatte daher seinen namen, vgl. Jordan de vicis urbis Romae in den Nuove memorie dell' Inst. p. 234. Ueber die gesetze gegen kornwucher (dardanariatus) vgl. Rein Kriminalrecht p. 829. Schaghen a. o. p. $63 \mathrm{ff}$.

33) Sueton Aug. 42: alque ita posthac rem temperavit, ut non minorem aratorum ac negotiantium quam populi rationem deduceret. Auch Tiberius nahm auf die interessen derselben möglichst rücksicht, da er nach dem berichte des Tacitus A. II, 87 im j. $19 \mathrm{n}$. Chr.: saevitiam annonae incusanie plebe staluit frumenio pretium quod emptor penderet, binosque nummos se additurum negotiatoribus in singulos modios; derartige preisfixirungen von seiten des kaisers, die natürlich den privatinteressen auf das gewaltsamste schaden mussten, scheinen öfters vorgekommen zu sein vgl. Tacit. A. 15, 39: pretiumque frumenti minutum usque ad ternos nummos. Noch nach Hadrian werden in einer stadtrömischen inschrift (Orelli 3331): mercatores frumentarii et olearii Afrarii genannt, doch sind derartige erwähnungen sehr selten (die inschrift bei Grut. 128, 2 der negotiatores frumentarii aus Titus zeit ist mir verdächtig); zu unterscheiden davon sind die kaufleute, welche nur den transport des getraides nach Rom für den staat besorgen vgl. Marquardt Handbuch $V^{2}$. p. 13 ff. Dass auch vor allem, das naturalsteuersystem, das hauptsächlich getraide erhob, dem privathandel nicht viel übrig liess", hebt Rodbertus zur geschichte der römischen tributsteuern seit Augustus in Hildebrand's Jahrbüchern für Nationalökonomie VIII, p. 418 anm. 60 mit recht hervor, unterschätzt dabei jedoch nach meiner ansicht die bedeutung der concurrenz des staates, die sich keineswegs, wie schon Kuhn a. 0 . nachgewiesen hat, nur auf die Frumentationes beschränkte.

34) In republikanischer zeit besonders aus Sicilien, Sardinien und später Afrika ; seit August kommt als ergiebigste bezugsquelle Aegypten hinzu; andere provinzen, die nach Rom getraide lieferten, nennt Plinius n. h. 18, 7, 66 (vgl. auch Orelli 756). Ueber diese sogenannten provinciae frumenlariae haben ausfübrlich gehandelt: Contareni a. o, cap. 10 und besonders Nasse p. $30-40$. Wichtig ist die bemerkung des letzteren (p. 3), dass das getraide aus Sicilien nur mit specieller erlaubniss des senats in republikanischer zeit anderswohin, als nach Ita- 
widrige winde in Rom grosser mangel eintreten (Nasse a. 0. p. 40. Friedländer Sittengesch. I, p. 34 f.). 'Diesem übelstande suchten die kaiser auf alle mögliche weise zu begegnen; sie törderten eifrigst die unternehmer, die für den transport des getraides thätig waren (Marquardt $V^{2}$ p. $13 \mathrm{ff}$.), und schon in früher kaiserzeit finden wir eine besondere getraideflotte für Aegypten errichtet (C. I. Gr. III p. 318a), der sich seit Commodus eine classis Africana anschloss (vita c. 17), quae subsidio esset, si forte Alexandrina frumenta cessassent (Marquardt $\mathrm{V}^{2}$ p. $14 \mathrm{f}$ ); über die hafenbauten des Claudius und Traian, die ebenfalls mit der getraidezufuhr im engsten zusammenhange standen, werden wir unten sprechen. Das sicherste mittel jedoch, die stadt vor mangel zu schützen, war die aufspeicherung von getraide in Rom selbst, das bei grosser theuerung und ausbleibender zufuhr als aushülfe dienen konnte. Schon unter Traian müssen bedeutende vorräthe vorhanden gewesen sein, da nach der freilich wohl etwas übertriebenen schilderung des Plinius (Panegyr. c. 30) aus Rom nach Aegypten bei einer sehr schlechten ernte getraide gesandt wurde. Noch nachdrücklichere vorsichtsmassregeln traf Septimius Severus, der, wie Spartian berichtet (vita c. 8): rei frumentariae, quam minimam reppererat, ita consuluit, ut excedens vita septem annorum canonem populo Romano relinqueret; vgl. c. 23: moriens septem annorum canonem, ita ut cotidiana septuaginta quinque milia modiorum expendi possent, reliquit. Nach den worten des Lampridius Vit. Heliogab. c. 27: iusserat et canonom populi Romani unius anni meretricibus ... dari .... cum eo tempore iuxta provisionem Severi et Traiani septem annorum canon frumentarius Romae ${ }^{35}$ ) esset, wäre diese massregel schon auf Traian zurückzufülıren, wie dies Nasse (p. 37), Marquardt (III ${ }^{2}$ p. 105) und neuerdings Dierauer (Beiträge zur Geschiehte Traians p. 54)

lien, exportirt werden durfte; in der kaiserzeit scheint für den export aus Aegypten ebenfalls die specielle bewilligung des kaisers erforderlich gewesen zu sein, wie mir aus der in Tralles in Carien gefundenen inschrift

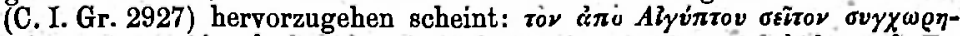

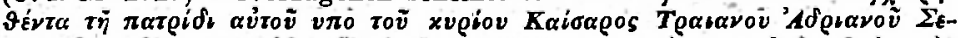

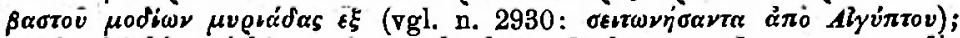
gewiss ist hier nicht an ein geschenk zu denken, sondern nur an die erlaubniss ( $\sigma v \gamma \chi \omega \rho \varepsilon i v)$, aus degypten eine bestimmte quantität getraide zu beziehen. Export von getraide aus Aegypten nach Judaea mit bewilligung des statthalters erwăhnt Joseph. archaeol. 15, 9, 2.

35) Ueber den Canon frumentarius urbis Romae in spăterer zeit vgl. Gothofred. zu Cod. Th. XIV, 15. 
wirklich thun; mir scheint jedoch in Traiani eine corruptel zu stecken, da die oben angefiulıten stellen aus Severs biographie darauf schliessen lassen, dass Septimius Severus der erste war, der so grosse quantitäten getraide aufspeicherte. Erwägt man ferner, dass zwischen dem tode des Septimius Severus und der thronbesteigung Elagabal's ein zeitraum von über sieben jalıren liegt, dass also, wenn Caracalla nicht die linterlassenen vorräthe vermelırt oder erhalten hätte, Elagabal nicht melır einen canon septem annorum vorfinden konnte, so glaube ich, wird man die änderung von Traiani in Bassiani, wie Caracalla vorwiegend bei diesen schriftstellern genannt wird, für gerechtfertigt halten. Von wichtigkeit ist die notiz, dass von diesem vorrathe täglich $\mathbf{7 5 , 0 0 0}$ modii ausgegeben (expendere ist dafür der technische ausdruck, vgl. z. b. Cod. Th. XI, 14, 1) werden konnten. Wenn unsere ansicht, dass bei weitem der grösste theil des getraides in Rom vom staate verkauft worden sei, richtig ist, so erscheint diese summe für den bedarf von Rom sehr klein ${ }^{36}$ ), da dies für das ganze jahr nur 27,375,000 modii ausmachen würde, wälırend der consum in der zeit des Augustus etwa 60,000,000 modii betrug (Marquardt III $^{2}$ p. 104); jedoch sind wir, wie ich glaube, nicht zu der annahme berechtigt, dass das getraide für die monatlichen frumentationen in dieser summe nicht einbegriffen sei, wenn auch Spartian von einer expensio cotidiana spricht. Hinzuzurechnen wäre etwa nur das getraide, das grundbesitzer zu ihrem eigenen gebrauch von ihren gütern bezogen (Marquardt a. o. p. 103 a. 494), ferner das von privathändlern importirte korn, so dass der ganze bedarf von Rom auf nicht viel mehr als 30,000,000 modii jährlich veranschlagt werden muss. Darnach muss Rom zur zeit des Septimius Severus nur etwas melı als die hälfte der einwohner gehabt haben, die es zur zeit des Augustus hatte, wobei allerdings zu berücksichtigen ist, dass gerade die stärksten getraideconsumenten, die sklaven, damals schon bedeutend abgenommen hatten (vgl. Marq. $\mathbf{V}^{1}$ p. 200). Da nun die einwohnerzahl von Rom nie viel mehr als $1^{1} / 2$ million betragen zu haben scheint (vgl. Friedländer Sittengesch. I p. 23 f.), so kann für den anfang des dritten jahrhunderts 8-900,000 woll als maximum angenommen werden;

36) Dass auf die angabe des scholiasten zu Lucan. I r. 319 p. 53 Weber Roma volebat omni die LXXX millia modiorum annonae kein gewicht zu legen ist, hat Nasse p. 37 f. nachgewiesen. 
mitgewirkt haben bei dieser abnalıme der bevölkerung olıne zweifel die grossen epidemieen unter M. Aurel und Commodus (Friedl. a. o. I p. $36 \mathrm{f}$ ), wenn dieselben auch nicht als die einzige ursache dieser erscheinung angeselien werden können ${ }^{37}$ ). Nach dem gesagten ist es selbstverständlich, dass dieser tägliche getraideverkauf nicht auf die zu den frumentationen berechtigten beschränkt war, sondern dass die ganze bevölkerung der stadt Rom hier iliren bedarf wenigstens zum grössten theile einkaufen konnte. Ob an jedem tage nur eine bestimmte quantität verkauft wurde und ob die käufer nur ein bestimmtes maass geliefert erhielten, ist fraglich; Marquardt schliesst letzteres aus Dio 55, 26 Zु. 2: $\varepsilon \times \alpha ́ \sigma \tau \omega) \pi \imath \pi \rho a ́ \sigma x \varepsilon \sigma \vartheta a \downarrow$, doch-beweist diese stelle nichts, da es sich dabei um die ausserordentlichen maassregeln gegen die hungersnoth vom j. 6 n. Chr. handelt. Natürlich musste man vermeiden, so grosse quantitäten zu verkaufen, dass damit privatspeculation getrieben werden konnte; von wichtigkeit war ferner natürlich die menge der aufgespeicherten vorräthe: im ganzen aber wird, da das getraide regelmässig nicht unter dem marktpreise abgegeben wurde und jeder berechtigt war dort zu kaufen, sich der absatz von selbst nach dem bedarfe regulirt haben; ron tesserae, deren gebrauch Marquardt a. o. p. 105 auch hierbei annimmt, ist nirgends die rede, und man kann wohl als sicher behaupten, dass dieselben nur bei den frumentationen behufs der legitimation anwendung gefunden liaben.

Wir schliessen hier den ersten theil unserer untersuchung, in dem wir nur beabsichtigten, einen kurzen abriss der geschichte der annona und der frumentationes zu geben und einige streitige fragen einer nochmaligen prüfung zu unterziehen; wir gehen jetzt zu der

37) Erwăhnt sei hier die stelle des Olympiodor bei Photius Biblioth.

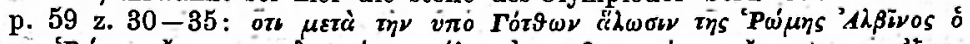

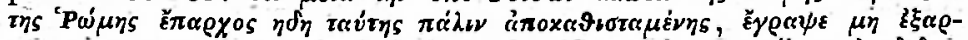

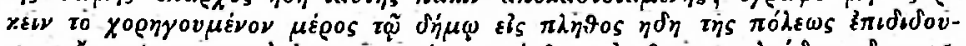

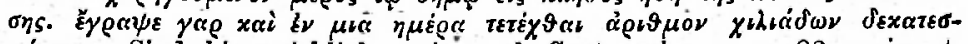

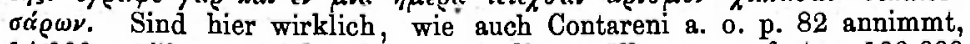
14,000 modii zu verstehen, so muss die bevölkerung auf etwa 120,000 seelen zusammengeschmolzen sein, was kurz nach der zerstörung durch die Gothen keineswegs unglaublich erscheint; Albinus war übrigens wahrscheinlich im j. 426 praefectus urbi vgl. Cod. Th. $\nabla, 1,7$ und Corsini series praefectorum p. 345 . Ueber die abnahme der bevölkerung in Italien und den provinzen vgl. Zumpt über den stand der bevölkerung $p .70 \mathrm{ff}$. 
darstellung der verwaltung dieser grossartigen einrichtungen in der kaiserzeit über und geben zunächst eine chronologisch' geordnete liste der

Praefecti annonae in der kaiserzeit:

a) Erstes jahrhundert:

1) C. Tumanius, schon bei Tiber's regierungsantritt (Tacit. A. I, 7) und noch im herbste des jahres 48 (Tac. A. XI, 31) im ante. Wabrscheinlich war er überhaupt der erste praefcctus annonae, doch ist dies nicht, wie Lipsius zu thun geneigt ist, aus den worten des Tacitus zu schliessen: primunque rei frumentariae praefectum Turranium, post Lusium Getam praetorianis impositum, percontatur, denn primum gehört, wie das folgende post zeigt, offenbar zu percontatur. Ob mit dem von Ovid. Epp. ex Ponto 4, 16, 29 als dichter erwähnten Turranius und mit dem von Plinius als schriftsteller öfters (NH. ind. auct. zu lib. III, 3. IX, 11. XVIII, 75 vgl. XV, 54: Turraniana pira), citirten Turranius Gracilis aus Hispania Baetica identisch, ist fraglich aber nicht unwahrscheinlich. Gewiss richtig bezieht Lipsius zu Tac. A. I, 7 auf ihn die worte des Seneca Brev. vit. c. 20: Turannius ${ }^{38}$ ) fuit exactae diligentiae senex, qui post annum nonagesimum cum vacationem procurationis ab $G$. Caesare ultro accepisset, conponi se in lecto et veht exanimem a circumstante familia plangi iussit. lugebat domus otium domini senis nec finivit, antea tristitiam, quam labor illi sutus restitutus est. Demnach muss er im j. 48 fast hundert jahre alt gewesen sein, und es ist daher sehr walırscheinlich, das er mit dem gleichnamigen Praefectus Aegypti des j. 7 v. Chr. (vgl. Franz C. I. Gr. 4923; nach anderer lesart fällt die präfectur in das j. 15 oder 10 v. Chr.) identisch ist, was auch Labus und Letronne annelimen (vgl. Franz im C. I. Gr. III, p. 310). Dass später die praefectura Aegypti über der praefectura annonae stand, beweist nichts für die zeit des Augustus, in der die ämterfolge noch keineswegs so genau reguliert war, als in spä-

38) Die richtige, durch inschriften. (Orelli 2276, 4298) gesicherte form ist Turranius; in den codices kommt daneben Turanius und $T u-$ rannius vor s. Haakh in Pauly R. E. VI p. 2256. 
terer zeit vgl. z. b. Dio 57, 19,6 über Seius Strabo, der unter Tiberius nacb der praefectura praetorii zum praefectus Aegypti befördert wurde, wälırend später bekanntlich die praefectura praetorii das höchste ritterliche ant war. Turranius starb oder dankte ab wahrscheinlich noch im j. 48 oder im folgenden jahre; sein nachfolger war:

2) Pompeius Paulinus, praefectus annonae im j. 49; vgl. über ihn meinen excurs über Seneca's schrift: de brevitate vitae.

3) Claudius Athenodorus praef. annonae: Orelli 3200; sein adiutor ist Carpus Aug. lib. Pallantianus: ein kaiserlicher freigelassener, der sehr wahrscheinlich aus dem besitze des bekannten Pallas in den des kaisers übergegangen war; seine frau heisst Claudia Cale, er selbst mag der soln eines freigelassenen des Claudius gewesen sein, und die inschrift ist daher wohl unter Nero gesetzt: vgl. Brunn in den Annali d. J. 1849, p. 137 ff.

4) Faenius Rufus wird im j. 55 n. Chr. praefectus annonae (Tacit. A. 13, 22) und bleibt in dieser stellung bis $62 \mathrm{n}$. Chr., in welchem jahre er praefectus .praetorio wird; vgl. Tacit. A. 14, 51: quippe Caesar duos praetoriis colortibus imposuerat, Faenium Rufum ex vulgi favore, quia rem frumentariam sine quaestu tractabat; im j. 65 wird er getödtet (Tacit. A. 15, 68).

5) Arrius Varts praefectus annonae im j. 71, Tacit. $H$. 4, 68: Varus praetorianis praepositus vim atque arma retinebat. eum Mucianus pulsum loco, ne sine solatio ageret, annonae praefecit; eine älnliche degradation, die übrigens ohne zweifel äusserst selten war, s. unt. bei M. Aurelius Papirius Dionysius. Varus hatte übrigens schon im j. 70 die praetoria insignia erhalten (Tacit. 4, 4), deren verleihung, wie Zumpt (Rh.' Mus. 1843 p. 268 ff.) nachgewiesen hat, nicht die erhebung in den senatorenstand zur folge hatte: vgl. über seine laufbahn Herzog in Pauly R. E. I, p. 1759.

,6) Kellermann vigiles p. 27 n. 6 :

$$
\begin{gathered}
\text { c. sextio..] F· AFRICANo } \\
\text { prae] F. VIGILVM } \\
\text { pr] AEF· ANNONAE } \\
\text { prae] F· AEGYPTI }
\end{gathered}
$$

etc.

So ergänzt Kellermann die inschrift; doch ist in der ersten zeile wohl vielmelır $C$. Tettio zu ergänzen, da er wahrscheinlich 
identisch ist mit dem praefectus Aegypti in der inschrift bei Orelli 520, die von Mommsen im C. I. L. III, n. 35 nach einem abklatsch in folgender weise publicirt ist:

FVNISVLANA VETTVLLA

CTETTI AFRICANI PRAEFAYG

VXORAVDI MEMNONEM

PR IDFEBR HORA IS

ANNO I IMP DOMITIANI AVG

CVM IAM TERTIO VENISSEM

Ist die angenommene identificirung richtig, so war er noch im februar 82 praefectus Aegypti und die letzte zeile der inschrift deutet darauf hin, dass er schon einige zeit im amte war. Seine praefectura amonae fallt daher wol noch vor $80 \mathrm{n}$. Chr. und wir können als seinen nachfolger betrachten :

7) Laberius Maximus procurator praefectus annonae ${ }^{39}$ ) im j. 80: Orelli 2537 = Marini Atti $\operatorname{CXXX}$, tab. 23, der iln richtig (p. 224) mit dem procurator Iudaeae im j. 71 identificirt (Ioseph. B. I. 7, 6, 6, wo noch immer fälschlich $L$ i berius Maximus im texte steht); wahrscheinlich sein solın ist Laberius Maximus der beim regierungsantritt des Hadrian suspectus imperio in insula exulabat (vit. Hadr. c. 5); er selbst wird damals schwerlich noch gelebt haben ${ }^{40}$ ).

\section{b) Zweites jahrhundert:}

8) C. Minicius C. fil Vel. Italus: Orelli 3651 wird nach bekleidung mehrerer procuraturen praefectus annonae und schliesslich praefectus Aegypti; die inschrift ist aus dem j. $105 \mathrm{n}$. Chr.

39) Ueber seinen titel und seine angeblichen beziehungen zum amphitheater vgl. Marini Atti p. 223, wo auch die falschen erklärungen von Morcelli, Torre, Guasco angeführt sind.

40) Nicht zu den praefecti annonae ist dagegen zu zählen: Plotius Gryphus, an den Statius Silv. 4, 9 gerichtet ist, vgl. v. 15-19: quae trino iuvenis foro tonabas, aul centum prope iudices, priusquam te Germanicus arbitrum sequenti annonae dedit omniumque late praefecit stationibus viarum, denn er war aus senatorischem stande, vgl. praef. ad Silv. lib. 4: Plotio Grypho, maioris gradus iuveni dignius opusculum reddam. Ueber ihn handelt Henzen (Arvali p. 48), der annimmt, dass hier die praefectura frumenti dandi gemeint ist; ich verstehe darunter die aufsicht über den proviant (annona) und die quartiere (stationes) für einen bestimmten feldzug, wahrscheinlich den letzten dacischen unter Domitian und halte ihn nicht für identisch, sondern für einen sohn des consul's im j. 88. 
9) Frgm. Vatic. 2. 233: . . secundum litteras divi Traiani ad Sulpicium Similem ... quae onnia litteris praefecti annonae significanda sunt. Er ist ohne zweifel identisch mit $\boldsymbol{S}$ imil is praefectus praetorio an anfange der regierung Hadrian's (Dio 69, 19. Vita Hadriani c. 9): vorher, im j. 109 war er praefectus Aegypti (Henzen $5309=$ C. I. L. III, n. 24 ${ }^{41}$ ); er war noch unter Traian centurio (Dio a. o.); vgl. über ihn Borghesi Oeuv. III, p. $127 \mathrm{f}$.

10) Frgm. Vatic. 2. 235: et ita (divi) Hadriani rescripto ad Cl. Iulianum praefectum annonae significatur. Borghesi (Oeuv. III, p. 128 f.) hält ihn für einen nachkommen des Claudius Iulianus, der auf befehl des Vitellius getödtet wurde und früher praefectus classis Misenensis gewesen war (Tacit. H. III, 57 und 77); ob er mit dem in einer inschrift genannten $\mathrm{Ti}$. Claudius Iulianus (Donati 454, $13=$ Murini Iscr. Alb. 79, 72) identisch ist, sei nicht festzustellen; ein eukel von ihm sei wahrscheinlich der gleichnamige praefectus annonae im j. 201 (s. unt.). Auf letzteren bezieht Lanciani in Bull. d. J. 1868, p. 235 die inschrift (Reinesius cl. 14, I. 194): d. m. Iavolenae Primillae. vix. ann. XVIII. m. IIII. d. XX. M. Claudius M. f. Iulianus uxori karissimae, jedoch ist es mir nicht unwahrscheinlich, dass statt Primillae vielmehr zu lesen ist: Priscillae und wir in ihr eine tochter des berühmten juristen Iavolenus Priscus zu erkennen haben. Ist diese vermuthung gegründet, so kann dieser Claudius Iulianus sehr wohl mit dem gleichnamigen praefectus unnonae unter Hadrian identisch sein, denn Iavolenus Priscus war etwa 79 n. Chr. geboren. Ob er mit dem Lei Gruter $(1035,2)$ erwäbnten Iulianus procurator Augusti zu identificiren sei, lasse ich dahingestellt.

11) L. Valerius L. f. quir. Proculus wird nach bekleidung hoher procuraturen [prae]f. [ann]on. und schliesslich praef. Aegypti: C. I. L. II, $1970=$ Henzen 6928 und besser p. 522 ; derselbe in der inschrift bei Henzen 7420e: Valeriae $C$. f. Lucillae

41) Henzen 5309: an. $\overline{X I I}$ Imp. Nerva Traiano Caesare Aug. Germanico Dacico per Sulpicium Simium praef. Aeg.; dazu bemerkt Henzen: "conlra Labusium (epigr. lat. scop. in Egillo p. 100-102), qui Si„m ile m legendum deque Sulpicio Simili praet. annonae Truiani imperato"ris cogitandum esse censuit, Letronnitus et Franzius Simium tueri student, „auctoritate nisi Gardneri Wilkinsonii qui ipse titulum exscripsit. Praefecti ",ero annonae saepe ad praefecluram Aegypli promoti sunt, et Simius for,,mam potius praebet nominis gentilicii, quam cognominis; quapropter La",busii mili certe magis placet sententia". 
L. Valeri Proculi praef. Aegypti r. p. Malac. Seine zeit wird bestimmt durch eine stadtrömische inschrift desselben mannes bei Grut. p. 255 n. 1-3, eine dedication des Corpus pistorum an Antoninus Pius aus dem j. 144 n. Cbr.: praef(ectura) L. Valeri Proculi. In einer ostiensischen inschrift (Grut. 1077) aus dem j. 152 n. Chr. wird unter der plebs des ordo corporatorum lenuncularior(um) tabulariorum auxiliare(n)s(ium) Ostiens(ium) ein L. Valerius Procultus genannt, den Haakh in Paurly's R. E. VI, p. 2366 für identisch mit dem praefectus annonae oder für den vater desselben hält; die erstere annahme ist sicher falsch und die zweite mindestens sehr unwahrscheinlich ${ }^{42}$ ).

12) Dedication an L. Aurelius Verus aus dem j. 166 von den [codica]ri. navicula [ri. infernates, cur.....] M. f. palatin $[a . . . .$. pr]aef, ann[onae]: Henzen $6479=7195$.

13) Ulpius Saturnimus praef, annon. C. I. L. II, $1180=$ Henzen 6522 aus der zeit des M. Aurel und L. Verus; sein vater ist vielleicht M. Olpius Aug. lib. Saturnimus a commentariis vehiculomim: Grut. 592, 4.

14) m.] Bassaeo M. f. s[tell.] Rufo pr. pr. [im]peratorum. M. Aureli Antonini et [l.] Aureli Veri et L. Aureli Commodi Augg. ... praef. Aegypti . praef. [ann.] proc. a rationibus . . . .: Henzen III, p. 372, schlecht: Orelli $3574^{43}$ ). Er war praefectus Aegypti zwischen 161-166 (Franz a. 0. p. 312); vgl. über ihn Dio epit. 71, 5 2. 2 (a. 172) und Excerpta Vaticana ed. Dindorf. V, p. 206. Mommsen I. N. 4916. Friedlaender Sittengeschichte I, p. 163.

15) M. Petronius M. f. quir. Honoratus wird nach verschiedenen hohen ritterämtern praef. ann(onae). praef. Aegypti: Reines. 459, $123=$ Labus epigr. d'Egitto p. 125, Labus (a. o. p. 123. 126) setzt seine ägyptische präfectur in die letzten jalıre M. Aurel's; eine etwas ältere inschrift von ihm s. bei Doni VI, $17=$ Murat. 1088, 4.

42) Haakh setzt diese inschrift, obgleich sie durch die consuln gená datirt ist, fälschlich in den a $\mathrm{nfang}$ des zweiten jahrhunderts.

43) Jebrigens ist, wie man sieht, aun(once) ergänzung; Orelli zu n. 3574 anm. 4 giebt aus den scheden des Cittadini: PRAEF. AEGYPT. PRAEF. VRB. PROC..... jedoch ist, wie mir Bormann schreibt, VRB. nur eine, natürlich falsche, vermuthung Cittadini's; möglich ist, dass statt ann(onae): vig(ilum) zu ergänzen ist vgl. Henzen 6947: praef. vigilum praef. Aegyp[ti]. 


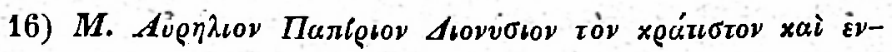

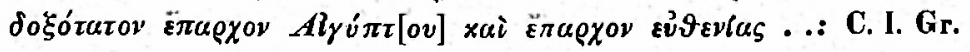
III, 5895. - Franz a. o. p. 313 lält ilın für identisch mit dem praef. ann. Papirius Dionysius im j. 189, der in diesem ant getödtet wurde (Dio ep. 72, 13 \&. 2 und 14, \&. 3) und bezielit auf seine degradation, die nothwendig angenommen werden muss, die notiz aus Aelian bei Suidas s. v. $\dot{\varepsilon} \lambda o \iota \delta o ́ \varrho \eta \sigma \varepsilon:$ o $\delta \varepsilon K \lambda \varepsilon a \nu \delta \rho o s$ żou-

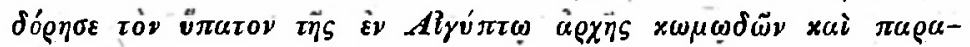

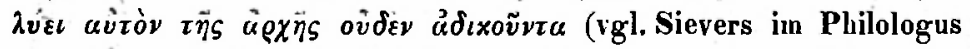
26 (1868), p. 42 und Friedlaender Sittengesch. I, p. 167); eine älndiche degradation haben wir oben bei Arrius Varus nachgewiesen und es ist daher kein grund vorhanden, an der identität zu $\mathbf{z w}$ eifeln.

Nicht genau zu bestimmen, aber wohl jedenfalls dem zweiten jahıhundert angehörig, sind:

17) C. Iunio C. $f_{i}$ quir. Flaviano praefecto annonae proc. a rationibus . ... Orelli 3331; dass die inscbrift nach Hadrian fallt, beweist der titel proc. a rationibus (Friedlaender Sittengesch. I, p. 160) und proc. Hispaniae citerioris per Asturiam et Gallaeciam (Marquardt III, 1, p. 83).

18) Ti. Claudio. Ti. fil. pal. Secundino L. Statio Macedon.... [proc]. a rationib(us). Aug. praef. an[non.] .... Kellermann vigiles p. 34, n. $31=$ Murat. 690, 6; die erwähnung der Legio II Traiana, wie der titel proc, a rationibus weisen die inschrift dem zweiten jalırhundert zu, womit auch der namenreichthum übereinstimmt; vielleicht ist er identisch mit: Ti. Cl(audius) Secundinus proc. Aug. bei Murat. 915,9 .

\section{c) Drittes jahrhundert.}

19) Cl. Iulianus p(erfectissimus) v(ir) praef. annonae im $\mathrm{j}$. 201: Grut. 313, $6=32,6$; derselbe C. I. Gr. 5973 : $\dot{\varepsilon} \pi i K \lambda$.

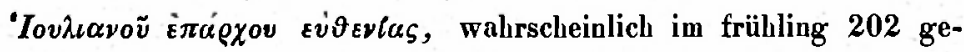
setzt (vgl. Lanciani a. o. p. 234 f.). Irrig ist die behauptung von Franz (a. o. p. 313) und Lanciani, dass er später praefectus Aegypti und unter Macrin praefectus praetorio gewesen sei; zweifelhaft die identificirung mit Claudius Iulianus, der im j. 224 zum zweiten male consul und unter Alexander Severus praefectus urbi 
war (Borghesi Oeuvres III, p. 128); ich halte ihn für identisch mit dem praefectus praetorio Iulianus, an den ein rescript ${ }^{\circ}$ des Septimius Severus und Caracalla gerichtet ist im Cod. Iust. VII, 33, 1.

20) Frgm. Vatic. 2. 235 : plus etiam imperator noster indusit... et ita Marco Diocae praefecto annonae rescripsit. Unter imperator noster ist Caracalla zu verstehen; dass statt Marco wahrscheinlich Marcio zu schreiben ist, hat schon Borghesi (a. o. p. 129) bemerkt ${ }^{44}$ ).

21) Vit. Heliogabali c. 12: ad praefectum praetorii saltatorem qui histrionicam Romae fecerat adscivit. praefectum vigilum Gordium aurigam fecit, praefectum annonae Claudium censorem (tonsorem Cuiacius; cursorem lordan), vgl. Vit. Alex. Sever. c. 22: oleum quod Severus populo dederat quodque Heliogabalus imminuerat, turpissimis hominibus praefecturam annonae tribuendo.... 22) Cod. Iust. VIII, 38, 4: Imp. Alexander A. Sabinae: secundum responsum Domitii Ulpiani, praef ecti annonae, iurisconsulti, amici mei.pp. II. kal. April. Alexandro A. Cons. (= 222 n. Chr.). Die praefectura annonae des Ulpian fallt demnach in den ersten anfang der regierung des Alexander Severus; wenn die angabe des Spartian (Vit. Pescenni Nigri c. 7): ut probant Pauli et Ulpiani praefecturae, qui Papiniano in consilio fuerunt ac postea cum unus ad memoriam, alter ad libellos paruisset, slatim praefecti facti sunt, richtig ist, so muts er das amt a libellis (Vit. Alex. Sever. c. 26 heisst er: consiliarius Alexandri et magister scrinii) nach der praefectura annonae bekleidet haben, obgleich es, wenigstens noch unter Commodus, im range niedriger war; jedoch scheint auch Papinianus, unmittelbar bevor er praefectus praetorio wurde, magister libellorum bei Septimius Severus gewesen zu sein, es mag daher diese stellung in dritten jahrbundert in höherem ansehen gestanden haben als früher. Was die notiz in der Vit. Alex. Sev. c. 26 betrifft, dass nach einigen berichten Paulus und Ulpian schon von Elagabal zu praefecti praetorio gemacht worden seien, so ist das von Ulpian wohl sicher falsch, obgleich Aurelius Victor (Caesar. c. 24, \&. 6)

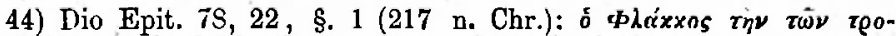

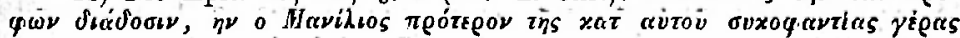

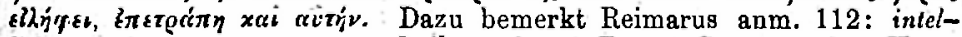
ligo praefecturam annonne und ilım stimmt Zumpt Comm. epigr. II, p. 49 bei : zu verstehen ist vielmehr die prafectura alimentorum, wie auch Manilius ausdrücklich als senator bezeichnet wird (Dio Epit. 78, 21 §.2).

Philologus. XXIX. Bd. 1. 
es ausdrücklich von ihm angiebt (vgl. Zosim. Hist. I, 11. Dio Epit. 80,2 ), von Paulus ist es eher möglich s. Bruns in Pauly's R. E. V, p. 1251; Ulpian wurde bekanntlich als praefectus praetorio im j. 228 von den prätorianern ermordet.

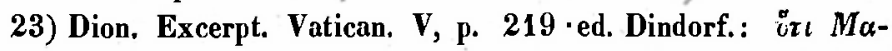

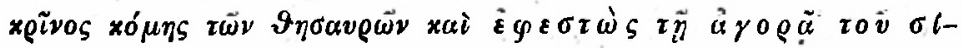
tov d. h. praefectus annonae. Es ist nicht der kaiser M. Opellius Macrinus, sondern der vater der gegenkaiser des Gallienus, Macrianus und Quietus; sein eigentlicher name ist ebenfalls Macrianus: vgl. Borghesi Oeuvr. III, p. 252. Bernhardt Gesch. Rom's von Valerian bis Diocletian I, p. 73 ff.

24) Maffei M. V. 462, 2, besser bei Guerin I, p. 432, n. 207, ergänzt von Mommsen in den Nuove memorie dell' Inst. p. 320: $C$. Attio Alcimo Feliciano p. v. vicepraeff. praet. praef, annonae. vicepraef, vigulum.' mag(istro) [rei] summae privatae etc. Die erwälnnung der res privata, der titel magister, die verschiedenen vicepräfecturen weisen die inschrift der mitte oder der zweiten hälfte des dritten jahrhunderts zu.

25) Vita Aureliani c. 13: Maecius Brundisinus praefectus annonae orientis, im j. 258 n. Chr.; über seinen titel s. unt.

26 Vita Aureliani c. 47: Aurelianus Augustus Flavio Arabiano praefecto annonae.

d) Die praefecti annonae im vierten bis sechsten jahrhundert.

27) Renier $2577=$ Henzen 5563: widmung an Constantius, walırscheinlich aus dem j. 305 (Henzen a. o.) von: P. VAL. aNTONinus proc. anNONAe sacrae PPP (= propria pecunia posuit); die ergänzungen sind von Renier, jedoch schwerlich richtig, denn procuratores annonae ohne weiteren zusatz kommen nie ver; vielleicht ist zu lesen : P. Val(erius) [a]nton[inus v(ir) p(erfectissimus) praef(ectus) an]nona[e].

28) Orelli 1084: dedication an Constantin der: Codicarii. Nabicularii. Infernates devoti n(umini). m(aiestati). $q(u e)$. eius curante Aur. Victoriano v. p. praef. ann(onae).

29) Cod. Th. XI, 30, 4 (a. 315):

Imp. Constantinus A. Amabiliano pf. annonae Africae: Cod. Th. XIII, 5, 2 (a. 315) und 3 (a. 319): 
Imp. Constantinus $A$. Amabiliano praefecto annonae.

30) Profuturus praef, annonae im j. 318 und 319: Cod. Iust. III, 11, 3. Cod. Th. XI, 29, 2 (vgl. Cod. Iust. VII, 61, 1). Cod. Th. XIV, 3, 1. III, 1, 1.

31) Cerealis praefectus annonae im j. 328 : Cod. Th. XIV, 24, 1.

32) C. Caelio Saturnino .... praefecto annon(a)e urbis : Mominsen in den Nuove memorie dell' Inst. p. 299 : in den jalren $323-$ 337 gesetzt.

33) Orelli $1091=3169$, verbessert von Henzen III, p. 291 : L. Crepereius Madalianus v. c. praef, anu(onae) cum iure gladii; derselbe bei Henzen $6480=$ Renier I. A. 2743: L. Crepercio Madaliano v. c. ... praef. ann(onae) urb(is) cum iure gladii .... Er war im jahre 341 vicarius Italiae, also etwa um das j. 340 praefectus annonae.

34) Mommsen I. N. $2618=$ Orelli 3191: M. Maecio Memmio Furio Baburio Caeciliano Placido clarissimo) v(iro).... praef(ecto). annonae urbis sacrae cum iure gladii. Fr ist consul ordinarius im j. 343, daher wahrscheinlich der unmittelbare nachfolger des Madalianus in der praefectura annonae ${ }^{45}$ ).

35) Claudius pf. annonae Alexandriae im j. 349: Cod. Th. XII, 6, 3 .

36) Imp. Constantinus A. Mastichiano praefecto annonae im j. 354: Cod. Iust. VI, 62, 1; varianten sind: Musciano und Martiano, vielleiclit ist zu lesen: Martiniano und derselbe identisch mit dem vicarius Africae d. j. 358, an den die erlasse im Cod. Th. XII, 1, 44-46 gerichtet sind.

37) Phosphoric Lucio Aur(elio). Avianio Symmacho v. c. praefecto urbi consuli propraefectis praetorio in urbe Roma fuitimisque provinciis praefecto annonae urbis Romae... Orelli 1186. Er ist der vater des bekannten schriftstellers und die inschrift aus dem j. 377 ; praefectus urbis war er 364 und daher praefectus annonae einige jahre vorher: vgl. Corsini series praefectorum p. 234 und A. Mai de Symmachorum gente p. $24 \mathrm{ff}$. in Iuris civilis anteiust. reliquiae ined. Rom. 1823.

45) Nicht mit ihm zu verwechseln ist der von Symmachus (Epp. 3, 36) erwähnte Caecilianus vir clarissimus, qui nunc communis patriae gubernat annonam; der brief ist an Ambrosius gerichtet und daher unter communis patria Gallien zu verstehen. 
38) Iulianus praefectus annonae im j. 366: Cod. Th. XIV, 15, $2=$ Cod. Iust. XI, 22, 1 vgl. Cod. Iust. XI, 10, $2:$ Impp. Valentinianus et Valens et Gratianus AAA. ad Iulianum p(raefectum) $p$ (raetorio), wo Gothofred. p(raef.) a(mnonae) lesen will.

39) Aurelianus praefectus amnonae im j. 367: Cod. Th. XIII, $6,5=$ Cod. Iust. XI, 2,1 .

40) Impp. Valentinianus et Valens AA. ad Maximum pf. annonae im j. 365: Cod. Th. XIV, 17, 3. - Gothofreda will das gesetz in das j. 368 setzen und identificirt ihn mit Maximinus hei Ammian. Marcell. 28, 1, 31 (a. 368): anhelans flatu superbo Maximinus, etiam tum praefectus annonae; andere stellen, wo er genannt wird, s. bei Gothofred. zu Cod. Th. 14, 7, 3: vgl. Haenel zu Cod. Th. 14, 7, 6: ad Maximum pf. amonae. Unter Gratian wird er hingerichtet: Ammian. 28, 1, 57.

41) Demetrianus praefectus annonae Africae: Cod. Th. XIII, 5, 12 (im j. 369) und XIII, 9, 2 (ohne jahr).

42) Ursicinus praef. annonae im j. 372: Cod. Th. 14, 3,14 .

43) Restitution von thermen durch Valens Gratian und Valentinian: Proculo Gregorio v(iro) g(larissimo) praefecto annon(ae) urbis Romae curante: 0relli 3327; aus der reihenfolge der kaiser ist ersichtlich, dass Valentinian der zweite gemeint ist und die inschrift fällt demnach in die j. $375-378$. Es ist mir daher unzweifelhaft, dass Proculus Gregorius identisch ist mit Gregorius praef. annonae im j.' 377, vgl. Cod. Th. XIV, 3, 15: Impp. Valens Gratianus et Valentinianus $A A A$. ad Gregorium v. c pf. annonae, an welchen, wie Gothofredus mit recht annimmt, sechs briefe des Symmachus (III, 17-22) gerichtet sind.

44) Ragonio Vincentio Celso v. c. . . . rexit annonariam potestatem urbis aeternae $\ldots$ im j. 389 : Gruter. 462, 1.

45) Vitalis praef. annonae im j. 403: Cod. Th. XIV, $3,21$.

46) Salvis d. d. n. n. (- dominis nostris) Theodosio et Placido Valentiniano .p. p. AAUUGG (= perpetuis Augustis) Fl(avius). [Al]exander Cresc[o]nius vc. praef. ann(onae). urb(is). Rom(a)e ad [0]rnatum porticus Placidianae posuit: Henzen 5592 ; die inschrift fallt in die j. $425-450$.

47) Hic requiescit in pace Sabmus $\overline{v s}, \overline{\text { pree. }} \overline{\text { anns }}$ etc.: de 
Rossi inscr. Christ. I, n. $978=$ Murat. 418, 7; die insclırift ist aus dem j. 522. De Rossi bemerkt dazu:, in v. 1 lege: vir spectabilis praefectus annonaes, de quibus huius tituli verbis egerunt Hagenbuch. epist. epigr. p. 339 et Suasco Mus. Cap. III, 148“. 48) Paschasio praefecto annonae: Cassiodor. Variar. XII, 9 zwischen 534-538.

Der praefectus annonae bei Murat. 810, 7 beruht nur auf falscher lesart: vgl. Marini Atti p. 765 und Henzen III, p. 75 zu Orelli n. 773.

\section{Subpraefecti annonae.}

1) Ulpio .... subpraef(ecto) annon(ae) sacrae urbis ... C. I. L. III, $1464=$ Henzen 6920; die inschrift wird von Momınsen in die j. $211-212$ n. Chr. gesetzt.

2) O. Cosconio M. f. Frontoni .... sub. praef(ecto). ann(onae), urb(is). proc. Augg. et praef(ecto) pr(ovinciae) Sardiniae: Henzen 6940 und derselbe bei Murat. 695, 1:

o. Cosconio M. f. Poll. Frontoni .... sub. praef. annonae urbis proc. Augg. ad vectig. pr. Gallic. proc. Augg. et praef. pr. Sard.

Beide inschriften sind nicht genau zu datiren, doch fallen sie nach meiner ansicht keineswegs vor Septimius Severus: über die procuratorischen praefecti der provinz Sardinien im dritten jahılundert vgl. Mommsen im Hermes II, p. 111, anm. 2; auch der proc. Augg. ad vectig(alia) pr(aediorum) Gallic(anorum) passt für diese zeit: vgl. die inschrift aus der zeit des Alexander Severus bei 0 relli 2952 : proc. (et) ad praedia Gallicana ${ }^{46}$ ); die beiden Augusti sind demnach wahrscheinlich Septimius Severus und Caracalla.

\section{Adiutores praefecti annonae.}

1) Carpus Aug. lib. Pallantianus adiutor Claudi Athenodori praef. annonae: Orelli 3200, wahrscheinlich aus der zeit des Nero (s. ob.).

2) Sex. Iulio Sex. f. quir. Possessori .... adiutori Ulpii Saturnini praef. annon(ae). ad oleum Afrum et Hispanum recen-

46) Cyriacus liest freilich: proc. at. praedia. Galliana: vgl. Friedlaender Sittengesch. I, p. 182. 
sendum item solamina transferenda item vecturas naviculariis exsolvendas . . .: C. I. L. II, $1180=$ Henzen 6522 , aus der zeit des M. Aurel und L. Verus (s. ob.).

\section{Falsche inschriften:}

\section{a) Praefectus annonae:}

Orelli 1247 (=Gud. 5, 9). Gudius 15, 6. 61, 1. 68, 5. 139, 1.

b) Praefectus annonae karae:

Mommsen I. N. falsae n. 283.

Gudius 5, 1. 17, 3. 45, 2. 125, 6. 131, 10 .

c) Adiutor praefecti annonae:

Reinesius VIII, 78.

Die aufsicht über den getraidemarkt in Rom hatten zur zeit der republik die aedilen, doch erscheint schon in früher zeit, im j. $315=439$ v. Clr. bei einer grossen lungersnoth ein ausserordentlicher praefectus annonae, L. Minucius Augurinus; erst beinahe 400 jahre später $(697=57)$ finden wir wieder diesen titel dem Pompeius verliehen ${ }^{47}$ ) dessen verwaltung, zu der ihm 40,000,000 HS bewilligt wurden, bis in die spätesten zeiten (Cassiodor. Variar. 6, 18) berühmt war. Im j. $732=22$ v. Chr., als wiederum in Rom getraidemangel herrschte, kam das volk zu Augustus: $\delta$ เxcá-

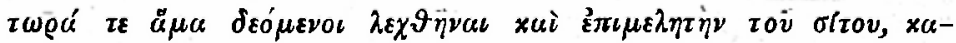

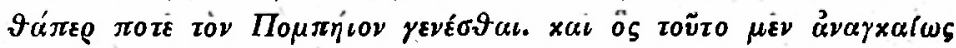
$\varepsilon \delta \xi \xi$ «to (Dio 54, 1, 3); lange scheint August diesen titel nicht geführt zu baben, denn zum j. 7 n. Chr., bei einer neuen grossen hungersnoth, die schon im jahre vorher wüthete, berichtet Dio (55,

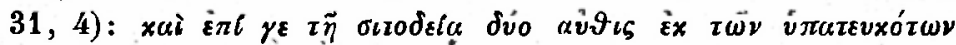

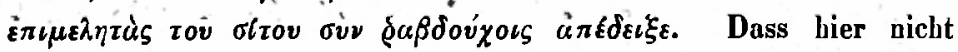
die praefecti frumenti dandi zu verstehen sind ${ }^{48}$ ), sondern eine

47) Zum j. 711 nach der niederlage des Antonius berichtet Dio

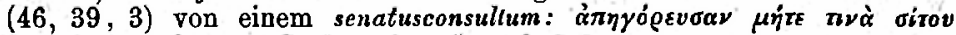

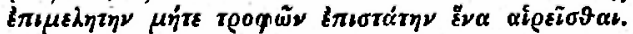

48) Darauf scheint Marquardt a. o. p. 108 anm. 529 sie fälschlich $\mathbf{z u}$ beziehen. 
ausserordentliche behörde für die Annona überhaupt, zeigen sowohl

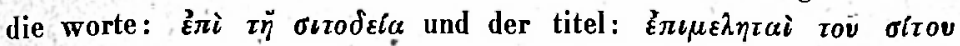
(derselbe, den August führte, s. ob.), als auch der umstand, dass schon seit $22 \mathrm{v}$. Chr. für die gewöhnlichen frumentationen eine reguläre behörde, und zwar gewesene prätoren, nicht consulare, eingesetzt war (s. unt.); nach den worten: $\delta \dot{v}$ a $u \vartheta \iota \varsigma$ muss August schon früher eine ähnliche maassiregel getroffen haben, doch ist darüber nichts bekannt. Dagegén ist es nach dieser stelle mehr als wahrscheinlich, dass damals noch nicht die praefectura annonae als ständiges amt existirte; ihre einsetzung muss demnach in die jahre 7-14 n. Chr. fallen, da bei Tiber's thronbesteigung. schon C. Turranius als praefectus annonae fungirt. Berichtet wird über die näheren umstände nichts, denn der vorschlag in der rede

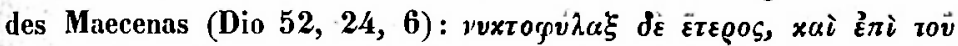

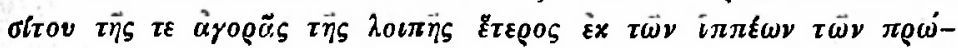

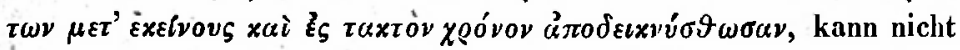
als zeugniss für die zeit des August gelten, da diese rede von anfang bis zu ende unzweifelhaft ein machwerk des Dio ist (vgl. Hoeck $R$. G. I, p. 318, anm. 2). Sehr wahrscheinlich hat gerade die hungersnoth in den jahren $6-7$ den kaiser bewogen, die prafectura amonae einzusetzen, wie es auch bezeugt ist, dass er gerade damals manches in der getraideverwaltung ${ }^{49}$ ) reformirte: vgl. Sueton. Aug. c. 42.

Ueber die competenz des praefectus annonae giebt am besten aufschluss die im jahr $\mathbf{4 9}$ (s. unt.) an Pompeius Paulinus gerichtete schrift des Seneca: de brevitate vitae, in der (c.18-19) $\left.{ }^{50}\right)$ die obliegenheiten

49) Auch mag damals die Lex Iulia de annona (Digg. 48, 12), die wohl mit recht dem Augustus zugeschrieben wird, erlassen sein, vgl. Rein in Pauly's R. E. VI, p. 10.

50) Characteristisch and besonders folgende worte (c. 18, §. 3-6): tu quidem orbis terrarum raliones administras tam abstinenter quam alienas, tam diligenter quam tuas, tam religiose quam publicas; in [eo] officio amorem consequeris, in quo odium vifare difficile est: sed tamen, milli crede, satius est bitae suae rationem quam frumenti publici nosse. Istum animi vigorem, rerum maximarum capacissimum, a ministerio honorifico quidem, sed parum ad beatam vitam apto, [ad le] revoca et cogita non id egisse te ab aetate prima omni culiu studiorum liberalium, ut tibi mulla milia frumenti bene committerentur...... non deerunt et frugalitatis exactae homines, at laboriosae operae . . cogita praeterea, quanium sollicitudinis sit ad tantam te molem obicere: cum ventre tibi humano negotium est . . quem tunc animum habuerunt illi, quibus erat mandata frumenti publici cura? . . c. $19, \S .1$ : simile tu putas esse, utrum cures, ut incorruptum 
des praefectus annonae, weun aucli unverkennbar in absichtlich geringschätziger weise, in den hauptzügen wenigstens getreu skizzirt sind: darnach hatte er hauptsächlich dafür zu sorgen, dass die zufulor für den bedarf von Rom ${ }^{51}$ ) reichlich und unverdorben ankam und in der stadt nach prüfung des maasses und gewichtes aufgespeichert wurde. Diese zufuhr kam aus allen theilen der welt, theils als naturalabgabe, theils aber auch als auf staatsrechnung gekauftes getraide; die aufsicht und bestimmung darüber, wie auch die anweisung der gelder hatte der praefectus annonae ${ }^{52}$ ) und darauf gehen die worte des Seneca: tu quidem orbis terrarum rationes administras.

Auf die schwierigkeit der stellung und die directen beziehungen zum volke, die bei eintretendem mangel selır unangenehmer natur sein mussten, wird nachdrücklish hingewiesen, und als notbwendigste eigenschaften hervorgehoben: uneigennützigkeit (abstinenter - religiose - frugalitas exacta, vgl. Tacit. A. 13, 22: ex vulgi favore, quia rem frumentariam sine quaest u tractabat) und sorgfalt (diligenter - laboriosa opera). Die monatlichen getraidevertheilungen werden dagegen mit keinem worte erwähnt, und dies bestätigt, dass der praefectus annonae mit denselben direct nichts zu thun hatte, wenn auch die herbeischaffung des zu vertheilenden getraides zu seinem ressort gelörte: für die leitung dieser frumentatiouen hatte vielmehr August schon im anfange seiner regierung eigene beamte eingesetzt, die hier eine kurze besprcchuug erfordern.

\section{Die Praefecti frumenti dandi.}

Welche beanten in der zeit der republik die monatlichen frumentationen beaufsichtigten, ist zweifelhaft (vgl. Contareni p. 72 f.); sicher ist, dass C. Gracchus bei der von ihm durchgesetzten getraidevertheilung wenigstens anwesend war (Cicer. Q. Tuscul. III, 20, 48) und möglich, dass er selbst die leitung dabei gehabt hat.

et a fraude advehentium et a neglegentia frumentum transfundalur in horrea, ne concepto humore vilietur el concalescal, ut ad mensuram pondusque respondeat . .

51) Mit der annona militaris hat dagegen der praefectus annonae sicherlich nie etwas zu thun gehabt: er war ein durchaus stadtrömischer beamter; daher können auch die liberi a copiis militaribus nicht, wie ich in Fleckeisen's Jahrbüchern 1868, p. 695 vermuthet iabe, unter seiner competenz gewesen sein.

52) Daher standen auch die getraideflotten unter seiner competenz: vgl. Lanciani Bull. d. J. 1868, p. 235. 
Nach der lex Terentia scheint die aufsicht einem prätor übertragen worden zu sein, wie Contareni a. o. wohl mit recht aus den worten des Asconius (argum. in Cornel. p. 59 Orelli) schliesst: P. Cassius practor. . . avocatus propter publici frumenti curam. Am anfange des j. 704 berichtet Caelius in einem briefe an Cicero (Epp. VIII, 6), dass der tribun Curio: legem alimentariam, qua iubet aediles metiri, iactavit; ich beziehe das auf die frumentationen, die von dem prätor an die ädilen abgegeben werden sollten; doch scheint das gesetz nicht durchgegangen zu sein oder wurde vielleicht nicht einmal eingebracht.

Aus der Lex Iulia municipalis vom j. $709=45$, z. 17 : queiquomque frumentum populo dabunt ${ }^{53}$ ) dandumve curabit, ist, wenn kein versehen des schreibers yorliegt, zu ersehen, dass die getraidevertheilung von ein em oberbeamten geleitet wurde, der melirere niedere beamte behufs der austheilung selbst dabei verwandte; ob derselbe prätor oder ädil war, lässt sich nicht entscheiden, doch spricht die bestimmung, die Cäsar im jahre vorher in bezug auf die frumentationen traf (Sueton. Caesar. c. 41): quotannis in demortuorum locum ex iis, qui receusi non essent, subsortitio a praetore fieret, dafür, dass derselbe prätor auch die vertheilung selbst leitete. $Z u$ dem folgenden jahre $(710=44)$ be-

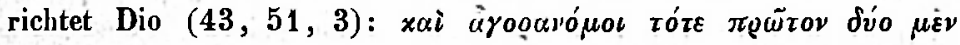

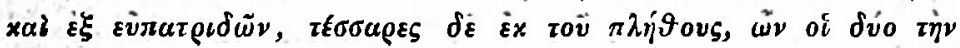

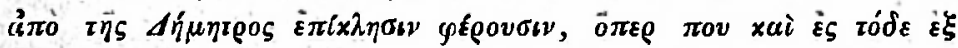

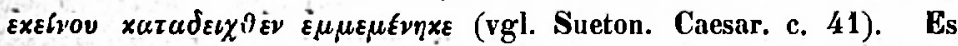
sind dies die Aediles Cereales, von welchen Pomponius (Digg.. I, 2, 32)-sagt: deinde Gaius Iulius Caesar duos praetores et duos aediles qui frumento praeessent at a Cerere cereales ${ }^{51}$ ) constituit. Dass sie ausserdem die cerealischen spiele zu besorgen liatten, berichtet Dio 47, 40 (vgl. Merkel zu Ovid. Fasti p. 161) und Goell (de Romanorum aedilibus p. 6) ${ }^{35}$ ) nimmt sogar an, dass sie nur von diesen spielen benannt worden wären und nichts mit der getraideverwaltung zu thun gehabt hätten, da diese unter dem prae-

53). So steht auf der tafel; die änderung von Mommsen (C. I. L. I, n. 206) in $d a b[i] t$ scheint mir nicht unbedingt nothwendig.

54) Mommsen bemerkt dazu: ,aut et delendum cum Haloandro aut et dicerentur a Cerere Cereales scribcndum cum Mureto".

55) Ich entnehme dieses citat dem artikel von Rein: Apdiles Ccreales in Pauly's R. E. I p. 219; die schrift selbst habe ich nicht erlangen kōnnen. 
fectus annonae und seinen unterbeamten gestanden habe: er übersieht aber dabei ganz, dass im j. 710 ein ständiger praefectus annonae überhaupt noch nicht eingesetzt war. Wenn nun auch allerdings die angaben des Pomponius reich an irrthümern sind, so scheint mir doch kein grund vorhanden, diese nachricht für falsch zu halten. Ohne zweifel hielt Cäsar die aufsicht über die getraidezufuhr für wichtig genug, um dafür zwei besondere ädilen einzusetzen; ausserdem mag er im anschlusse an seine reform der frumentationen vom j. $708=46$ ihnen zugleich die leitung derselhen übertragen haben, ja es ist nicht unwahrscheinlich, dass er schon früher ähnliches beabsichtigte und durch den oben erwähnten gesetzvorschlag des Curio durchführen wollte ${ }^{56}$ ). Allerdings können die Aediles cereales, die übrigens noch unter Gordian III erwähnt werden (0relli 977), dieses amt nur kurze zeit behalten haben, denn schon im j. $732=22$ v. Chr. befahl Augustus: dvo ä $\nu \delta \rho a_{\varsigma} \tau \tilde{\omega} \nu$

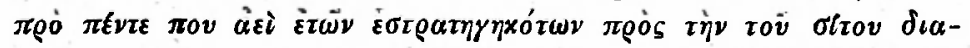

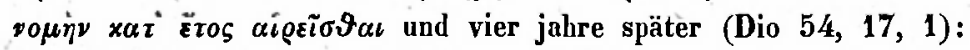

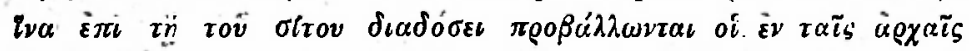

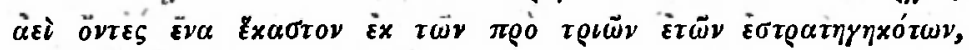

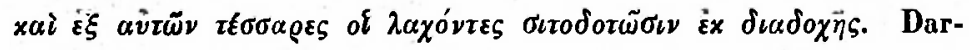
auf beziehen sich die worte des Sueton (August. c. 37): nova of ficia excogitavit: curam operum publicorum, viarum, aquarum, alvei Tiberis, frumenti populo dividundi. Erwähnt werden dieselben in dem senatusconsult vom $\mathrm{j} .743=11 \mathrm{v}$. Chr. über die Curatores aquarum bei Frontin (de aquis II 2.100-101), wonach sie, wie andere senatorische magistrate als unterbeamte scribae $l$ brarii, accensi und praecones hatten, die ihre besoldung aus dèm aerarium Saturni bezogen, und, wie schon Zumpt Rhein. Mus. n. f. II (1843) p. 281 mit heranziehung der obenange-

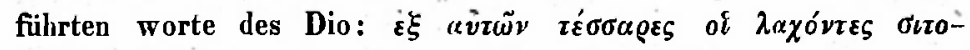
$\delta o \tau \tilde{\omega} \sigma \iota \nu \dot{\varepsilon} \boldsymbol{x} \delta_{\iota} \alpha \delta \circ \chi \vec{\eta} \zeta$ hervorgehoben hat, nicht zu gleicher zeit ihr amt versahen, sondern nach einander: ein jeder drei monate ${ }^{57}$ ). Die annahme von Zumpt (a. o.), dass in späterer zeit statt vier immer nur e in praefectus frumenti dandi ernannt worden sei, lässt

56) Dass dies gesetz auf Cäsar's antrieb eingebracht wurde, sagt Cicero a. o. ausdrücklich: (Curio) transfugit ad populum et pro Caesare loqui coepit, legemque ... alimentariam, qua iubet aediles metiri, iactavit.

57) Mit recht erklärt Zumpt a. o. die stelie des Frontin für ver- 
sich zwar nicht direct beweisen, ist aber selir wahrscheinlich. - Auch in inschriften werden diese beamten läufig erwälnt und zwar bis auf die zeit des Alexander Severus (Henzen 6048), theils unter dem titel praefectus frumenti dandi, theils mit dem zusatze: ex s(e-

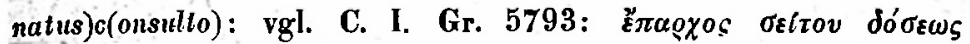
dáguatı бvyxiñzov 'P $\omega \mu \alpha\left(\omega \nu{ }^{58}\right)$ : dieser zusatz, der sich schon unter Tiber (Henzen 5368. Orelli 3141. C. I. Gr. 5793) und noch unter Caracalla (0relli 77) findet, geliörte vielleicht nur zur vollständigen titulatur und konnte daher auch fortbleiben (vgl. dagegen Zumpt a. o. p. 282 und Marquardt a. o. p. 108 a. 532): die art der ernennung, die Dio $(54,17,1)$ angiebt, galt gewiss nur für die ersten wahlen.

Nach der oben angeführten stelle des Dio waren diese praefecti gewesene prätoren und im allgemeinen bestätigen dies die inschriften; dagegen spricht nicht, dass der titel zuweilen (Mommsen I. N. 4234. 5471. Grut. 440,2) ausserhalb der reihe der regulären ämter gesetzt ist. Jedoch muss M. Opsius Novius Fannianus dieses amt zwischen ädilität und prätur bekleidet haben (vgl. C. I. Gr.

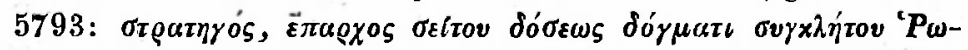

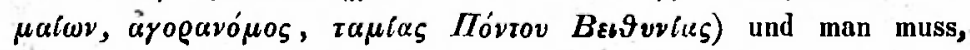
wenn man sich nicht zu der immer sehr bedenklichen annahme eines irrthums seitens des steinmetzen verstehen will, wirklich hier eine ausnahme von der regel anerkennen, die leicht durch einen augenblicklichen mangel an prätoriern herbeigefülırt sein konnte und besonders bei einem so unwichtigen amte mir unbedenklich erscheint. Ueber L. Memmius C. F. Gal. q. tr. p[leb. (Henzen, richtiger Borghesi : $p[l . p r$.) frumenti curator ex s. c., Henzen 6493, hat Borghesi (0euvres I p. 153) gehandelt; sein vater war consul im j. 720 und er selbst der älteste der uns überlieferten praefecti frumenti dandi: es scheint demnach in der ersten zeit der titel frumenti curator gelautet zu haben; doch finden sich schon in dem senatusconsultum aus dem j. 743 bei Frontin (s, ob.) beide titel neben einander.

derbt und glaubt, dass in dem codex einige worte ausgefallen seien; es ist mir jedoch nicht undenkbar, dass Frontin selbst den schluss des senatusconsultum auf ungeschickte weise verkürzt hat.

58) Ueber Henzen 5368: praef. frum. ex s. c. s. vgl. de Rossi im Bull. d. I. 1852 p. 57 und Mommsen R. g. d. A. p. 128 a. 2. 
Es standen also die monatlichen frumentationen unter der aufsicht von beamten senatorischen ranges, welche die nöthigen apparitores zu ihrer verfügung hatten; dass ihrer nach Alexander Severus nicht mehr erwähnung geschieht, ist nic.lt zufall; denn, wie wir oben bemerkt haben, hörten auch die monatlichen frumentationen schon vor Aurelian auf und an ihre stelle traten tägliche brodvertheilungen, die unter der aufsicht des praefectus annonae standen ${ }^{59}$ ). Traian oder vielleicht schon einer seiner vorgänger hatte ein collegium von bäckern eingesetzt ${ }^{60}$ ), die, wenigstens im dritten jahrhundert, vom kaiser selbst ernannt wurden und unter der cufsicht des praefectus annonae standen; sie waren vor den anderen bäckern privilegirt und erhielten das getraide aus den kaiserlichen speichern zu mässigem preise, mit der verplichtung, gutes und billiges brod zu backen ${ }^{61}$ ).

59) Dasselbe gilt von den ölvertheilungen: vgl. Vit. Alex. Sever. c. 22. Symmach. Epp. X, 48 . Cod. Th. XIV, 24, 1 mit dem commentar von Gothofredus; an ihn wird natürlich auch das zu vertheilende öl abgeliefert, vgl. die dedication der mercatores frumentarii et olearii Afrarii an C. Iunius Flavianus praefeclus annonae (Orelli 3331) und der negotiatores olearii ex Baetica an ihren patron M. Petronius Honoratus praef. ann. (Reines. 459, 123). Auch die suarii Romanae copiae causa reperti stehen unter seiner aufsicht (Cassiodor. Variar. 6, 18); über die vertheilung von schweinefleisch 8 . oben.

60) Vgl. Aurelius Victor Caesar. c. 13 \&. 5: et annonae perpetuae mire consultum, reperto firmatoque pistorum collegio. Borghesi (Oeuvres III p. 134) schreibt: recepto firmatoque (ebenso Marquardt $V^{2}$ p. 26 a. 185) was wohl nur auf versehen oder conjectur beruht. Richtig ist übrigens die überlieferung reperto schwerlich, wenn auch nicht, wie Borghesi und Marquardt thun, aus der inschrift bei Spon Miscell. p. $64=$ Doni Cl. IX n. $11 \mathrm{zu}$ schliessen ist, dass. schon unter Augustus ein collegium siliginariorum existirt habe, denn diese inschrift ist, wie mir Bormann mittheilt, ron Ligorio gefälscht; trotzdem glaube ich, dass bei Victor zu lesen ist: reparato firmatoque pistorum collegio. Diese einrichtungen Traian's sind erst durch die auffindung der fragmenta Vaticana genauer bekannt geworden; besonders wichtig ist dafür \$. 233 und 235. Dass dieses collegium jedoch nicht aus 100 mitgliedern bestanden hat, wie Huschke u. a. angenommen haben, sondern centenarium vielmehr auf pistrinum zu beziehen ist, beweist die durch Studemund's neue collation restituirte stelle bei Gaius I: §. 34, die mit seinen ergänzungen folgendermassen lautet: denique Traianus constituit, ut, si (Latinus) in urbe tr[ien] nio pistrinum exercuerit, [in quo in] dies singulos non minus quam centenos m(odios) frumenli $p[i]$ nserel, ad ius Quiritium perve$n$ [iret], vgl. Studemund a. o. p. 10. Ausführlich hat über diese backer gehandelt Marquardt $V^{2}$ p. 26 ff.; über die thätigkeit der ädilen in früherer zeit bezüglich der backer vgl. Jahn in den Annali d. J. $1838 \mathrm{p}$. 246: das monument des M. Vergilius Eurysaces, der in der inschrift pistor redemptor heisst.

61) Vgl, Cod. Th. XIV, 15, 1 (a. 364): Impp. Valentinianus et Va- 
Für die organisation dieses collegium ist eine dedicationsinschrift des Corpus pistorum an Antoninus Pius aus dem j. 144 von interesse (Grut. 255 n. 1-3); auf der rechten seite des steiues steht praef(echura, nämlich annonae, s. ob.) L. Valeri Proculi, darüber ein korb mit ähren; auf der linken seite ein mühlstein und darunter:

\section{Curantibus}

I. Caeret . . Zmaragdo

L. Maevio. Epicteto. Quinq(uennale). II Quaestoribus

C. Pupio. Firmino. II

C. Calpurnio. Maximo.

Die beziehungen des praefectus annonae zu dem brode und den bäckern treten in den späteren quellen mehr und mehr in den vordergrund, ja man kann sogar behaupten, dass zu Cassiodor's zeit die beaufsichtigung der backer und der bäckereien ${ }^{62}$ ) die hauptsächlichste obliegenheit dieses beamten bildete, vgl. Cassiodor. Variar. 6, 18: tui si quidem studii est, ut sacratissimae Urbi praeparetur

lens AA. ad Symmachum pf. U.: ne pessimus panis populi Romani usilus ministretur sola ducentena milia modiorum frumenti integri ulqne intemerati iuxta priscum morem mensores et caudicarii levioribus preliis pistoribus venundare coganlur (vgl. Cod. Th. XIV, 19: de prelio panis Ostiensis). Ausserordentlich häufig ist die erwähnung dieser pislores in später zeit, vgl. besonders Cod. Th. XIV, 3: de pistoribus et catabolensibus mit dem paratitlon des Gothofredus und seinem commentar zu 1. 1 und 18; auch der titel im Cod. lust. XI, 15 handelt von ihnen.

62) Es gab nach der Noitia urbis in Rom 254 pistrina (im breviarium werden sie officinae pistoriae genannt); in Constantinopel waren unter Theodosius dem jüngeren 10 pistrina pullica und 120 privata (vgl. Preller Regionen p. 112 anm.). - Die geschäftsfuhrer der backer, die die contracte mit der regierung abschlossen, heissen mancipes (vgl. Marquardt $V^{2}$ p. 28 a. 204); der titel im Cod. Th. XII, 16 ist de mancipibus betitelt und dieselben werden auch in Constantinopel erwähnt (Cod. Th. XIV $, 16,3)$. Dass aber auch diese für eigene, nícht für kaiserliche rechnung geschäfte machten, scheint mir aus der bestimmung im Cod. Th. (XIV, 3, 15) hervorzugehen, dass die decoctores (bankerotteure) nicht wieder in das Corpus pistorum aufgenommen werden sollen. Sie scheinen in späterer zeit (de Rossi: inscr. christ. I, 495 und 972 aus den j. 401 und 520) auf eine bestimmte region in Rom beschränkt gewesen zu sein, doch wird schon unter Trajan ein pislor Romaniensis ex. reg. XIIII (Orelli 1455) genannt, vgl. Marquardt $V^{2}$ p. 27 a. 197. Ueber die patroni pistorum vgl. Gothofred. zu Cod. Th. XIV, 3, 7 (t. V p. $174 \mathrm{ff}$.); in einer inschrift aus dem j. 575 aus Ravenna (Henzen 6336) findet sich ein pater pistorum regis Theodorici; über die mühlen am Ianiculum vgl. Preller Regionen p. 214 f.; über das. Forum pistorium: das. p. 205 . 
annona, ubique redundet panis copia, et tam magnus populus tamquam una mensa satietur. Per officinas pistorum cibosque ${ }^{63}$ ) discurris, pensum et munditiam panis exigis .... ne quis autem provocet abiectis te hominibus imperare, dignitati quoque tuae pistorum iura famulata sunt, quae per diversas mundi partes possessione latissima tendebantur.

Die aufsicht über die zufuhr des getraides aus den provinzen, die früher jedenfalls die wichtigste seite dieses amtes gewesen war, hatte in späterer zeit, wahrscheinlich seit Constantin, nicht mehr der praefectus annonae, sondern der praefectus praetorio (s. unt. und Cassiodor. a. o.: triticeas quidem copias praefectura praetoriana procurat) und dieser umstand, wie noch andere ursachen bewirkten, dass die praefectura annonae allmählich zu einem unbedeutenden und wenig geachteten amte herabsank; wie und wann dies geschehen ist, wollen wir jetzt näher untersuchen.

\section{Rang und titel des Praefectus annonae.}

Die praefectura annonae gehörte von August bis auf Constantin zu den höchsten ritterämtern; dies zeigt z. b. die erwähnung bei Tacit. A. I, 7, wo mit den consuln der praefectus praetorio und der praefectus annonae dem Tiber den eid der treue leisten; ebenso XI, 31: tum potissimum quemque amicorum vocat; primumque rei frumentariae praefectum Turranium, post Lusium Getam praetorianis inpositum percontatur; auch Dio $(52,24,6)$ lässt dem August durch Maecenas rathen, den praefectus annonae ix $\tau \ddot{\omega} \nu$ i $\pi$ $\pi \epsilon \omega \nu \tau \tilde{\omega} \nu$ $\pi \varrho \omega ́ \tau \omega \nu$ zu wählen. Noch deutlicher sprechen die inschriften für diese hohe stellung; denn die praefectura annonae wird erst nach den höchsten procuraturen, sogar nach der praefectura vigilum (Kellermann p. 27 n. 6) und unmittelbar vor der praefectura Aegypti (Orelli 3651. Kellermann a. o. Reines 459, 123) bekleidet, ja es ist, wie gesagt, wahrscheinlich, dass der erste praefectus annonae Turranius schon vorher praefectus Aegypti gewesen $\operatorname{war}^{64}$ ): es .wäre das ein deutliches zeichen, einen wie hohen

63) Cibosque muss corrupt sein, vielleicht ist zu lesen: clibanosque: vgl. die pistores clibanarii und die panes in clibanis cocti bei Marquardt $V^{2}$ p. 29 , a. 217.

64) Ueber die degradation des Arrius Varus (ne sine solatio ageret) und des Papirius Dionysius s. ob. 
werth Augustus auf dies von ihm neu gesclaffene amt legte. Dass noch am ende des dritten und anfang des vierten jahrhunderts die praefectura annonae, obgleich die rittercarriere scbon mannigfache änderungen erfahren hatte, ihren hohen rang behauptete, beweisen die inschriften bei Guerin n. 207 (vice praeff. praet. praef. annonae vice praef vigulum .....) und in den Nuove memorie dell' Instit. p. 298 (. . . vicario praefecturae urbis iudici sacrarum cog. vicario praeff. praetorio bis in urbe Roma et per Mysias examinatori per Italiam praefecto. annone urbis rationali private....). Noch im j. 389 heisst es: amplissimi honoris et qui solet seniorib(us) provenire ornamenta promeruit nam rexit annonariam potestatem urbis aeternae (Grut. 462, 1). Jedoch ist es sehr natürlich, dass dieses amt durch die verlegung der hauptstadt nach Constantinopel und die gänzliche unterordnung unter die praefectura $u r$ bis $^{65}$ ) bedeutend an ansehen einbüssen musste, und dies ist auch in der schwülstigen formula praefecti annonae bei Cassiodor (Variar. VI, 18) ${ }^{66}$ ) zwischen den zeilen zu lesen, während es der gleichzeitige Boethius (de consol. philos. III, 4) mit nackten worten ausspricht: si quis quondam populi curasset annonam, magnus habebatur: nunc ea praefectura quid abiectius? ${ }^{67}$ ).

Wenn Pomponius (de origine iuris Digg. I, 2, 33) sagt: praefectus annonae et vigilum non sunt magistratus, sed extra ordinem utilitatis causa constituti sunt, so versteht er unter magistratus die beamten, die sich aus der zeit der republik noch in der kaiserzeit erhalten haben, wie die quästoren, ädilen u. s. w. In

65) Notitia dign. occid. c. 4: sub dispositione viri Illustris praefecti urbis Romae habentur administrationes infra scriptae:
1) Praefectus annonae.
2) Praefectus vigilum. etc.

Vgl. Boecking N. D. II p. 179 f. und Gothofred. index zum Cod. Th. p. $10 \mathrm{f}$.

66) Dieselbe beginnt folgendermassen: si ad hanc mensuram censendae sunt dignitates, ut tanto quis honorabilis habetur quanto civibus profuisse cognoscitur: is certe debet esse gloriosus, qui ad copiam Romani populi probatur electus. Sowohl dieser eingang, wie auch die ganze folgende definition des amtes, zeigt, dass die praefectura annonae sehr an bedeutung verloren hatte.

67) Jedoch führt er, wenn die ergänzung bei de Rossi Inscr. Christ. I n. 978 richtig ist, gerade in dieser zeit den titel vir spectabilis, während die praefecti annonae bis auf Constantin nur viri perfectissimi, später clarissimi sind: man scheint demnach officiell dem bedeutungslos gewordenen amte äusserlich eine hohe stellung gelassen zu haben. 
diesem sinne ist der praefectus annonae allerdings kein magistratus, sondern ein procurator Caesaris; aber man muss die worte des Pomponius nicht so verstehen (wie es z. b. Boecking N. D. II p. 177 zu thun scheint), als ob praefecti annonae in der frühen kaiserzeit nur, wenn es nöthig war, eingesetzt worden wären; vielmehr ist es sicher, dass seitdem August dieses amt geschaffen hatte, es stets besetzt wurde und einen festen platz in der reihe der ritter-. würden einnahm.

Ueber das gehalt des praefectus annonae ist nichts bekannt; da aber die höchste procuratur mit 300,000 HS jährlich dotirt war, und noch die praefectura vigilum dazwischen lag, so muss das gehalt 400-500,000 HS betragen haben.

Der titel: $v$ (ir) p(erfectissimus), der sich zum ersten mal in einer inschrift aus der zeit des Antoninus Pius findet (Naudet de la noblesse p. 98), erscheint mit der praefectura annonae verbunden im j. 201 (Grut. 313, $6=32,6$; in der griechischen inschrift desseḷen mannes : C. I. Gr. 5973 fehlt er dagegen) und denselben titel führte der praefectus annonae noch unter Constantin (Orelli 1084); nach Constantin oder vielleicht noch in der späteren zeit seiner regierung erhält er den titel $v$ (ir) c(larissimus) (vgl. Mommsen Nuove memörie d. J. p. 318); es ist sehr wohl möglich, dass diese veränderung zusammenhängt mit der ertheilung des ius gladii, die ebenfalls in dieselbe zeit fält. $V($ ir) $s$ (pectabilis) heisst der praefectus annonae in der inschrift vom j. 522 hei de Rossi 1. n. Chr. 978; dagegen bezieht sich im Cod. Th. 12, 6, 24: andiente viro spectabili vicario et praefecto annonae der titel wohl nur auf den vicarius (vgl. Boecking N. D. II p. 177). Bemerkenswerth ist es, dass in den inschriften der ersten drei jahrhunderte bei dem titel: praefectus annonae sich nie der zusatz urbis oder urbis Romae findet; ja noch in der inschrift bei Orelli 1084 aus der zeit des Constantin heisst es: curante Aur. Victoriano v. p. praef. ann(onae). Characteristisch ist dafür ferner Vit. Aurelian. c. 47: quadam epistula data ad praefectum annonae urbis etiam ipse gloriatur; es folgt dann die authentische adresse, ohne den zusatz urbis: $\mathbf{A u -}$ relianus Augustus Flavio Arabiano praefecto annonae: zum ersten mal findet sich dieser zusatz in der inschrift des C. Caelius Saturninus praefectus annon(a)e urbis, doch ist daraus nicht der schluss zu ziehn, dass dieselbe erst nach der gründung Constanti- 
nopel's gesetzt sei, denn einerseits fehlt dieser zusatz auch in der nachconstantinischen inscbrift bei Orelli $1091=3169$, andrerseits findet sich schon im anfange des dritten jahrhunderts ein subpraef(ectus) amon(ae) sacrae urbis (C. I. L. 3, 1464) und ein subpraef(ectus) ann(onae) urb(is) (Henzen 6940 und Murat. 695, 1); auch machen der praefectus annonae Orientis (Vit. Aurelian. c. 13) und der prqefectus annonae Africae aus dem j. 315 (Cod. Tl. XI, $30,4)$, über die wir später sprechen werden, gegen eine solche annalıme bedenklicl,

\section{Dauer des amtes.}

In der oft citirten stelle des Dio $(52,24,6)$ giebt Maecenas dem August den ratb, den praefectus vigihum und den praefectus annonae auf bestimmte zeit ( $\xi_{\zeta} \tau \alpha x \tau$ ò $\chi^{\prime}$ qóvov) zu wällen: $x a \vartheta a ́-$

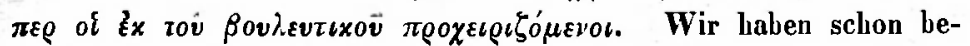
merkt, dass alle diese angaben für die zeit des August keinen glauben verdienen und löclsstens als zeugniss für Dio's zeit. gebrauclit werden können ${ }^{68}$ ); doch ist es kaum denkbar, dass jemals die praefectura annonae ein amt von einer bestimmten zeitdauer gewesen sei, denn dadurch unterscheiden sich die procuraturen von den senatorischen ämtern, dass sie sämmtlich auf unbestimmte zeit verliehen werden, d. h. auf so lange, als es dem kaiser gefällt, das mandat seinem procurator zu belassen: ein kaiserlicher procurator war aber sowohl der praefectus vigilum als der praefectus annonae ${ }^{69}$ ). Ausserdem aber sind wir in der lage, schlagende beispiele einer nicht begränzten amtsdauer anfüliren zu können; so war Turranius schon im jabre 14 n. Chr. praefectus annonae und noch im j. 48 (Tacit. A. I, 7 und XI, 31), also mindestens 34 jalıre; Faenius Rufus wird im j. 55 praefectus annonae und direkt von diesem amte im j. 62 zur praef praetor. befördert (vgl. Tacit. A. 13, 22 und 14, 51); Amabilianus ist praefectus amnonae im j. 315

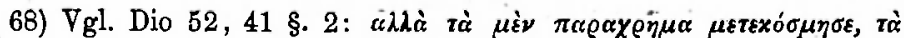

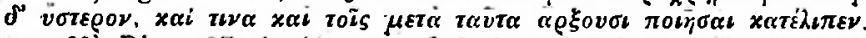

69) Digg. 27, 1, 41 pr. und §. 1: administranles rem principum .... a tulela itemque cura tempore administrationis excusantur. Idemque custoditur in his qui praefecturam annonae vel vigilum gerunt, und Seneca de brev. vit. c. $20 \S$. 3: Turannius...cum vacationem procuration is ab C. Caesare ultro accepissel.

Philologus. XXIX. bd. 1. 
und noch 319 (Cod. Tb. 13, 5, 2 und 3). Es soll jedoch nicht damit geleugnet werden, dass eine bestimmte antsdauer in späterer zeit gebrauch geworden sei, wie dies gewiss, je fester sich die procuratorische carriere ausbildete, allmablich bei den meisten ritterämtern geschehen ist: eine ernennung auf bestimmte zeit, wie sie Dio angiebt, hat aber sicherlich weder in früher noch später zeit stattgefunden.

\section{Die gerichtsbarkeit des Praefectus annonae.}

Dass der praefectus annonae civilgerichtsbarkeit in sachen der annona besass, bezeugen mebrere stellen in den Digesten aus der zeit des M. Aurel $(48,12,3)$ und dem dritten jahrhundert $(48,2$, $13 ; 14,5,8 ; 14,1,1$ \&. 18). Das recht über leben und tod hat dagegen der praefectus annonae bis auf Constantin nicht gehabt, erst in nachconstautinischer zeit findet sich der titel praefectus annonae cum iure gladii, zuerst bei L. Crepereius Madalianus (Orelli $1091=3169$ und Renier 2743), der etwa in den jahren $337-340$ dieses amt bekleidete; Caelius Saturninus ist noch praefectus annonae obne das ins gladii. Ausserdem findet sich nur noch $M$. Maecius Memmius Furius Baburius Caecilianus Placidus c. v. cum iure gladii: Mommsen I. N. $2618=0$ relli 3191; es feblt dagegen dieser zusatz schon bei Symmachus (Orelli 1186), der um das j. $\mathbf{3 6 0}$ praefectus annonae gewesen sein muss und ebenso bei allen späteren: es scheint daher das ius gladii ihnen, nachdem sie es höchstens dreissig jahre besessen batten, wieder entzogen worden zu sein. Ich halte es nun für wahrscheinlich, dass das ius gladii dem praefectus annonae bei der verlegung der hauptstadt nach Constantinopel verlieben $\cdot$ worden sei ${ }^{70}$ ), da früher die appellation von demselben sehr wahrscheinlich direct an den kaiser ging ${ }^{71}$ ), und dies

70) Darnach müsste Caelius Saturninus vor 330 praefectus annonae gewesen sein.

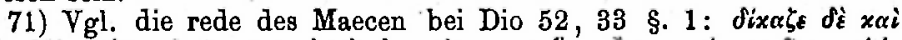

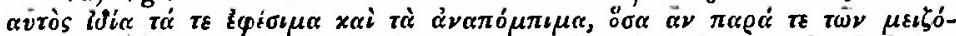

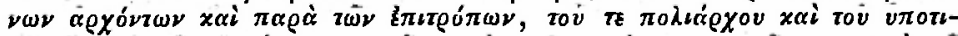

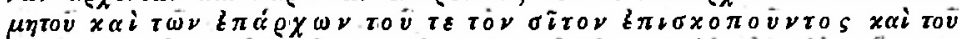

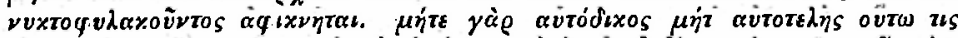

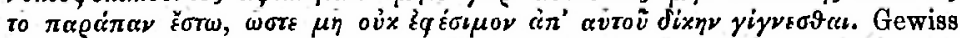
mit unrecht nimmt Marquardt $\mathrm{II}^{3}$ p. 280 an, dass schon seit August von dem praefectus annonce an den parefectus urbis appellirt worden sei. 
sich nach der verlegung der, residenz nicht melır durchfülıren liess. Später lielt man es dann woll für zweckmässig, dem praefectus amnonae, der durch die vollständige unterordnung unter den praefectus urbi melır und melır an anselın verlor,(s. oben), dies recht wieder zu entziehen und die oberste entscheidung über die fälle, welche die annona betrafen, dem praefectus urbi zu übertragen und davon finden sich selır deutliche spuren im Cod. Theodosianus (vgl. die stellen bei Gothofredus in dem index zum Cod. Th. p. 10-11). Eine gewisse iurisdiction behielt er freilich auch noch in späterer zeit, vgl. z. b. Grut. 462, 1 aus dem j. 389: rexit annonariam potestatem urbis aeternae ea aequitate ut inter omnes qui ad eum anmo litigantis intrassent parentem se plerumque magis lis quam indicem praebuisset; wichtigere fälle entschied aber, wie gesagt, der praefectus urbi mit zuzieliung des praefectus annonae, vgl. z. b. Cod. Th. 13, 5, $38^{72}$ ).

Was die subpraefecti annonae urbis anlangt, die in inschriften des dritten jalırhunderts erwälint werden, so halte ich dieselben flir eine schöpfung des Septimius Severus, der überhaupt bedeutende reformen im verwaltungswesen vorgenommen hat. Sie waren olne zweifel in Rom selbst angestellt, wenn auch die betreffenden inschriften, da sie dieses amt nicht zuletzt bekleideten, in Sardinien und Dacien gefunden sind; dasselbe wird nach niederen procuraturen und vor einer provinzialprocuratur bekleidet und sie gehören dem ritterstande an. Ob dieses amt sich lange erhalten liat, ist fraglich, keineswegs länger, als bis zur reform Diocletian's, denn nirgends geschieht desselben in den späteren quellen erwälnnung. In früherer zeit scheint die stelle des subpräfectus durchi einen beamten ausgefüllt $\mathrm{zu}$ sein, der den titel adiutor praefecti annonae führte; ein solcher wird genannt in einer stadtrömischen insclirift aus der zeit des Nero (Orelli 3200) und zwar war er ein kaiserlicher freigelassener; über den adiutor praefecti annonae in Spanien (C. I. L. II, 1180) werden wir unten sprechen.

\section{Die unterbeamten:}

a) Officium annonae :

1) Henzen 6569 (Bononiae):

72) Bethmann-Hollweg Civilprocess III p. $64 \mathrm{f}$. 
Festus Caes. n. tabellarius ex officio annonaes; wahrscheinlich aus der zeit der Flavier, denn seine frau heisst Flavia Cominia.

2) Marini Atti p. 531 und 614 n. 48 (Romae):

M. Aurelius [aug. lib.] Aloides tab[ulari oder cllari]us ex officio [urba oder anno]nae, praefe[cturae oder cti]. Die ergänzungen sind von Marini; die inschrift ist aus der zeit des M. Aurel.

3) Henzen 6541 (Zagaroli) :

Abascantus Caes. n. ser. ver. n. (= verna) disp(ensator). annon(ae), aus unbestimmter zeit.

Falsche inschriften:

Mommsen I. N. falsae $156=$ Orelli 4002:

C. Memmio C. f. Gal. Luperco disp. annon. Aug.

Gudius 5, 1. 17, 3. 45, 2. 125, 6. 131, 10. 141, 1:

Gudius 123, 5: procurator annonae karae.

proc. annonae Flaminiae et Picen.

Mommsen I. N. falsae 675:

proc. leg. $\bar{X}$. Freteusis annonae $\operatorname{kar}(a)$.

Gudius 67, 1: procur. olearii Afrarii.

b) Horrea :

1) Murat. 891, 2 (Romae):

Calamus Ti. Claudii. Caesaris Augusti Germanici Pamphilianus vilicus, ex horreis Lollianis; aus der zeit des Claudius.

2) Murat. 888, 1 (Rumae):

$\begin{array}{cl}\text { ROS } & \text { M. ANTONI } \\ \text { caesARIS. HORR. } & \text { PELORIS }\end{array}$

LOLLIANIS

Die inschrift gehört der frühen kaiserzeit an.

3) Garrucci inscr. Reatinae n. $12=$ Doni 334, 81 (Reate):

Ti. Claudius Dafnio horrearius; aus der zeit des Claudius oder Nero.

4) Henzen 7233 (Romae):

M. Cocceius Hilarvs offici(i)s suis hic in horreis Nervae amorem habuit maxumum; aus der zeit des Nerva. 
Aus unbestimmter zeit:

5) Murat. 916, 3 (Romae):

Stephanus Caesar(is servus) horr(earius).

6) Maffei M. V. 133, 7 (in museo Veronensi):

... amus. horearius Agripp. Antiocini coniugi Arscusa.

7) Orelli 46 (Romae):

C. Iulius Hermes conductor horreorum Seianorun lustri. ter. $\mathbf{t} 1$.

Falsche inschriften:

Orelli 3214 (Romae):

A. Menenio. A. f, qui. Capitio horeario ple. et trib. Pal.

Fabretti 37, $180=$ Reines. VI, 126 :

L. Pallius L. f. Sulpicianus nat. Bessus Tlırac. procurator horreor. Galbianorum Avent .....

Gudius 5, 2:

L. Helvius L. l. Hermodorus nat. Hermopolit. proc. horreorum Helvianor. region. Coelimon.

\section{c) Porticus Minucia:}

1) Gruter 173, 1 (Romae):

Ti. Claudius Aug. lib. Innuarius curator de Minucia die XIIII ostio XLII

2) Orelli 516 (in agro Attidii):

C. Camurio C. f. Lem. Clementi . . . proc. Aug. ad Miniciam; aus der zeit des Traian, denn er ist praef. $i . d$. imper. Caes. Traiani Aug.

3) C. I. L. III, $249=$ Grut. 402,4 (Ancyrae):

. L. Didio Marino v. e..... proc. Minuciae; er ist proc. provinc. Arabiae, also ist die inschrift nach $105 \mathrm{n}$. Cbr. (Marquardt III ${ }^{1}$ p. 201), wahrscheinlich in der letzten lälfte des zweiten jahrh. gesetzt.

4) Orelli 2852 (Romae):

Alciniades publicus Minicianus.

Deber den angeblichen Miniciae rationalis bei Grut. $622,5=$ Murat. 680, 6 vgl. Marini atti p. 807 . 
d) Fiscus frumentarius :

1) Gori I. E. $345,25=$ Murat. 1489,5 (Florentiae):

T. F(lavii). Phoebi tab(ularii) f(isci) f(rumentarii).

2) Fabretti 249, 22 (Romae):

Athicti Ang. l. a libellis fisci frum(entarii), walsscheinlich aus der zeit der Flavier, denn seine frau heisst: Flavia Eutycha.

3) Fabretti 37, $183=$ Gud. 124, 1 (Romae):

T. Flavio Apollonio a libellis f(isci). f(rumentarii).

4) Gori I. E. 1, 296, $25=$ Murat. 68, 13 (Florentiae)

Crescens Alypianus Imp. Caesaris Nervae Traiani Aug. Germ. Dacici disp(ensator) fisci fr(umentarii).

Derselbe bei Orelli 790 (Romae): A

Dedication an Traian von Crescens Alypianus disp(ensator) fisci frumentarI.

5) Grut. 592, 1 (Romae):

Donato Augustorum tabulario rationis fisci frument(arii). Sein vater heisst P. Aelius Aug. lib. Donatus, die inschrift gehört daher in die mitte oder die letzte halfte des zweiten jahrhunderts.

6) Marini Atti p. 553 (Romae):

Geniali Aug. l. tabulario fisci frumentar(ii) aus unbestimmter zeit.

Falsch ist Orelli 3215 (Romae):

M. Caecilio. M. f. Q. n. Paullino a libellis fisci $f$.

e) Beamte a frumento.

1) Doni XIII, 31, daraus Murat. 894, 7 (Romae in vinea quadam in via Appia): Ti. Claudius Aug. l. actor a frumento .... Die inschrift ist mir des fehlenden cognomen wegen verdächtig, denn actor ist schwerlich als cognomen zu fassen; auch die ortsbezeichnung ist nicht gerade vertrauenerweckend. Doni nalm sie „ex antiquo Cod. mis."; andere quellen liegen auch, wie mir Bormann schreibt, in den scheden des C. I. L. nicht vor; in den ligorischen scheden ist sie jedoch nicht.

2) Murat. 769, 3 (Velitris): . . a cubiculo proc. . . . a a frum. accensus. patron ... Scheint aus früher zeit, da zwei Clau- 
diae, wahrscheinlich kaiserliche freigelassene, darin erwähnt werden.

3) C. I. L. 3, $333=$ = C. I. Gr. 3738 (Cii Bithyniae): Flaviae Sopheni [ge]nialis Caesaris Aug. |se]rvos verna dispen(sator) [ad]

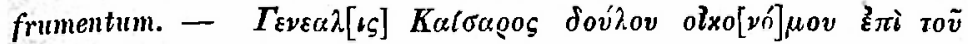

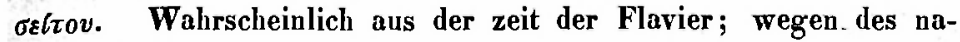
mens der frau wohl nicht identisch mit Genialis bei Marini Atti p. 553 (s. oben fiscus frum.).

4) Gruter 593, 1 (Romae):

Nitoris Domitiae Aug. (besser nach handschriftlicher überlieferung: Nitori Domitiaes Aug.) actori a frumento, also aus der zeit des Domitian.

5) Marini sched, ined, vol. 84 (Romae):

S AVG...

A. FRVMENT...

SIBI. ETVLPIA...

ET. LIBERTIS. LI... POSTERI...

Scheint nach dem namen der frau aus Trajan's zeit.

6) Muratori $888,2=$ Maffei M. V. 130, 7 (Romae, vielmehr li Prati bei Praeneste, s. unt.): dis manibus M. Antoni Pallantis Nobilis Abascantus Aug. disp(ensator) a frument(o). Vielleicht ist der verstorbene ein sohn des M. Antonius Pallas, cos. suff. im j. 167, vgl. Borghesi im Bull. d. I. 1853, p. 138.

7) Orelli 895 (Mediomatrici):

Widmung an Pertinax aus dem j. 193 von: Oceanus ser. verna. dispen[s(ator)] a frumento.

8) Marini sched. ined. vol. 88 (Pisauri):

C. Clodius C. f. quir. Maximus || proc. Aug. a frumento \| quaest. aedil. $\overline{I I}$ vir $\|$ signum. Spei. d. d. Aus unbestimmter zeit.

Vgl. die privatbeamten a frumento:

Orelli 2825 (Romae): Athictus $L(u c i)$. N(ostri), a frumento. Mommsen I. N. 6910 (in museo Borbonico, früher in Rom):

Pallans o(uinti). $\bar{n}$ (ostri). a frum(ento).

Ueber Henzen 6315: disp, a fruminto Puteolis et Ostis s. unten.

$\left.e^{a}\right)$ a frumento ministratorum und cubiculariorum.

1) Murat. 894, 3 (Romae) : Chrysaon Caes. i. ser. a fru- 
mento ministratorum. Seine frau heisst Claudia Tyche und ist walırscheinlich eine freigelassene des Claudius oder Nero.

2) Unedirt (Romae in horreis musei Lateranensis): copie von Detlefsen; die ergänzung in z. 3 ist von miṛ:

\section{dis MANIBVS}

TI. AFRVMENTO

ministRATORVM. AVG

CAESARIS. MEDICA

cASTRENSI. CONIVGI

fECIT. ET. SIBI. POSTERisqVe SVIS.

3) Gruter 592, 9 (Romae):

Cointo Aug. lib. a frum(ento) ministrat(orum).

4) Bullet. d. I. 1864, p. 9 (Romae):

d. m. P. Aeli. Aug. lib. Clrysanthi q(ui) f(uit) a frum(ento). otb(ioulariorum).

5) Fabretti 369, 131 (Romae):

T. Aelius Aug. lib. Aelianus a frumento oub(ioulariorum) Caesar(is) $\bar{n}$ (ostri) sta(tionis). I.

Singular sind:

1) Donat. 311, 2 (Romae): Lysimacho. Aug. disp. frument(i) mancip(alis). fec(it) Fl(avia). Corinthias. Fällt wegen des namens der frau woll in die zeit der Flavier.

2) ined. (Ephesi): [C. Vibius. C. F. Uof. (statt ouf(entina)) Sahu[t]aris. promag. portuum [pr]ovinc. Siciliae. item. promag. frumenti mancipalis. Aus der zeit des Traian; die copie ist von Waddington; ich verdanke die mittheilung dieser insclirift, die im nächsten liefte des Hermes publicirt werden wird, lirn. prof. Mommsen.

b) Beamte in den häfen.

1) Murat. 682, 4 (Calari)

L. BALbio. L. F. CAL. AVRelio

IVNCINO. PROC. HEREDIT

Proc. AVG. PRaEF. PRov. SARD.

PRAEF. VEHICVL. AD. $\overline{\mathrm{H}-\mathrm{S}} . \overline{\mathrm{CC}}$

PRAEF. VEhICVL. AD. H-S. C.

PROC. AD ANNONAM. OSTIS 


\title{
AD. H-S. IX. PROC, BIRLOTHEC
}

\author{
AD. $\mathrm{H}$ - S. IX. \\ etc.
}

Die inschrift ist schlecht copiert, einzelue fehler hat Muratori (v. 7: bibliothec. statt birlothec.) und Eichhorst in Fleckeisen's jahrbüchern 1863, p. 212 f. (v. 7 und $8: L \bar{X}$ statt IX ) verbessert; ob v. 4 nicht vielleicht interpoliert ist, will ich hier unerörtert lassen. Proctratores Augusti als praefecti provinciae Sardiniae finden sich auch sonst (0relli-Henzen 4929. 6940 vgl. Murat. 695, 2), nach Mornmsen (Hermes II, p. 111, anm. 2) allerdings erst im dritten jahrhundert. Es ist jedoch nicht möglich, aus der verwaltungsform Sardiniens das alter der inschrift zu bestimmen, denn diese provinz war zuerst senatorisch, dann von 6 n. Chr. bis auf Nero kaiserlich, unter einem procurator stehend; Nero gab sie dem senat zurück, doch findet sich wieder unter Vespasian ein procur. et praes. prov. Sardiniae (Henzen 5190); unter Commodus ${ }^{73}$ ) dagegen ein proconsul prov. Sardiniae und im dritten jahrhundert wieder ein procurator als statthalter (Mommsen a. o.). Es könnte darnach unsere inschrift dem ersten, zweiten oder dritten jahrhundert angehören; ihr alter wird aber einigermassen bestimmt durch eine inschrift aus Messana (Grut. 373, 4), die, nach den namen zu schliessen, sehr wahrscheinlich dem vater dieses mannes gesetzt ist; sie lautet:

L. Baebius L. f. Gal(eria) Inncinus praef. fabr. praef. col.

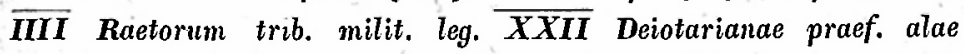
Astyrum praef. vehiculorum iuridicus Aegypti. Es ist demnach die erste zeile unserer inschrift zu lesen:

\section{BAeBIO. L. F. gAL. AURELIO.}

die legio $\overline{\boldsymbol{X X I I}}$. Deiotariana bestand aber aller wahrscheinlichkeit nach nur bis auf Traian und wurde von diesem kaiser durch die legio II Traiana ersetzt (vgl. Grotefend in Pauly's R. E. 4, p. 899); demnach kann die inschrift des vaters kaum nach Traian gesetzt sein und die inschrift des sohnes fällt wahrscheinlich in die erste hälfte

73) Nach der notiz in dem leben des Septimius Severus c. 2, er sei quaestor in Sardinien gewesen und habe nachher Marco imperatore decernence (c. 3) das volkstribunat bekleidet, muss Sardinien spätestens unter M. Aurel wieder senatorisch gewesen sein; die quästur des Severus fällt wahrscheinlich in das j. 171 n. Chr. vgl. Tillemont h. d. e.: Severe article 7 (II, p. 22 der Brüsseler ausgabe 1707-1739). 
des zweiten jalrhunderts: dem ersten jalıhundert kann sie ilırer ganzen fassung nach nicht angehören.

2) Mommsen I. N. $2464=$ Henzen 6315 (Neapel, gefunden in Puteoli):

dedication an Antoninus Pius Augustus nnd M. Aurelius Caesar von

CHRYSANTIVS (sic) AVG DISPAFRVMINTO (sic)

\section{PVTEOLIS ET OSTIS}

3) Maffei M. V. 319, 5 (Romae):

T. Ael(ius). Augg. lib. Saturnin(us) . . . tabul(arius) • Ostis ad annona $(m)$; aus der zeit des M. Aurel.

4) Orelli 1888 (Ostiae):

dedication an $M$. Aurel, Faustina und ilire kinder von

C. Pomponius Turpilianus proc. ad oleum in Galbae Ostiae portus utriusque; wahrscheinlich gesetzt im j. 175 vor der grossen reise des kaisers in den orient, vgl. Preller in den Ber. d. sächs. g. d. w. 1849, p. 20, anm. 108.

5) Henzen 6520 (Romae, gefunden in 0stia):

P. Bassilio P. filio Crescenti . . . proc. annonae Aug. Ostis .... scheint dem zweiten jahrhundert anzugehören, im 33sten lustrum des colleg(ium) fabrum tignuar(iorum). Ostis.

6) Visconti sched. Paris. ined. (ortsangabe fehlt):

C. Valerio || Ouir. Fusco || proc. XX. per Cam \| pan(iam). proc. ad XX. per \| Asiam [l]yciam Pam \| plyliam. proc. ad. \| annona[m o]stiae \| pro[c]. ab. alementa \| pro[c]. ab. XX per. Hisp(aniam)\| ceter. proc. ab. XX pr \|Syriam. Curatores. Die inschrift scheint am schlusse unvollständig zu sein; die copie ist sehr fehlerhaft; ausser den von mir im texte gemachten ergänzungen ist in v. 8 . 9. 10 wahrscheinlich ad für $a b$ zu setzen; v. 8 lies al[i]menta; v. 10: c[i]teriorem und $p[e] r$ für $p r$. Sie fallt gewiss in das zweite jahrhundert, wahrscheinlich bevor die theilung von Syrien durch Septimius Severus (vgl. Bormanu de Syriae partibus. Berlin 1865 p. 23) vollzogen war.

7) Guerin voyage II p. 111 n. 307 - Henzen 6521, restituirt von Mommsen in den Nuove memorie dell' Inst. p. 320 a. 1 (Thibursicumbure):

O. Acilio C. f. Papir. Fusco v. e. proc. annonae Angg[g]. 
m[n. o]stiensium .... Die 3 Augusti sind Septimius Severus, Caracalla und Geta.

8) Henzen 6523 (Portus):

Petronius Maxsimus centurio anu(onae); aus dem j. 224 n. Chr. (s. unt.).

Hinzuzufügen ist noch:

Orelli 3489 (Classe prope Ravennam):

T. Flavio T. f. Pup. Rufo .... cornicular(io) praef(ecti). anno(nae) $\ldots$.

Die inschrift muss in die erste hälfte des zweiten jalıhunderts fallen, da seine schwester Ulpia und die andere erbin Aelia offenbar freigelassene von Traian und Hadrian (resp. Antoninus Pius) sind.

Henzen 6520 (Romae gef. in Ostia):

C. Vettius Mercurias corn(icularuus) eius, nämlich des $P$. Bassilius Crescens, proc. annonae Aug. Ostis (s. ob.).

g) Beamte in den provinzen:

1) Renier I. A. 2715 (Kalamae) :

T. Flavio T. f. quir. Macro ..... curatori frumenti comparandi in annona[m] urbis facto a Divo Nerva Traiano ...

2) Herzog Gallia Narbonensis n. $323=0$ relli 3655 (Arelate):

.. Cominio Claud. Boi(onio) Agricolae Aelio Apro .... procur. Augustorum ad annonam provinciae Narbonensis et Liguriae .... Die Augusti sind wahrscheinlich M. Aurel und L. Verus.

Aus der gegebenen zusammenstellung geht hervor, dass die beamten der Annona, wie aller kaiserlicher verwaltungen, aus rittern, kaiserlichen freigelassenen ${ }^{74}$ ) und sklaven bestehen; die Ingenui, die nicht dem ritterstande angehören, finden sich ohne ausnahme nur in falschen inschriften.

Auffallend ist in einer so umfangreichen und weitverzweigten administration die geringe zahl der überlieferten subalternbeamten; es ist dies wohl nicht nur dadurch zu erklären, dass in inschriften

74) Wenn auch ausnahmsweise die ausdrückliche bezeichnung: $A u$ gusti libertus fehlt, so lassen doch die namen selbst keinen zweifel darüber vgl. Henzen 7233: M. Cocceius Hilarus und Murat. 1489, 5:

T. F(lavius) Phoebus. 
überhaupt mehr hochstehender männer als unbedeutender persönlichkeiten erwähnung geschieht, denn das hauptmaterial liefern hier nicht dedicationsinschriften, sondern grabsteine: es ist vielmehr wahrscheinlich, dass wirklich in der getraideverwaltung nicht sehr viele subalternbeamte fungirt haben, da ein grosser theil der untergeordneten geschäfte durch die verschiedenen unter der aufsicht des praefectus annonae stehenden collegien in Rom, 0stia, Portus und den provinzen versehen wurde; besonders kommen dabei iu betracht: die getraidemesser, mensores frumentarii, vgl. z. b. Orelli $1567=$ 4235 verbessert von Henzen Ill p. 460 : mesorib(us) mach(inariis) f(rumenti) p(ublici) quib(us) ex s(enatus) c(onsulto) coire licet aus dem j. 198 n. Chr., und die verschiedenen collegien der see- und flussschiffer, navicularii marmi und amnici, lenuncularii u. a. m., besonders die sogenannten caudicarii ${ }^{75}$ ), die den transport des getraides von Ostia auf dem Tiber nach Rom besorgten ${ }^{76}$ ); ähnliche collegien von schiffern in den provinzen werden nicht selten in inschriften erwähnt ${ }^{77}$ ). Die thätigkeit dieser collegien muss, nach der häufigen erwähnung derselben zu schliessen, eine sehr bedeutende gewesen sein und tausende von menschen waren offenbar im dienste der hauptstädtischen getraideverwaltung thätig; ohne zweifel waren sie contractlich zu bestimmten leistungen verpflichtet und bildeten gewissermassen eine mittelstufe zwischen privatunternehmern und kaiserlichen beamten; für letztere waren nur gewisse zweige der administration reservirt, die noch eine nähere betrachtung verdienen:

\section{Die getraidespeicher im Rom, Portus und den provinzen ${ }^{78}$ ).}

Die horrea in Rom dienten hauptsächlich zur aufbewahrung

75) Vgl. Seneca de brev. vit. c. 13 §. 4: et naves nunc quoque, quae ex antiqua consuetudine commeatus [per Tiberim] subvehunt, codicariae vocantur, Varro bei Nonius XIII, 12 p. 535,21 u. a.

76) Ueber diese und ähnliche collegien im dienste der Annona hat vortrefflich gehandelt Preller in den Ber, d. s. G. d. W. 1849 p. $147-$ 151 : vgl. Henzen in den Annali d. I. 1851 p. 159-162. Marquardt $\nabla^{2}$ p. 18 f. Rodbertus a. o. p. $418 \mathrm{ff}$.

77) Zahlreiche beispiele bei Marquardt $\nabla^{8}$ p. 19 f.; vgl. auch Boissieu inscr. de Lyon p. 397 und Mommsen in der Kieler Monatsschrift 1853 p. 653.

78) Ueber dieselben hat ausführlich gehandelt: Preller, Regionen p. $101 \mathrm{ff}$. Deber die bedeutung dieser horrea s. die schönen bemerkungen von Rodbertus a. 0. p. $413 \mathrm{ff}$. 
des getraides, obgleich auch horrea chartaria, piperataria, candelaria daneben erwähnt werden; die ältesten, die wir namentlich kennen, sind die horrea Sempronia, die ohne zweifel in folge der gracchischen getraidegesetze erbaut worden sind (Festus s. ข. Sempronia horrea p. 290 Mueller.); aus der kaiserzeit sind besonders zu erwähnen die horrea Agrippiana und Germaniciana, die horrea Lolliana, die horrea Seiana u. a. m. (vgl. Preller Regionen p. 103) ${ }^{79}$ ). Wobl die bedeutendsten von allen waren die horrea Galbae, die in dem regionenverzeichniss als horrea Galbes et Aniciana, in der Notitia dignitatum (Boecking N. D. Il p. 16 und 202) als horrea Galbana erwälnt werden. Das Breviarium des Curiosum Urbis zählt im ganzen 290, das der Notitia 291 horrea in Rom, die aber wohl nur zum theil öffentliche speicher waren; die meisten (35) finden sich in der 13 ten region $d$. b. bei dem emporium am Aventin, wo die schiffe anlandeten und ausgeladen wurden ${ }^{80}$ ).

Die beamten dieser öftentlichen ${ }^{81}$ ) speicher waren theils kaiserliche sklaven, theils freigelassene ${ }^{82}$ ) mit dem titel horrearius oder auch vilicus ex horreis (Murat. 891, 2); der conductor horreorum Seianorum lustri tertii (0relli 46) zeigt, dass die kaiserlichen

79 Hinzuzufügen sind den von Preller angeführten die horrea Vespasiani, die Domitian vollendet zu haben scheint (vgl. Mommsen Chronograph vom j. 354 p. 646 und 652) und die horrea Nervae bei Henzen 7233.

80) Dort lagen auch die horrea Galbes et Aniciana und die dedication an die Foriuna horrcorum (Orelli 4881-82) ist ebenfalls beim emporium gefunden.

81) Ueber die horrea privata vgl. Gothofred. zu Cod. Th. XI, 20, 3 und Salmasius zur vita Alex. Severi c. 39 , ferner die inschrift bei Henzen 6290: Thalamus M. Furi Camilli ab horr(eis) und bei Mommsen I. N. 1387 in Benevent: Concordius co[l(oniae servus)] horr(earius). Ueber die horrearii bei den Vigiles vgl. Kellermann p. 18 und Bremer Process der Fullonen im Rhein. Mus. f. Phil. b. 21 separatabdruck p. 36 a. 67. Aus dem j. $223 \mathrm{n}$. Chr. werden solche privatspeicher für getraide, wein und ôl erwähnt im Cod. Iust. IV, 48, 2.

82) In der angeführten inschrift aus Reate.(Doni 334,81 ) lautet der name nach Mommsen's copie, wie mir Bormann mittheilt: Ti. Claudius Dapnio und diese worte sind, in rasura reposita, in cuius fine apparet CAESARIS antiquae scripturae". Darnach war Dapnio sehr wahrscheinlich noch kaiserlicher sklav, als er die inschrift setzte und hat nachher auf dem steine seine freilassung bemerken wollen; die ursprüngliche fassung war also wohl: Dapnio Caesaris (servus) horrearius.... 
speicher - denn das waren ohne zweifel die horrea Seiana -auch vermiethet wurden ${ }^{83}$ ).

Bemerkenswerth ist, dass die wenigen inscliriften, die kaiserliche beamte der horrea nennen, sämmtlich der frühen kaiserzeit anzugehören scheinen; auch wäre es nicht richtig, aus den worten des Scaevola in der eben erwälıten. Digestenstelle $(20,4,21$ 8. 1): conductor horreorum Caesuris fuit, ob quorum pensiones aliguot annis non solutas procurator exactioni praepositus ad lapidum venditionem officium suum extendit zu schliessen, dass damals, also zu M. Aurel's zeit, diese speicher unter einem besonderen procurator gestanden haben, vielmehr ist hier ohne zweifel ein procurator fisci gemeint, der mit der eintreibung der miethen von kaiserlichen gebäuden betraut war. Dagegen findet sich in einer stadtrömischen inschrift aus dem j. 159 n. Clir. (Mommsen I. N. 6760) ein sodalic(ium) horr(eorum) Galban(orum) cohort(alium) und auf ein ähnliches collegium deuten die inschriften bei 0relli 45 (= Grut. 75, 1) . . Genio Conservatori horreorum Galbianorum $M$. Lorinus Fortunatus magister ${ }^{84}$ ) s. p.d. d. (ähnlich Gruter 75, 2)

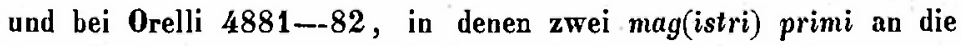
Fortuna horreorum eine dedication vollziehen. Es ist daher sehr wahrscheinlich, dass im zweiten jahrhundert diese collegien an stelle der kaiserlichen beamten getreten sind und ihnen die speicherverwaltung, natïrlich unter aufsicht des praefectus annonae, übertragen worden ist.

Auch noch in später zeit werden diese horrea in Rom häufig erwähnt ${ }^{85}$ ) (vgl. Cod. Th. XI, 14: de conditis in publicis horreis) und der curator horreorum Galbanorum stand, wie auch der praefectus annonae, sub dispositione praefecti urbis (Not. dign. II c. 4 p. 16) ${ }^{86}$ ). - Wenn Preller (Regionen p. 101 f.) von den horrea

83) Dies wird auch durch eine stelle des Scaevola (Digg. 20, 4, 21 §. 1) bestätigt, die beginnt: conductor horreorum Caesaris fuit; dem widerspricht nicht, auch abgesehen von der verschiedenheit der zeit, die bestimmung aus dem j. 375 im Cod. Th. XII, 6, 16: non autem oportet in horreis fiscalibus nisi fiscalia frumenta constitui vgl. Cod. Th. XV, 1,12 .

84) Es ist daher eigentlich nicht richtig, wenn Henzen ihn im index (p. 120) als magister horreorum Galbianorum anführt. I p. 182.

85) Ueber die horrea publica in Constantinopel vgl. Böcking N. D.

86) Ueber die praepositi horrcorum vgl. Gothofr. zu Cod. Th. XII, 
sagt: „, sie scheinen über die ganze stadt zerstreut, nicht nach den „14 regionen, sondern nach den 35 tribus der städtischen plebs „vertheilt und verwaltet zu sein, wenigstens wird in einer inschrift bei Orelli n. 3214 ein horrearius plebis et tribus Palatnae genannt", so berult diese behauptung eben nur auf dieser inschrift, die, wie schon bemerkt, von Ligorio gefalscht ist. - Auch in den provinzen waren speicher zur aufbewalırung des getraides, das für Rom bestimmt war, angelegt; schon in der zeit der republik und in der ersten kaiserzeit werden solche horrea in Africa, Aegypten und Britannien erwälnnt (s. die stellen bei Nasse a. o. p. 36 und Ioseph. contra Apion. II, 5 a. e.) ${ }^{87}$ ); in einer inschrift aus dem j. 349, gefunden in Steinamanger, heisst es (Henzen 5583): provisa copia quae horreis deerat posteaquam condendis horrea deesse coeperunt und zum ,j. 368 berichtet Ammianus (28, 1, 17): cum Africam (Hymetius) pro consule regeret, Carthaginiensibus victus inopia iam lassatis, ex horreis Romano populo destinatis frumentum dedit: paulloque postea, cum provenisset segetum copia integre sine nlla restituit mora ${ }^{88}$ ).

\section{Die Porticus Minucia.}

Es gab in Rom zwei porticus Minuciae ${ }^{89}$ ), die jedoch offenbar zu ein und derselben anlage geliörten und von demselben manne erbaut waren, vgl. Velleius II, 8, 3: per eadem tempora clarus cius Minuci, qui porticus, quae hodieque celebres sunt, molitus est, ex Scordiscis triumphus fuit: es ist der consul des j. 644 M. Minucius Rufus. Sie lagen in der neunten region und heissen in der Notitia: Minucia vetus et frumentaria. Auf diese porticus Mlinucia hat Mommsen unzweifelhaft richtig die notiz in dem chronographen vom j. 354 bezogen: Servius Tullius serva natus regnavit ann.

6, 33; über den comes horrearum vgl. Boecking N. D. I, 182 und II, 203.

87) Ueber die horrea in Portus s. unt.; horreorum librarii beim heere: Digg. 50, 6, 6 vgl. Salmas. zur vita Hadr. c. 11 über die condila militaria.

88) Auch ortsnamen, wie Capul Saltus Horreorum: Henzen 5337 und Horrea Margi s. Boecking N. D. I p. 244 deuten auf solche anlagen hin.

89) Vgl. über die porticus Minucia Mazocchi a. o. p. $319 \mathrm{ff}$. und Preller Regionen p. 168. 
XLV. Hic votum fecit ut quotquot amos regnasset, tot ostia ad frumentum publicum constitueret. Diese ostia werden in den kinderinschriften bei Henzen 6663 erwähnt: frumentum accepit die X. ostio $X X X I X$ und $d(i e)$. VI. ostio $X V$; jeden zweifel, dass es sich um die porticus Minucia handelt, hebt endlich der curator de Minucia die XIIII ostio XLII bei Gruter 173, 1 und die worte des Apuleius de mundo c. 35: alius ad Minuciam frumentatum venit ${ }^{90}$ ). Man hat nun allgemein, besonders Mazocchi und Preller, aus diesen angaben gefolgert, dass in der porticus Minucia die monatlichen frumentationen stattgefunden haben; jedoch halte ich diese annahme für nicht begründet, und glaube vielmelır, dass die porticus.Minucia zum verkaufe des öffentlichen getraides, der täglich zu bestimmten preisen stattfand (s. ob.), gedient habe und erst später dort auch das getraide für die pueri alimentarii ausgetheilt worden sei. Schon die ganz allgemein gehaltenen worte der lex Iulia municipalis v. 15: ibei ubei frumentum populo dabitur, machen es walırscheinlich, dass damals keine bestimmte anlage für diese vertheilungen existirte; auch die nachricht des Plutarch (0tho c. 4), die schon Preller (a. o. p. 168) auf die porticus Minucia bezogen hat, der Tiber hätte überschwemmt $\pi 0 \lambda \grave{v} \mu \varepsilon$ gos $i \vec{\eta} s \pi o ́-$

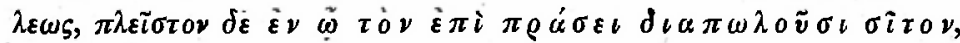

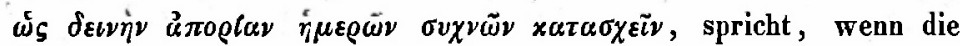
beziehung wirklich richtig ist, dafür, dass die porticus Minucia zum verkaufe, nicht zur unentgeltlichen vertheilung des getraides diente ${ }^{91}$ ). Dazu kommen aber andre gewichtige gründe; der schon oben angefülirte: Ti. Claudius Aug. lib. Ianuarius curator de Minncia die XIIII ostio XLII (Gruter 173, 1), muss, wie sein name beweist, aus der zeit des Claudius oder Nero sein; damals erhielten aber kinder noch nicht getraide, sondern es fanden nur monatlich an einem tage die frumentationen statt; es ist daher unmöglich, die worte die XIIII ostio XLII auf dieselben zu

90) Wahrscheinlich beziehen sich auf dieselbe auch, wie Gothofredus zu Cod. Th. XIV, 25, 1, angenommen hat, die worte des Suidas

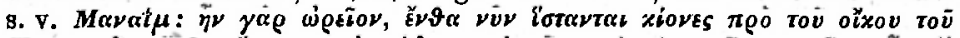

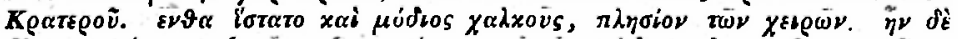

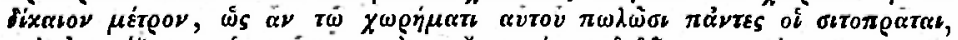

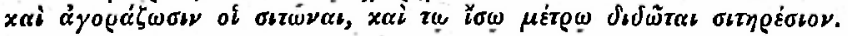

91) Allerdings ist diese beziehung nicht zwingend, denn auch der vicus frumentarius und das forum pistorium lag in der nähe des Tiber. 
beziehen, während sie vortreftich passen zu einem täglichen verkaufe des getraides, der natürlich von kaiserlichen beamten beaufsichtigt werden musste ${ }^{92}$ ). Erinnert man sich ferner, dass die kinder, wie wir oben nachuuweisen versucht haben, in besonderen listen verzeichnet standen und nicht zusammen mit der plebs frumentaria das getraide erhielten; dass die angabe des tages und des ostium sich nur in kinderinschriften findet, dass ferner auf der einzigen uns erhaltenen tessera frumentaria (0relli 3360) nichts davon vermerkt ist, so wird man zugeben müssen, dass diese umstände fïr ineine ansicht und gegen die frülıer recipirte sprechen: gründe, die dagegen anzufülıren wären, sind mir wenigstens unbekannt ${ }^{93}$ ). Aus 'Traian's zeit finden wir einen proc. Aug. ad Miniciam (Orelli 516) aus dem ritterstande, der vorher schon eine praefectura alae bekleidet hat; in einer vielleicht nicht viel späteren inschrift (C. I. L. 3, 249 = Grut. 402, 4) einen proc. Minuciae ebenfalls aus dem ritterstande, der dieses amt erst nach verwaltung von drei anderen procuraturen erhält ${ }^{94}$ ). Dass diese beamten zu dem ressort der Annona gehörten, kann keinem zweifel unterliegen; ist unsre obige ausfübrung über die bestimmung der porticus Minucia ${ }^{95}$ ) richtig, so standen dieselben unter der competenz des praefectus annonae und nicht, wie (Henzen tabul. alim. p. 56 a. 2) und Marquardt (a. o. p. 108) annehmen, unter den praefecti frumenti dandi. Wenn diese procuratoren sich noch im dritten jahrhundert erhalten haben sollten, wofür freilich keine beweise vorliegen, so können dieselben doch nicht die oberaufsicht über die porticus Minucia gehabt haben, denn aus der zeit des Septimius Severus ${ }^{96}$ )

92) Undenkbar ist nur, dass jeden tag im monate für jedes ostium ein verschiedener curator gewesen sein soll $\mathrm{d}$. $\mathrm{h}$. also im ganzen $30 \times$ $45=1350$; vielmehr muss man annehmen, dass an den einzeinen tagen nur bestimmte ostia geöffnet waren.

93) Frumentari in der angeführten stelle des Apuleius bedeutet nur: „getraide holen", kann also ebensowohl auf verkauf, als auf vertheilung gehen; auch brauchen die worte des Sueton (Caligula c. 26): nonnumquam horreis praeclusis populo famem indixit nicht auf directen verkauf aus den speichern gedeutet werden.

94) Dass aus der inschrift bei Gruter. 622, $5=$ Murat. 680, 6 nicht, wie Mazochi a. o. p. 322 und andere thun, ein Miniciae rationalis zu entnehmen ist, hat Marini Atti p. 807 nachgewiesen.

95) In den inschriften wird stets von der Minucia (oder Minicin, beide formen kommen vor) ohne zusatz von velus oder frumentaria gesprochen; es ist dies ein beweis dafür, dass beide zu ein und derselben anlage gehörten vgl. Mazochi a. o. p. 320 .

96) Undenkbar ist es nicht, dass schon früher dieser posten von

Philologus. XXIX. Bd. 1. 
findet sich in einer inschrift (Grut. 422, $7=$ Borghesi III p. 109) ein gewesener praetor als praefectus Minicia(e) und in einer anderen, ziemlich gleichzeitigen, (Grut. 407, 1 = Marini iscrix. Albane p. 50) ein gewesener consul als cur(ator) Min(uciae). Es ist sehr auffallend, dass dieses amt so hohen beamten übertragen wurde und es kann daher kaum zweifelhaft sein, dass . wenigstens in der späteren zeit die porticus Minucia, die eine anlage von bedeutender ausdehnung gewesen sein muss, (vgl. Preller a. o. p. 168), noch zu anderen zwecken als zum getraideverkaufe gedient hat. Dies wird ausser allen zweifel gestellt durch eine reihe von inschriften theils aus, theils nach der zeit des Alexander Severus, in denen der titel: curator aquarum et Miniciae (Orelli 60. 1194, 3042. $3151=3183$. Grut. 381,1 und 3) erscheint; in einigen inschriften des vierten jahrhunderts (Orelli $2284=$ Mommsen I. $\mathbf{N}$. 4036. Grut. 54, 6): consularis aquarum et Miniciae. Wenn nun derselbe Q. Fl. Messius Egnatius Lollianus, der bei Mommsen I. N. 4036 consularis aquarum et Minuciae heisst, in einer späteren inschrift einfach consularis aquarum genannt wird (Henzen 6481), so beweist das, dass die cura Miniciae auf das engste mit der cura aquarum zusammenhing und es sich hier nicht um eine zufällige cumulation zweier ämter handelt. Man kann daher mit sicherheit behaupten, dass die porticus Minucia seit der zeit des Alexander Severus theilweise oder ausschliesslich für die zwecke der verwaltung der aquäducte diente, ohne dass wir freilich bis jetzt im stande sind, diese bexiehungen präcisiren zu können ${ }^{97}$ ). Was schliesslich den (servus) publicus Minicianus (Orelli 2852) an-"

senatorischen beamten bekleidet worden ist, doch fehlen dafür die belege.

97) In dieser zeit hörten, wie wir oben nachgewiesen haben, auch die frumentationen auf und wahrscheinlich zugleich der verkauf von getraide: an ihre stelle traten brodvertheilungen und brodverkauf, erstere von den gradus (panis gradilis), letzterer (panis fiscalis) aus den pistrina: es ist daher sehr wahrscheinlich, dass seit dieser zeit die porticus Minucia mit der getraideverwaltung gar nichts mehr zu thun hatte, obgleich sie noch den alten namen frumentaria beibehielt. Marini (Atti p. 801) bezieht die verbindung mit den aquae nur auf die Minicia velus, was wir, da weder früher, noch später, der zusatz vetus oder frumentaria in inschriften sich findet, nicht billigen können; keineswegs aber wird man Boecking (N. D. II, 185) beistimmen, der diese verbindung erklärt aus der ", cognatio administrationum annonariae el aquarum", die er aus dem scslt. bei Frontin. de aquis II \&. 100 ableiten will. 
langt, so kann ich nicht mit Orelli darin einen ,servus publicus qui ad porticum Minuciam frumentum publicum distribuebat" erkennen; aber auch in dem officium annonae findet er keinen platz, da hier nur servi Cassaris nicht servi publici ${ }^{98}$ ) fungiren; es ist daher sehr walırscheinlich, dass er zu dem officium des senatorischen curator Minuciae (Grut. 407, 1) gehörte; leider ist die iuschrift nicht datirbar.

\section{Der Fiscus frumentarius.}

Das getraide, das zu den frumentationen in der kaiserzeit verwandt wurde, lieferten nur zum theile die provinzen als naturalabgabe; zur zeit der republik wurde es in den meisten füllen, mit speciell zu diesem zweck ausgesetzten fonds in den getraidereicben provinzen eingekauft, vgl. Kuhn a. o. p. 1001 ff. ${ }^{99}$ ). Da in der kaiserzeit ferner der staat dafür sorgte, dass Rom mit getraide reichlich versehen war und selbst den verkauf desselben übernahm, so werden ausser den naturalabgaben auch bedeutende aufkäufe in den provinzen nöthig gewesen sein ${ }^{100}$ ). Nehmen wir nun auch an, dass dieser verkauf in gewölnlichen zeiten wenig oder gar nicht unter dem reellen werthe geschehen sei (vgl. Kuhn a. o. p. 1081) ${ }^{101}$ ), so war doch die ausgabe resp. die einbusse, welche die staatskasse durch die frumentationen erlitt, sehr beträchtlich. Es nahmen von Augustus bis Septimius Severus, wenn man die Prätorianer einrechnet, mindestens 200,000 empfänger an denselben theil; ein je-

98) Ueber die servi publici in senatorischen verwaltungen und bei den gesellschaften der publikanen werde ich an einem anderen orte sprechen; sehr lehrreich ist in dieser hinsicht die auseinandersetzung des Frontinus (de aquis II §. 116) über die fumilia publica und die familia Caesaris, die neben einander in der verwaltung der aquae thätig sind.

99) So wurden für die lex Terentia Cassia 12,200,000 HS, für die catonischen frumentationen 30,000,000 HS jährlich ausgesetzt: Kuhn a. o. p. 1003 . f.

100) Darauf gehen auch die worte des Plinius (Paneg. c. 29): devehunt ipsi quod terra genuit, quod sidus aluit, quod annus tulit, nec novis indictionibus pressi ad vetera tributa deficiunt. Emit fiscus quidquid videtur emere. Inde copiae, inde annona, de qua inter licenlem vendentemque conveniat; inde hic satielas, nec fames usquam.

101) Dass dieser verkauf in zeiten der noth von dem kaiser zur bereicherung benutzt wurde, geschah sicher äusserst selten; von Nero berichtet es Sueton. (Nero c. 45): ex annonae quoque caritate lucranti adcrevit invidia. 
der erhielt sehr wahrscheinlich jährlich 60 modii, dies macht im ganzen jährlich 12,000,000 modii. Setzen wir den modius mit den transportkosten zu vier sesterzen an, was kein zu hoher preis für diese zeit ist ${ }^{102}$ ), so ergiebt sich eine jährliche ausgabe von $48,000,000 \mathrm{HS}=$ etwa $3,480,000$ pr. rth. Rechnet man hierzu noch das getraide, das an die vigiles, an kaiserliche diener (s. unt.), an die kinder vertheilt wurde, ferner die unkosten der verwaltung, so wird man, auch ohne die gewiss häufig sehr beträchtlichen zuschüsse zur Annona in betracht zu ziehn, die einbusse der staatskasse für diese getraidevertheilungen auf mindestens 4,000,000 rth. jaihrlich veranschlagen müssen ${ }^{103}$ ). Es ist daher sehr wahrscheinlich, dass die von Tacitus berichtete äusserung Nero's (Ann. 15, 18) se annum sexcenties sestertium rei. publicae largiri auf die ausgal,en für die frumentationen und die unkosten für die Annona, wie Kuhn (a. o. p. 1008) vermuthet hat, zu beziehen sei; die summe $(60,000,000 \mathrm{HS}=$ etwa 4,350,000 rth.) stimmt sehr wohl mit dem von uns gemachten kostenanschlage. Ob Nero der erste war, der diese ausgabe aus dem fiscus bestritt, ist mir dagegen sehr zweifelhaft; zu August's zeit freilich trug ohne zweifel noch das aerarium Saturni die kosten, da der fiscus noch nicht als besondere kaiserliche kasse constituirt war ${ }^{104}$ ), ja es ist sogar nicht

102) Vgl. Mommsen: edict des Diocletian p. 70 und die dort citirten schriften. $6^{1 / 4}$ modii sind etwa so viel, als ein preussischer scheffel, demnach wäre der durchschnittspreis desselben, den denar zu 8 sgr. 7 pf. gerechnet (Hultsch Metrologie p. 239 f.), in den ersten jahrhunderten der kaiserzeit in Rom etwa 54 sgr. gewesen; Friedländer (in Hildebrand's jahrbüch. f. nationalök. VII p. 308) nimmt 55-68 sgr. als durchschnittspreis in jener zeit in Italien an.

103) Für die republikanische zeit hat Marquardt a. o. p. 95 einige summen zusammengestellt; im j. 46 v. Chr., als 320,000 empfänger waren, nimmt er eine ausgabe von $57,600,000$ HS an, wobei der modius zu 3 HS gerechnet ist. Doch ist dies sicher zu niedrig, um so mehr, als in jener zeit der sesterz nur etwa 1 sgr. 9 pf. pr. galt (Hultsch a. o. p. 225); den modius zu einem denar gerechnet (vgl. Mommsen R. G. I p. 851 anm.: „als hauptstädtischer mittelpreis des getraides kann wenigstens für das siebente und achte jahrhundert Roms angenommen werden 1 denar für den römischen modius"), hätte die ausgabe in jenem jahre 76,800,000 HS d. h. nicht, viel weniger als 4,500,000 pr. thaler letragen: es ist daher keine zu grosse übertreibung, wenn Cicero (p. Sest. $25,55)$ von der lex Clodia frumentaria sagt: ut remissis senis et trientibus quinta prope pars vectigalium tolleretur vgl. Marquardt III $^{2}$ p. 214.

104) Dies geht auch hervor aus der leider sehr verstümmelten stelle im Monum. Ancyr. III, 40-42, wo August über die unterstützungen, die er dazu dem aerarium aus seinen mitteln hat angedeiben lassen, berichtet vgl. Mommsen R. g. d. A. p. 51. 
unwahrscheinlich, dass auch noch in späterer zeit das aerarium Saturni zu diesem zwecke beisteuern musste; es wird nirgends ausdrüicklich erwälnt, dass der fiscus alle in diese last zu tragen hatte; bedenkt man ferner, dass aus den senatorischen provinzen, wenigstens in der früheren kaiserzeit, die algaben zum grossen theile in naturallieferungen von getraide bestanden (vgl. Nipperdey zu Tacit. A. 15, 18. Kuln a. o. p. 998), so wird man die annalıme natürlich finden, dass von diesem getraide ein theil für die frumentationen verwandt worden sei; darin bestärkt mich besonders die stadtrömische inschrift bei Donati 311, 2, wahrscheinlich aus der zeit der Flavier, in der ein Lysimachus Ang. disp(ensator) frument(i) mancip(alis) erwähnt wird, wie auch die unedirte ephesische inschrift des promag. frumenti mancipalis Vibius Salutaris, ein aut das wohl jedenfalls von ihm in Rom bekleidet worden ist. Denn es ist mir selır wahrscheinlich', dass unter frumentum mancipale das von den publicani als abgabe gelieferte getraide zu verstehen ist ${ }^{105}$ ); an abgaben aus kaiserlichen provinzen zu denken, geht nicht an, da dort dieselben nicht an publicani verpachtet waren, sondern direct erhoben wurden (vgl. Husclke Census der früheren Kaiserzeit p. 85) ${ }^{106}$ ); die anstellung von kaiserlichen be-

105) Cic. de domo s. 10 §. 25: hic vir extra ordinem rei frumentariae praeficiendus non fuit? scilicet tu .... Sex. Clodio ... . omne frumentum privalum el publicum, omnis provincias frumentarias, omnis mancipes, omnis horreorum claves lege tua tradidisti vgl. Paulus Diac. p. 151 Mueller und Pseudo-Asconius in divinationem §. 33. Das wort mancipalis kommt meines wissens sonst nirgends vor.

106) Die von mir versuchte erklärung des frumenlum mancipale wäre nicht möglich, wenn wirklich die behauptung von Mommsen richtig ist (R. G. III p. 490), dass schon Caesar in den provinzen die directen abgaben nicht mehr an die publikanen verpachtet, sondern sie behandelt habe ,als unmittelbar an den staat abzufuhrende naturalleistungen"; Marquardt III" p. 178 a. 45 schreibt diese neuerung dem Augustus zu. Allerdings ist nicht zu leugnen, dass das princip der directen steuererhebung in der kaiserzeit mehr und mehr hervortritt; irrig dagegen ist die besonders von Savigny vertretene ansicht, dass fast sämmtliche naturalabgaben in eine feste grundsteuer verwandelt worden seien; vielmehr hat neuerdings Rodbertus (a. o. p. 406 ff.) auf das überzeugendste nachgewiesen, dass bis in die späteste kaiserzeit diese naturalabgaben auf den provinzen lasteten. Dass nưn dieselben'schon seit Caesar in sämmtlichen provinzen direct erhoben seien, scheint mir keineswegs sicher; ausdrücklich sagt Tacitus (A. IV, 6) zum j. 23 n. Chr.: congruens crediderim recensere celeras quoque rei publicae parles, quibus modis ad eam diem habilae sinl.... . al frumenla el pecuntae vectigales, cetera publicorum frucluum socielatibus equilum Romanorum ogitabanlur; vielmehr glaube ich, dass nur in allen kaiserlichen provinzen, 
amten in Rom als dispensator resp. promag(istro) frumenti mancipalis deutet dagegen an, dass dieses getraide nicht an das aerarium Saturni, sondern an- eine kaiserliche behörde d. h. ohne zweifel an den praefectus annonae direct abgeliefert werden musste. Es scheint mir demnach, wenn meine erklärung richtig ist, der schluss unabweisbar, dass auch getraide aus den senatsprovinzen für die frumentationen und die Annona überhaupt in Rom verwandt wurde (vgl. Kuhn a. o. p. 998 f.), wobei es allerdings denkbar ist, dass der fiscús dem aerarium Saturni eine entschädigungssumme zu zahlen hatte. Wie dem auch sei, jedenfalls der grösste theil der ausgabe fiel dem fiscus zu; und wenn Statius in dem bekannten gedichte an Clatudius Etruscus, der wahrscheinlich unter Nero (vgl. Friedländer Sittengeschichte I p. 162) das amt a rationibus führte, sagt (Silvae III, 3 v. 98 ff.):

\section{vigil iste animique sagacis}

Exitus (?) evolvit, quantum Romana sub omni

Pila die quantumque tribus... . poscant, so ist gewiss dabei vor allem an die frumentationen zu denken. Ob schon in der ersten kaiserzeit dafür fest bestimmte fonds existirt haben, ist fraglich; seit der zeit der Flavier, als man überhaupt anfing, die einzelnen kaiserlichen verwaltungen strenger von einander zu scheiden, finden wir auch für die getraideverwaltung eine besondere kasse unter dem namen fiscus frumentarius mit eigenen beamten: tabularii ${ }^{107}$ ), a libellis, dispensatores, theils freigelassenen, theils sklaven der kaiser; dieselben erscheinen in inschriften seit der zeit der Flavier bis auf M. Aurel. Ein procurator fusci frumentarii wird nicht erwähnt und es ist selır walır-

wo die finanzverwaltung überhaupt weit energischer war, schon seit Augustus eine directe steuererhebung stattfand, während in den senatorischen theilweise wenigstens die naturallieferungen im ersten und im anfang des zweiten jahrhunderts noch verpachtet waren.

Keineswegs aber darf man nach meiner ansicht das frumentum mancipale auf das an die backer gelieferte getraide beziehen, deren geschäftsfuhrer ebenfalls mancipes hiessen (vgl. Gothofr. zu Cod. Th. XIV, 3, 18. Dirksen Manuale s. v. manceps. Marquardt Handbuch $\nabla^{2}$ p. 28), denn während diese bezeichnung sich erst in spăten quellen findet, fällt die inschrift des dispensator frumenti mancipalis sehr wahrscheinlich noch vor Traian, der zuerst die oben besprochenen bestimmungen über das corpus pislorum traf.

107) Identisch mit den tabularii fisci frumentarii ist auch der tabularius rationis fisci frumentarii. 
scheinlich, dass der praefectus annonae selbst die verwaltung dieser kasse geführt hat: denn es ist unzweifelhaft, dass dieselbe unter di e s e m beamten, nicht, wie Marquardt (a. o. p. 108) annimmt, unter den praefecti frumenti dandi stand, da letztere, wie wir nachgewiesen haben, nur mit der austheilung, aber nichts mit dem ankaufe und der verwaltung des getraides zu thun hatten. Es kann dies um so weniger fraglich sein, als der fiscus frumentarius augenscheinlich nicht nur die kasse für die frumentationen war, sondern für die Annona überhaupt, da er sicher identisch ist mit dem in einer stadtrömischen inschrift (Orelli $4107=$ 4420) genannten fiscus stacionis annonae. Dies wird bestätigt durch eine notiz bei Herodian (VII, 3, 5) aus dem j. 236 n.

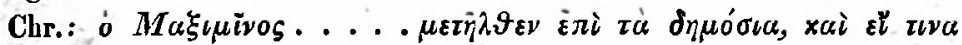

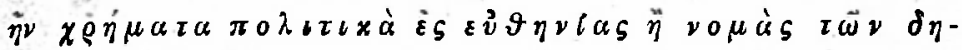

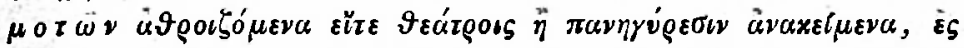
¿aviò $\mu \varepsilon \imath \ddot{\eta} \gamma \varepsilon .$. , also offenbar die gelder für die annona und die frumentationen in gleicher weise verbunden, wie für die $9 \varepsilon \dot{\varepsilon} u-$

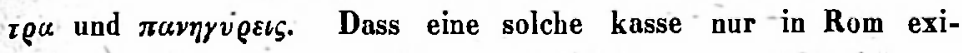
stirte, wo die ganze verwaltung centralisirt war, versteht sich von selbst, und die fundorte der inschriften, welche beamte des fiscus frumentarius nennen, dienen dafür zur bestätigung ${ }^{108}$ ).

\section{Die beamten a frumento.}

Wenn auch, wie wir erwähnt haben, eine reihe von collegien Im dienste der Annona thätig war, so erforderte doch die beaufsichtigung des getraides bei der ablieferung und während der aufbewalrung u. a. m. zahlreiche subalternbeamte, die zu dem officium des praefectus annonae gehörten. Nur sehr spärliche erwähnung von diesen findet sich in den inschriften: genant wird ein tabel-

108) Ob die inschriften bei Gori 1. E. I, 345, 25 und 296, 25 aus Rom stammen, ist nicht bezeugt, doch nicht unwahrscheinlich, da viele inschriften aus Rom in das florentiner museum gekommen sind; überdies findet sich derselbe Crescens Alypianus (Gori I. E. 1, 296, 25) auch in einer stadtrömischen inschrift (Orelli 790). - Ueber die arca frumentaria und olearia in später zeit in Rom vgl. Gothofred. zu Cod. Th. XII, 11, 2; über die arca vinaria: Cod. Th. XIV, 6, 3 und Symmach. Epp. IX, 121; X, 42 und 47. Auch in Constantinopel wird im j. 409 eine arca frumentaria erwähnt vgl. Gothofred. zu Cod. Th. XIV, 16, 1 und 3 ; über ähnliche kassen in den municipien 8. unt. 
larius ex officio annonaes (Henzen 6569: vgl. über diese tabellarii d. h. briefträger, Marini Atti p. 614) aus Bologna und ein disp(ensator) annon(ae) (Henzen 6541) ${ }^{109}$ ), ausserdem die oben besprochenen beamten der horrea und der porticus Minucia. Als ihre collegen 'glaube icb jedocb die beamten a frumento ansprechen $z u$ dürfen, die ebenfalls durchgebend aus kaiserlichen sklaven ${ }^{110}$ ) unter dem titel actor und dispensator bestehen; in der griech.-latein. inschrift C. I. L. $3,333=$ C. I. Gr. 3738 wird der titel dis-

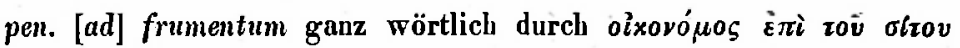
übersetzt. - Dass diese beamte zur verwaltung der Annona, nicht etwa ausschliesslich der frumentationen gehören, dafür sprechen folgende gründe:

1) die inschriften sind zum theil weit von Rom in den provinzen gefunden, so C. I. L. 3, 333 in Cius (Bitlynnien) und Orelli 895 in Mediomatricum; die erste ist eine grabschrift der frau, die zweite eine dedication an den kaiser Pertinax. Es ist daher bei diesen niederen beamten mindestens äusserst unwalırscheinlich, dass sie in Rom fungirt hätten: beamte für die frumentationen hat es aber sicher nur in Rom selbst gegeben.

2) Murat. 888, 2 wird genannt: Abascantus Aig. disp. a frumerit(o). und Henzen 6541: Abascantus Caes. $\bar{\imath}$. ser. ver. n. disp. annonac. Allerdings ist dieser name bei sklaven zu läufig, um mit sicherheit hier eine identität anzunehmen; es wird dieselbe aber dadurch wahrscheinlich, dass die erste inschrift nahe bei Zagarolo (vgl. Cecconi storia di Palestrina p. 153: „ritr. nella via consolare proveniente dalla Labicana in quella parte che dicesi li Prati"; Muratori setzt sie fálschlich nach Rom) und die zweite in Zagarolo selbst gefunden ist.

3) In der inschrift bei Henzen 6315: Chrysanthus Aug. disp. a frumento Puteolis et Ostis zeigt der zusatz, wie der fundort (Puteoli), dass dieser beamte in den bäfen für das vom orient kommende getraide (s. unt.) angestellt war.

4) Schliesslich spricht dafür die geringe zahl derjenigen, die ausdrücklich als zu dem officium annonac gehörig bezeichnet wer-

109) Zweifelhaft ist der iab[ellari]us ex officio [anno]nae praefe[cti] s. ob.

110) Murat. 894, 7: Ti. Claudius Aug. l. actor a frumento ist aus den oben angeführten gründen verdäehtig. 
den und der entsprechende titel: a frumento bei privatsklaven (Orelli 2825. Mommsen I. N. 6910), wo natürlich nur von aufsicht über getraidevorrätlıe die rede sein kann.

Diese kaiserlichen sklaven gehörten also zu dem officium praefecti annonae, standen aber nicht direct unter diesem, sondern einem ritterlichen procurator, den eine unedirte inschrift aus Pesaro nennt (Marini sched. ined. vol. 88):

C. Clodius C. t. Quir. Maximus

proc. Aug. a frumento

quaest. aedil. II vir.

signuu Spei, d. d.

Leider ist die zeit der abfassung nicht zu bestimmen; Maximus war, obgleich er in Pisaurum die municipalämter bekleidete, doch seiner abstammung nach kein Pisaurenser, denn diese stadt gelörte nicht zur tribus Quirina, sondern zur Camilia (vgl. Grotefend imperium R. tributim descriptum p. 70); die procuratio a frumento lat er selır wahrscheinlich in Rom selbst bekleidet, gewiss nicht in Pisaurum, das nie, da es keinen hafen besass, merkantilisch irgend welche bedeutung gehabt hat. Ebenfalls ein proc. a frum(ento) scheint in der verstümmelten insclirift aus Velletri bei Murat. 769, 3 erwälnt zu sein; dieselbe ist walıscheinlich aus der zeit der Claudier; die übrigen datirbaren inschriften dieser beamten beginnen mit den Flaviern und hören auf mit Pertinax (Orelli 895).

Die inschriften schliesslich, die kaiserliche freigelassene und sklaven a frumento ministratorum und cubiculariorum nennen, beweisen, dass schon in der früleren kaiserzeit diese kaiserlichen hofbeamten ausser ilırer besoldung umsonst getraide erhielten ${ }^{111}$ ); die ministratores sind bekanntlich die tafeldiener, die in grosser zahl bei den kaiserlichen malızeiten fungiren, vgl. Seneca Epp. mor. XV, 3 (95) 8. 24: transeo pistorum turbam, transeo ministratorum, per quos signo dato ad inferendam coenam discurritur; übrigens kommt dieser titel meines wissens nur in insclıriften des ersten jahrhunderts vor, wie auch die oben angefülıten inschriften der beamten a frumento ministratorum dieser zeit anzugehören scleinen. Der titel a frumento cubiculariorum resp. cub(iculario-

111) Ueber die naturallieferungen an kaiserliche beamte in spãterer zeit vgl. Rodbertus a. o. p. 411. 
rum) Caesar(is) n(ostri) sta(tionis) I (vgl. Friedländer a. o. I p. 100. Marquardt $V^{1}$ p. 149 a. 51) findet sich in zwei inschriften aus der zeit des Hadrian und Antoninus Pius (vgl. Marini Atti p. 504).

Andere unterbeamten, die in Rom selbst für die getraideverwaltung thätig waren, sind weder von schriftstellern, noch in inschriften überliefert; ilıre zahl ist, wie gesagt, klein, und dieser umstand wohl hauptsächlich durch die mithülfe zahlreicher collegien, die unter der aufsicht des praefectus annonae standen, zu erklären. Wir haben oben nachgewiesen, dass der import des getraides und die beaufsichtigung desselben, sowoll für den täglichen bedarf der stadt Rom, als die monatlichen frumentationen zu den befugnissen des praefectus annonae gehörten, dass dagegen die praefecti frumenti dandi nur die vertheilung desselben zu leiten hatten. Dasselbe resultat hat sich aus der genaueren betrachtung der unterbeamten ergeben: sie stehen sämmtlich unter der competenz des praefectus annonae und gehören alle einer und derselben verwaltung an; aus denselben fonds und derselben kasse werden die kosten für die annona und die frumentationen bestritten; die sämmtlichen verwaltungsgeschäfte besorgen kaiserliche beamte: ritter, freigelassene und sklaven, an ihrer spitze der praefectus annonae; die monatlichen vertheilungen: die senatorischen praefecti frumenti dandi mit ihren gehülfen. Als dann im laufe des dritten jahrhunderts die täglichen brodvertheilungen an stelle der monatlichen getraidevertheilungen treten, fallen auch diese dem praefectus annonae zu und die praefecti frumenti dandi verschwinden aus der reihe der römischen magistrate.

Eigenthümlich ist es, dass alle diese unterbeamte nur in inscliriften der ersten zwei jahrhuuderte der kaiserzeit erwähnt werden; ob dies zufall ist oder ob vielleicht schon Septimius Severus in gewissen zweigen der verwaltung eine ähnliche reorganisation begonnen hat, wie sie Diocletian in so grossartigem maasstabe später durchgeführt hat, lässt sich bei der dürftigkeit unseres materials vorläufig nicht entscheiden; für alle diese fragen ist die zeit von Alexander Severus bis auf Diocletian in ein fast undurchdringliches dunkel gehüllt; ein urtheil wird sich, erst darüber einigermassen fälen lassen, wenn sämmtlicbe zweige der kaiserlichen verwaltung von August bis auf die reform Diocletians einer detaillirten unter- 
suclıung unterzogen sein werden. Dass Diocletian sclion manclies vorfand, woran er bei seiner reform anknüpfen konnte, und dass man mit unrecht meistentheils annimmt, dass er alle älteren institutionen verworfen und eine durchaus neue verwaltungsform an die stelle gesetzt labe, ist mir unzweifelhaft; sicherliclı war in den grossen umwälzungen des dritten jahrhunderts vieles schon vorbereitet, was er nur weiter ausbaute und zu dem systeme gestaltete, das "für das römische reich bis in die spätesten zeiten in geltung geblieben - ist.

\section{Die beamten der Annona ausserhalb Rom's.}

a) In den häfen.

Das getraide, das nacl Rom importirt wurde, kam fast olıne ausnahme aus überseeischen provinzen ${ }^{112}$ ); in der kaiserzeit $2 / 3$ des gánzen bedarfs aus Aegypten und Africa (Nasse a. o. p. 32); die scliffe, die aus diesen und anderen kornreichen provinzen, wie Sardinien, Sicilien, Spanien u. s. w. kamen, nahmen ilıren weg meistentheils über Puteoli ${ }^{113}$ ) nach Ostia, dem lafen Roms (vgl. Friedländer a. o. II p. 75). Dieser hafen war allmählich sehr versandet und so wenig geschützt, dass im winter die schiffe nicht anlanden konnten (Dio 60, 11, 1); daher latte sclıon Caesar beabsiclitigt, denselben zu verbessern, war aber durch die enormen schwierigkeiten von diesem vorlıaben abgeschreckt worden (Plutarch. Caesar. 58. Sueton Claudius 20). Erst Claudius fülırte diesen plan mit ausserordentlichen kosten aus, hauptsächlich bewogen durch die grosse lungersnoth, die bei seinem regierungsantritte herrsclite (Dio 60, 11 2. 2, Sueton Claudius 20) ${ }^{114}$ ) und legte ausserdem nach

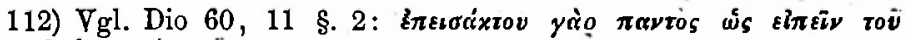
oitov roîs 'Peprioss öros...

113) Interessant sind in dieser hinsicht zwei in Rusicade (Numidien) gefundene inschriften bei Renier 2182: Gen(io) Col(oniae) Put(eolanorum) Aug(usto) sac[r(um)] und $2174=$ Henzen 5320: statuas duas Genium Patriae n'(ostrae) et Annonae sacrae urbis sua pecunia posuit; offenbar war Rusicade der ausfuhrhafen für das numidische getraide, das über Puteoli nach Rom ging.

114) Ueber diese bauten ist besonders zn vergleichen: Nibby dintorni II p. $610 \mathrm{ff}$, und Preller Rom und der Tiber in den Ber. d. s. G. d. W. 1849 p. $10 \mathrm{ff}$. und p. $27 \mathrm{ff}$., der auch die wichtigkeit und den engen zusammenhang derselben mit der hauptstädtischen getrajdeversorgung nachdrücklich hervorgehoben hat. 
Puteoli und Ostia je eine cohors vigilum ad arcendos incendiorum casus (Sueton Claudius 25): diesem bafen, der meistens portus Augusti genannt wird ${ }^{115}$ ), fügte Traian einen zweiten binzu, wie das schol. zu Iuven. 12, 76 berichtet: Traianus portum Angusti restauravit in melius et interins tutiorem sui nominis fecit; die vielfach angefochtene richtigkeit dieser angabe hat Nibby a. 0 . p. 615 ff. und nach ihm Preller a. o. p. 19 ff. gründlich nachgewiesen; es ist bekannt, dass allmählich der neu aufblülıende ort Portus das alte Ostia durch seine günstige lage überflügelte und verdrängte (Nibby a. 0. p. 432-436; Preller a. 0. p. 51 ff.).

Die aufsicht über die getraidezufuhr in Ostia hatte zu Cicero's zeit ein quästor unter dem namen quacstor Ostiensis; das amt war nicht selır angesehen und äusserst mühsam, -aber von hervorragender wichtigkeit (Preller a. o. p. 28. Becker $\mathrm{II}^{2}$ p. 346 a. 866); diese einricbtung blieb bis auf Claudius, der nach Sueton c. 24: collegio quaestorum ... detracta Ostiensi et Gallica provincia curam aerari Saturni reddidit: eine maassregel, die ohne zweifel durch die von ihm ausgefülirten hafenbauten veranlasst war. Wen Claudius an die stelle des quastor Ostiensis setzte, giebt weder Sueton noch ein andrer schriftsteller an, jedoch können wir mit sicherheit behaupten, dass es ein kaiserlicher procurator war, ja ein glücklicher zufall hat uns wahrscheinlich den ersten oder mindestens einen der ersten von diesen überhaupt nur selır selten genannten procuratores portus erhalten in einer inschrift bei Murat 894, 5 :

\section{CLAVDI OPTATI \\ AVG $\cdot \mathbf{L}$ \\ PROC $\cdot$ PORTVS \\ OST TENSIS 116)}

115) Auch andere namen kommen vor, wie portus Ostiae Augusti, portus Romanus, portus Tiberis u. s. w., vgl. Nibby a. o. p. 613 f. und Preller a. o. p. $14 \cdots 17$.

116) $\mathrm{Ob}$ dieser Claudius Optatus identisch ist mit dem von Plinius (n. h. 9, 62: Tiberio Claudio principe ... Oplatus e libertis eius praefectus classis inter Ostiensem et Campaniae or $(m)$ und in zwei inschriften (Cardinali diplomi tav. 1 v. 7 und $1 \mathrm{~b}$ v. $5-6=$ Orelli 2652 : in classe quae est Miseni sub Ti. Iulio Aug. l. Optato und bei Gruter 423, 8: Ti. Iulio Aug. l. Optato Pontiano procuratori et praefec(to) classis; ich habe diese inschrift in Fleckeisen's Jahrb. 1868 p. 697 mit unrecht für 
noch im j. 224 finden wir einen kaiserlichen freigelassenen als proc(urator) p(ortus) $u$ (triusque): Henzen $6523^{117}$ ). Die aufsicht iiber die getraidezufuhr wurde olne zweifel dem procurator Ostiensis vorläufig belassen, wie sie der quaestor Ostiensis gehabt hatte; erst im zweiten jahrhundert, vielleicht seit den neuen bauten Traian's, erscheinen in inschriften besondere beante für die Annona, natïrlich unter der competenz des praefectus annonae in Rom stehend, unter dem namen procurator annonae oder ad annonam. Sie sind sämmtlich aus dem ritterstaude, als gehalt wird einmal (Murat. 682 , 4) $\mathbf{L} \overline{\mathbf{X}}$ BS $=60,000$ sesterzen genannt (das ist das niedrigste gehalt der ritterlichen procuratoren); den titel $v$ (ir) e(gregins) fuhrt der proc. annonae Augg[g]. $m n[n$. o]stiensium bei Guerin II p. 111 n. 307; ein kaiserlicher freigelassener fungirt als tabularius Ostis ad annona(m) (Maffei M. V.319, 5) und ein kaiserlicher sklav als dispensator a frumento Puteolis et Ostis (Henzen 6315): eigenthümlich ist es, dass derselbe für beide häfen angestellt war, doch waren die geschäfte in Puteoli, das nur eine zwischenstation für die Annona war, gewiss sehr unbedeutender art, da die ausladung und abrechnung in Ostia bzw. Portus stattfand; ausser diesem dispensator ist auch daher bis jetzt kein in Puteoli angestellter beamter der Annona gefunden worden. Es war natürlich. nothwendig für die masse der ankommenden waaren, besonders des getraides, am hafen speicher zu erbauen, da ohne zweifel oft der transport nach Rom nicht sofort erfolgen konnte ${ }^{118}$ ).

verdächtig erklärt, Cardinali a. o. p. 15 hat sie selbst in Terracina gesehen) als praefectus classis Misenensis erwähnten Optatus, ist zweifelhaft. Nach den militärdiplomen hiess er 7i. Tulius, muss also ein freigelassener des kaiser Tiber gewesen sein; möglich wäre es, dass Tiber ihn vor seiner adoption freigelassen habe und daher der wechsel von Iulius und Claudius zu erklären sei; nach Plinius war er ein freigelassener des kaiser Claudius, doch ist ein solcher irrthum bei Plinius sehr leicht denkbar. Das militärdiplom gehört in das j. $52 \mathrm{n}$. Chr.; wenn derselbe nun wirklich auch procurator portus Ostiensis war, so muss er dieses amt vorher bekleidet haben; der hafenbau des Claudius fällt aber in die j. 42-45 (vgl. Lehmann a. o.), demnach war er, immer die identität vorausgesetzt, der erste oder wenigstens einer der ersten kaiserlichen hafenbeamten.

117) Unter Portus uterque ist der hafen des Claudius und des Traian zu verstehen vgl. Preller a. o. p. 20 a. 108; über die hafenbeamten in später zeit: den comes portus und centenarius portus sub dispos. praef. urbis Romae vgl. Boecking II p. 189 ff. und Henzen im Bull. d. J. 1863 p. 208 ff.

118) In Puteoli werden schon aus der zeit der republik solche 
Eine in Ostia gefundene insclirift (Orelli 1888) aus der zeit des $\mathbf{M}$. Aurel nennt einen procurator ad oleum in Galbae Ostiae portus utriusque; wir ersehen daraus, dass Galba, wie in Rom, so auch in Ostia grossartige speicheranlagen gemacht laben muss, da ein ritterlicher procurator für das öl speciell in Galbae (horreis) angestellt war. Selır häufig erwähnt werden die horrea Portuensia in später zeit (vgl. Gothofred. im Cod. Theod. t. V p. 201.252. 293. 323); sie wurden beaufsichtigt von gewälılten, jälırlich wechselnden patroni horreorum (vgl. Cod. Th. 14, 23: de patronis horreorum Portuensizm und Gotlofred. t. V p. 201 ff. und 293; Preller a. o, p. 30 a. 148); hier fand noch Alarich im jalıre 409,

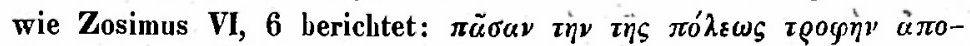

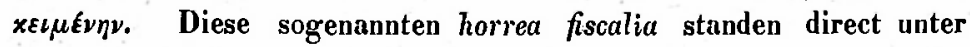
dem praefectus amonae, die oberaufsicht über sie, wie über den ganzen lafen, hatte in jener zeit der praefectus urbis (Cod. Th. 15, 1, 12. Boecking N. D. Il p. 189). -

Ein cornicularius eines proc. annonae Aug. Ostis wird erwälınt bei Henzen 6520, und ein comicularius praef(ecti) anno(nae) in einer am lafen von Ravenna gefundenen insclirift (Orelli 3489), wobei es freilich fraglich bleibt, ob der letztere wirklich dort als comicularius fungirt habe ${ }^{119}$; jedenfalls kann man annehmen, dass diese militärischen adjutanten (vgl. über dieselben Marquardt $11 I^{9}$ p. 420 a. 2443) gerade in den läfen von wichtigkeit sein mussten ${ }^{120}$ ). Diese kaiserlichen procuratores annonae und ihre unterbeamten fallen sämmtlich in die zeit von Hadrian bis auf Septimius Severus, der letzte ist (Guerin. 11 n. 307) aus der zeit des Severus und seiner sölne; aus späterer zeit wird nur noch erwälnt ein 7 (= centurio) ann(onae) in einer zu Portus gefundenen inschrift aus dem j. 224 (Henzen 6523). Es ist eine dedica-

kornspeicher (granaria) erwähnt vgl. Marquardt $\mathrm{II}^{2}$ p. 92 a. 436 ; über die darstellung des hafens von Puteoli auf dem von Bellori publicirten gemälde, wo auch horrea erwähnt werden, vgl. Jordan: di i $\mathbf{k} u ̈$ s te von Puteoli a uf einen römischen glasgefasse in der Archäol. Zeitung 1868 p. 92 f.; über die ruinen der gebäude am hafen von 0stia s. Nibby a. o. p. 615 f., und die abbildung einer münze des Traian bei Preller in den Ber. d. s. G. d. W. 1849 taf. I n. 4.

119) Derselbe ist später centurio in verschiedenen legionen.

120 In einer ostiensischen inschrift (Orelli 4109) werden beneficiarii proc(uraloris) Aug(usti) erwähnt; es ist darunter keineswegs der proc. annonae, möglicherweise der proc. portus zu verstehen. 
tion an die kaiserliche familie von der statio frumentariorum und dazu ist der locus adsignatus ab Agricola Aug. lib. proc. p(ortus) u(triusque). et Petronio Maxsimo 7. ann(onae) et Fabio Maronae (sic) 7. operum; wäre dieser centurio annonae nur ein offizier im dienste der Annona ${ }^{121}$ ), unter dem procurator annonae Ostiis stehend, so würde er schwerlich in dieser weise mit dem procurator portus utriusque zusammen genannt erscheinen, vielmelr ist mir diese inschrift ein deutliches zeichen, dass die Annona in Portus bzw. Ostia nicht mehr unter einem kaiserlichen procurator, sondern einem centurio stand; doch wage ich nicht daraus den schluss zu ziehn, dass schon zu der zeit des Alexander Severus dem praefectus annonae die aufsicht über die zufulr genommen und dem praefectus praetorio zugetheilt war, wie dies in der zeit des Cassiodor unzweifelhaft der fall war (s. unt.). Es mochte sich empfehlen, gerade in den häfen einen militärischen schutz für das getraide zu haben; die ausschliesslichen verwaltungsgeschäfte waren vielleicht wieder, wie im ersten jahrhundert, dem procurator portus übertragen.

Ueber die collegien der schiffer, getraidemesser, sackträger u.s.w. in 0stia und Portus, die unter der aufsicht des praefectus annonae und seiner beamten standen, haben wir schon oben gesprochen; leider sind wir nicht im stande, auch nur annähernd die zahl ihrer mitglieder angeben zu können; dass dieselbe jedoch sehr bedeutend gewesen sein muss, kann nach den uns erhaltenen inscbriftlichen zeugnissen nicht zweifelhaft sein, und es ist dies eines der sichersten kriterien für die grossartigkeit der hauptstädtischen getraideverwaltung...

\section{b) In den provinzen:}

In einer in Arles gefundenen inschrift, die wahrscheinlich der zeit des Marc. Aurel angehört, wird ein procurator Angustorum ad amonam provinciae Norbonensis et Liguriae ${ }^{122}$ ) (Orelli 3655) genannt; das amt steht zwischen dem legionstribunate und der praefectura alae, ist also niedriger im range, als die meisten procura-

121) Ein solcher wird schon von Scaevola (Digg. 13, 7, 43-§. 1) erwähnt: missus ex officio annonae centurio.

122) Unter Liguria ist ohne zweifel das stück land zu verstehen, das mit der provincia Narbonensis combinirt worden war, vgl. Strabo IV, 6, 4 p. 203; über die naturalabgaben von Gallia Narbonensis vgl. Herzog Gallia Narbonensis p. 246. 
tureu, die regelmässig erst nach der präfectur einer ala bekleidet werden. Die inschrift ist gesetzt von den navic(ulariomem) marin(ortm) Arel(atensium) corp(ora) quinq(ue) patrono optimo et innocentissimo, und dieser umstand spriclit ausser dem fundorte dafür, dass er in Arelate selbst, das sich durch seine lage besonders zu merkantilischen zwecken qualificirte, als unterbeamter des praefectus annonae ${ }^{123}$ ) angestellt war: denn das patronat über die collegien der seeschiffer, die den überseeischen transport des getraides nach Rom zu besorgen hatten, war ilsm olne zweifel in dieser ei-genschaft übertragen worden. Er ist daher sicherlich nicht wesentlich verschieden von dem in einer gleichzeitigen inschrift aus Hispalis (= Sevilla) in Baetica (C. I. L. 2, $1180=$ Henzen 6522) genannten adiutor praef. annon. ad oleum Afrum et Hispanum recensendum item solamina transferenda item vecturas naviculariis exsolvendas. Dass für das spanische und afrikanische öl, das vortrefflich war und viel nach Rom exportirt wurde (vgl. z. b. Orelli 3254. 3331. 4077, Casaub. zur vita Severi c. 18), ein besonderer adiutor praefecti annonae angestellt war, zeugt ebenfalls von der bedeutung dieses exportes ${ }^{124}$ ); die inschrift wird ilhm gesetzt von den scapharii Hispalenses ${ }^{125}$ ), jedoch sind unter den navicularii (ad vecturas naviculariis exsolvendas) nicht nur diese, sondern unzweifelhaft auch die seeschiffer zu verstehen, die den transport des öles uud des getraides, nachdem dasselbe von Hispalis, wo dieser adiutor praefecti annonae stationirt war, auf dem schiffbaren Baetis durch die scapharii Hispalenses an das meer geschafit war, nach Rom besorgten $\left.{ }^{126}\right)$ : daher lhalte ich auch die erklärung von solamina -

123) Verfehlt scheint mir die erklärung dieses amtes bei Herzog a. o. p. 247 : ,annonae vero maior utique pars dependebatur procuratori Caesaris". . . nämlich die naturalabgaben: „quae ad usum exerciluum Li änseuntium erant pendenda. Ilaque videmus peculiarem procuratorem annonae esse instilulum, cuius eral per Narbonensem et Liguriamannonarias collationes administrare el quae per duas has regiones exlabanl horrea custodire" vgl. p. 248.

124) Ueber die naturallieferungen aus Spanien nach Rom, vgl. Gothofred. zu Cod. Th. XI, 9, 2 und XIII, 5, 4. Baetis.

125) Sein nächster und letzter titel ist: proc. Augg. ad ripam

126) Ueber diese spanischen navicularii handelt Cod. Th. XIII, 5 , 4 a. 324, vgl. Boissieu inscr. de Lyon p. 397 über die annonarii riparii in Lyon. Aehnliche collegien finden sich auch in anderen provinzen (vgl. Marquardt $\mathrm{V}^{2}$ p. 19 f. Kuhn Verfassung des R. R. I p. 76 ff.), die direct oder indirect den zwecken der hauptstädtischen getraideverwaltung dienstbar waren. 
annonaria subsidia (Forcellini s. v.), so auffällig auch dieser übertragene ausdruck in einer insclırift ist, für begründet (vgl. Cod. Iust. 1, 52, 1: solatia annonarum und Benzen im Bull. d. J. 1863 p. 208). Bemerkenswerth ist, dass Hispania Baetica, wie Gallia Narbonensis, ia denen diese procuratoren fungiren, senatorische provinzen sind; auch der dispensator [ad] frumentum in der zu Cius gefundenen inschrift (C. I. L. III, 333) scheint aus der zeit der Flavier zu sein, als Bitlyuien noch senatorisch war. Es ist demnach, wie wir schon hei besprechung des dispensator frumenti mancipalis verınuthet baben, sehr wahrscheinlich, dass auch die provinzen des senates zu der annona urbis Romae beizusteuern hatten, nicht etwa allein durch privatexport, sondern durch directe naturalabgahen an den fiscus ${ }^{127}$ ); dafür spricht auch der ausdruck ad olentm recensendum in der spanischen inschrift, während man, wenn es sich um ankäufe gehandelt hätte, emendum oder comparandam (s. unt.) erwarten müsste.

Ausserdem aber ist hervorzuheben, dass in kaiserlichen provinzen sich besondere procuratoren für die Annona bis jetzt nicht gefunden haben, und wenn es bei der dürftigkeit der uns erhaltenen zeugnisse auch zu gewagt erscheint, aus diesem nichtvorkommen bestimmte schlüsse zu ziehen, so sprechen doch analoge erscheinungen in anderen verwaltungszweigen ${ }^{128}$ ) dafür, dass die praxis in den kaiserlichen provinzen etwas verschieden war; wir haben dafür zwei beispiele aus der zeit des Traian: in einer zu Kalama in Numidien gefundenen inschrift (Renier 2715) heisst es:

T. Flavio T. $f$. Quir. Macro II vir(o) flamini perpetuo Ammaedarensium praef(ecto) gentis Musulamionm curatori frument; comparandi in annona[m] Urbis facto a Divo Nerva Traiano proc. Ang. praediorum...

Sowohl der titel curator, als auch die erwahnung der directen ernennung durch den kaiser zeigen deutlich, dass Macer ein

127) In der zeit des M. Aurel, in der diese inschrift gesetzt ist, waren jedoch die naturalabgaben wahrscheinlich nicht mehr verpachtet, sondern wurden von den provincialen direct geliefert (s. ob. anm. 106); über die naturallieferungen Italiens seit Maximian für die kaiserliche hofhaltung (regiones annonariae), wahrseheinlich schon seit Aurelian für den bedarf der stadt Rom (regiones w bicariae oder suburbicariae) vgl. Mommsen zu den Gromatici II p. $198 \mathrm{ff}$.

128) So z. b. in der kaiserlichen erbschaftsverwaltung, auf die wir hier nicht näher eingehen können.

Philologus. XXIX. bd. 1. 
ausserordentliches commissariat erhalten hatte, um getraide in Numidien fiir die annona urbis Romae aufzukaufen, jedenfalls mit dem range und der competenz eines kaiserlichen procurator, wie seine spätere carrière beweist.

Finden wir hier einen ausserordentlichen commissar speciell für diesen zweck ernannt, so zeigt das zweite beispiel ein ähnliches verfahren: man betraute einen schon in der provinz stationirten procuratorischen beamten mit einem solchen auftrage. Plinius schreibt nämlich in seinem 27sten briefe an Traian, dass Maximus (libertus et procurator tuus) zu seinem schutze soldaten wünsche, die er ihm auch gelassen habe: praesertim cum ad frumentum comparandum iret in Paphlagoniam. Traian antwortet darauf (epp. 28): Maximum libertum meum recte militibus instruxisti. Fungebatur enim et ipse extraordinario munere. Cum ad pristinum actum reversus fuerit, sufficient illi duo a te dati milites et totidem a Virdio Gemellino, procuratore meo, quem adiuvat.

Man sieht, in beiden fällen ist vom ankaufe (comparare) des getraides die rede ${ }^{129}$ ); die naturalabgaben, die auch in manchen kaiserlichen provinzen neben den geldabgaben erhoben wurden (vgl. Marquardt III² p. 183 ff. Rein in Pauly's R. E. VI p. 2409) gingen ohne zweifel direct von den municipalbehörden an die stelienden verwaltungsbeamten ${ }^{130}$ ). Gewiss überliess man diesen in den meisten fällen auch den für die annona urbis zuweilen nothwendigen ankauf von getraide in ihrer provinz und die ernennung eines eigenen commissars für diesen zweck war wohl nur ausnahme. Möglich ist es, dass man im allgemeinen auch in den senatsprovinzen den provinzialprocuratoren dieses geschäft übertragen und nur an einigen, besonders wichtigen punkten eigene beamte hinge-

129) Auch das getraide für Constantinopel wurde theils als abgabe geliefert, theils angekauft, vgl. Gothofred. zu Cod. Th. XIV, 16 im paratitlon und zu l. 3.

130) Von unterbeamten der annona in kaiserlichen provinzen ist nur noch der dispensator a frumento in einer zu Metz (Gallia Belgica) gefundenen inschrift aus dem j. 193 zu nennen. - Dass auch in Aegypten die getraideverwaltung von kaiserlichen beamten besorgt wurde, bedarf keines beweises; über die art der erhebung s. Rudorff im Rhein. Mus. f. Philol. 1838 p. 136 ff.; früher waren Aegypter und Juden in Alexandria damit betraut vgl. Joseph. c. Apion. II, 5 fin. : nam admanistratio tritici nililo magis ab eis (Judaeis) quam ab aliis Alexandrinis translata est. 
setzt lat: die äusserst seltene erwähnung von kaiserlichen beauten in den provinzen macht dies wenigstens sehr wahrscheinlich.

\section{Die Getraideverwaltnug in den Municipien.}

Wir haben uns bis jetzt in unserer untersuchung auf die stadt Rom beschränkt, und dies um so mehr thun können, als alle die kaiserlichen und senatorischen beamten für die Annona sich ausschliesslich bis auf die gründung Constantinopel's auf Rom bezieben; jedoch wird es keiner rechtfertigung bedürfen, wenn wir zum schluss wenigstens noch einen flüchtigen blick auf die analogen einrichtungen in den municipien in und ausserhalb Italiens werfen. Es springt bei dieser betrachtung sofort die für die römische anschauungsweise sehr characteristische erscheinung in die augen, dass der staat resp. die kaiser ihre grossartige fïrsorge fast einzig und allein auf die hauptstadt beschränkten und in den municipien alles der privatinitiative überlassen war ${ }^{131}$ ). Daher ist vou monatlichen getraidevertheilungen oder täglichen schenkungen von brod, öl u. s. w. auf öffentliche kosten, die in Rom seit C. Gracchus bis in die späteste zeit eine so grosse rolle spielten, in den municipien nie die rede; daher bezieht sich, wie gesagt, die ganze grossartige verwaltung der frumentationen und der annona und ibre beamten ohne ausnahme auf die hauptstadt ${ }^{132}$ ); ja selbst die inmu-

131) Unterstützungen, die einzelne städte von den kaisern bei ausserordentlichen unglücksfüllen erhielten, wie z. b. die durch ein erdbeben zerstörten asiatischen städte von Tiberius (Tacit. A. II, 47. Dio $57,17,7)$ u. a. m. kommen hier natürlich nicht in betracht; eher die

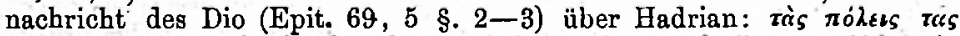

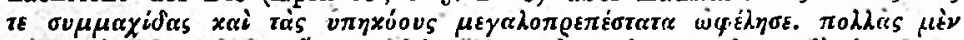

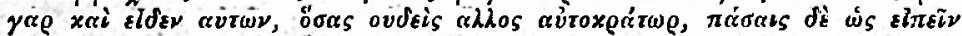

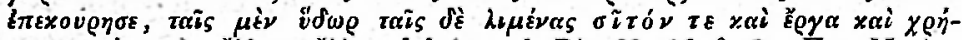

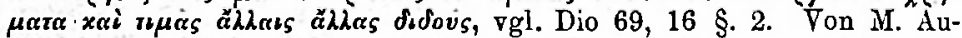
rel (vita 11) wird gerühmt: Italicis civitatibus famis tempore frumentum ex urbe donavillomnique frumentariae rei consuluit, auch scheint die einsetzung der Iuridici damit im zusammenhange gestanden zu halen, vgl. Borghesi in den Annali d. J. 1853 p. 222 f.; die bemerkungen von Zumpt (Comment. Epigr. If p. 50) über die iuridici und die frumentationen in Italien sind durchaus verkehrt.

132) Die anschauung, die dieser erscheinung zu grunde liegt, ist die durch die ganze römische geschichte seit der unterwerfung Italiens und der provinzen durchgehende, dass Rom die alleinige herrscherin, alle anderen städte die untergebenen seien und dass daber ausschliesslich die hauptstädtische, bevölkerung zu privilegien auf kosten der übri- 
nitäten, die an negotiatores und navicularii verliehen werden, gelten nur für diejenigen, qui annonae $U \cdot b$ is serviunt (z. b. Digg. 50, 6, 5 2. 3). Um so melır hlieb der mildthätigkeit der bürger zu thuu übrig, die sich, nach vielen inschriftlichen erwäbnungen zu schliessen, besonders in den municipien Italiens, wo in alter, wie neuer zeit, ein reger lokalpatriotismus herrschte, in reichlichen vertheilungen von getraide und öl manifestirte, vgl. z. b. Orelli-Henzen: 80. 748. 2172. 3848. 5323. 6759. 7173. C. I. Gr. 378. 2930. 3831a. Mommsen I. N. 190. Grut. 434, 1. 478, 9. Guerin 233

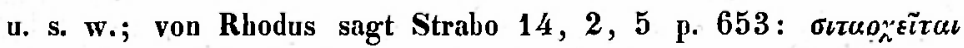

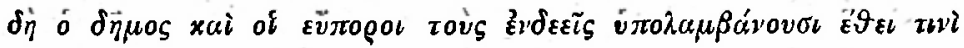
$\pi \alpha \tau \rho l \omega$.

Ausserdem aher war es die pflicht der municipalbehörden, in kleinerem maasstabe das nachzuahmen,- was von den kaiserlichen behörden für Rom geschah, und dieser pflicht müssen dieselben vortrefflich nachgekommen sein, denn au wenigen beispielen zeigt sich die ausbildung der communalverwaltung in der römischen kaiserzeit in so vortheilhafter weise, als bei der sorge für reichliche und billige zufulbr. Wie in Rom der fiscus frumentarius, so bestand auch in den municipien eine eigene arca frumentaria (Digg. $50,4,1$ 2. 2 : Mommsen I. N. 4771 praepositus pecuniae frumentariae: Mommsen I. N. 1955 annonaria pecunia: Digg. 16, 2, 17 und 50, 8, 2 2. 3 frumentaria pecunia: Digg. 50, 8, 9 2.. 5: pecunia ad annonam destinata) zum ankaufe von getraide. Von den stehenden municipalmagistraten waren es natürlich die ädilen, denen die sorge für das getraide und den ganzen markt oblag ${ }^{13 s}$ ) (vgl. Digg. 16, 2, 17: condemnatus quod arotiorem annonam aedilitatis tempore praebuit); in Caere waren zu Traian's zeit die obersten magistrate ein dictator, ein aedilis iuri dicundo und ein ae-

gen welt berechtigt sei. Die stiftung der alimentationen für Italien war-der erste bruch mit der aus dieser anschauung hervorgehenden praxis und unzweifelhaft eine der humansten schöpfungen des alterthums: es ist characteristisch, dass Nerva, der stifter dieser alimentationen, kein geborener Römer war, sondern aus Narni in Umbrien stammte.

133) Vgl. die aediles (resp. II viri) v(iis) a (nnonae) s(acris) $p$ (ublicis) $p$ (rocurandis) in pompejanischen inschriften: Henzen index $\mathrm{p}$. 159. Petron. c. 44: aediles male eveniat, qui cum pistoribus colludunt, und Appuleius Metam. I c. 24: annonam curamus, ait, et aedilem ge, imus. 
dilis annonae (Mommsen I. N. 6828 vgl. 5039: aedili annonae curatori), meistentheils findet sich jedoch dafür ein beamter unter dem titel curator annonae (Orelli 2391. 2532. Mommsen I. N. 4250. 5630. 5633 (?) 6036. Digg. 49, 1, 21 ¿.. 2) ${ }^{134}$ ), oder auch unter dem uamen curator frumenti (Mommsen I. N. 1954. Heuzen $\mathbf{7 1 4 7}^{155}$ ), curator rei frumentariae (Mommsen I. N. 189), cltr(ator) ann(onae) frum(enti) populi (Mommsen I. N. 5696). Auch für den getraidekauf finden sich besondere curatores, so bei Mommsen I. N. 2454 : cur. $\overline{I I}$ frum. compar. vgl. Digg. 50, 4, 3 \&्ष. 12 : cura frumenti comparandi munus est und 50, 4, 18 \%. 5: cura quoque emendi frumenti, olei, nam harum specierum curatores quos

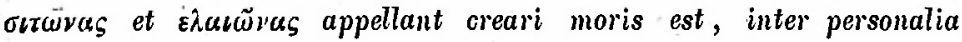
munera in quibusdam civitatibus numerantur.

Aus den hier angeführten beispielen, die sich leicht vermeliren liessen ${ }^{136}$ ), geht zur genüge hervor, dass auch in den municipieu die lieferung und der verkauf des getraides nicht allein der privatspeculation überlassen war, sondern von den municipalbehörden überwacht uud geleitet wurde; auch scheint von ilnen ein fester marktpreis für iliren verwaltungsbezirk festgestellt zu sein (Digg. $50,1,8.50,8,5)$. Es zeigt sich demnach in der getraideverwaltung, wie in fast allen municipalen einrichtungeu, der enge anschluss an die stadtrömischen institutionen ${ }^{137}$ ) und auch hierfür gilt der bekannte ausspruch des Gellins $(16,3,9)$, dass die römischen colonieen effigies parvae simulacraque populi Romani zu sein scheinen.

\section{Die getraideverwaltung nach der reform Diocletian's.}

Die quellen für diese späte zeit sind ausserordentlich reichhaltig und Gothofredus hat in seinem bewundernswerthen commen-

134) Ein cur(ator) ann(onae) populo praebitae bei Orelli 3908 ; $\varepsilon v$ -

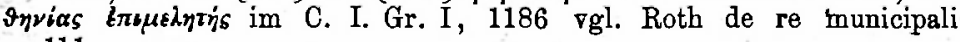
p. 111.

135) In der inschrift bei Reines. VI, 112 :

$$
\begin{aligned}
& \text { RVFIVS - CAT V L VS } \\
& \text { CVRATOR - NRVII - VIVVS } \\
& \text { etc. }
\end{aligned}
$$

ist sehr wahrschemlich: CVRATOR FRVM(enti) VIVVS zu lesen.

136) Ueber diese municipalbeamten handelt Kuhn Verfassung des röm. Reichs I p. $46 \mathrm{f}$.

137) Auch Kuhn Zeitschr. f. Alterthumsw. 1845 p. 1078 macht darauf aufmerksam. 
tar zum Codex Theodosianus die einschlägigen notizen an verschiedenen stellen gesammelt und verwerthet ${ }^{138}$ ); wir werden uns daher mit einigen andeutungen über die beamten dieser verwaltung begnügen können.

Die verlegung der residenz von Rom nach Constantinopel im j. 330 musste nothwendiger weise in der verwaltung der Anuona bedeutende veränderungen hervorrufen: bis dalin war Rom die einzige stadt, für deren unterhalt-auf statskosten gesorgt wurde und auf sie concentrirten sich alle die grossartigen einrichtungen für diesen zweck. Als ilır nun in Constantinopel eine begünstigte uebenbuhlerin erwuchs, als die öffentlichen brodvertheilungen und öffentlicher verkauf ${ }^{139}$ ) dort, wie hier, eingefülırt wurde, ergab sich die nothwendigkeit von selbst, für Constantinopel eine ausreichende zufulır zu schaffen, die natürlich, zum theile wenigstens, der alten hauptstadt entzogen werden musste. Aegypten und Africa waren die provinzen, von denen der hauptsächlichste bedarf in der kaiserzeit geliefert wurde (s. ob.); man nalım jetzt eine theilung in der art vor, dass alles getraide aus Aegypten für Constantinopel bestimmt und Rom nur das getraide aus Africa belassen wurde ${ }^{110}$ ). Ein eigener praefectus annonae für Constantinopel scheint jedoch nicht eingesetzt worden zu sein, wenigstens wird er nie erwälnt ${ }^{141}$ ) und die ganze sorge für die aunona muss dem praefectus urbis zugefallen sein, der ja auch in Rom die oberaufsicht über dieselbe in dieser zeit hatte ${ }^{142}$ ). Dagegen

138) Ihn hat Beseke a. o. besonders p. 107-142 ausgeschrieben.

139) Vgl. Cod. Th. XIV, 16: de frumento urbis Constantinopolitanae; Naudet a. 0. p. 48 ff. Lipsius admiranda II, c. 10 p. 83 f.: diese brodvertheilungen in Constantinopel waren hauptsächlich für die besitzer von häusern bestimmt und sollten vorzugsweise dazu dienen, die baulust in der neuen residenz anzustacheln, vgl. Gothofr. zu Cod. Th. XIV, 16,2 und XIV, 17, 1.

140) Vgl. Gothofr. zu Cod. Th. XIV, 26, 1 und die dort citirten stellen; besonders characteristisch ist die klage Rom's darüber bei Claudian de bello Gildoniaco v. 52 ff.

141) Nur in einer von Beseke (p. 148) citirten novelle Justinian's

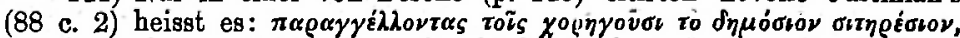

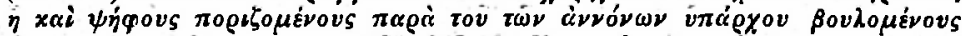

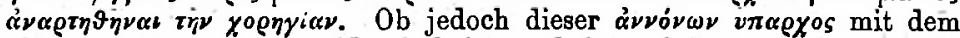
alten praefectus annonae identisch ist, scheint mindestens sehr zweifel-

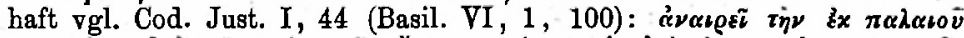

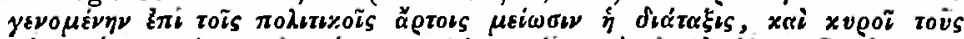

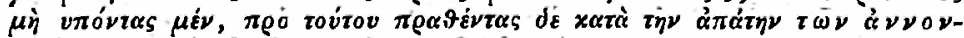

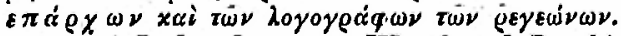

142) Lydus de magg. III, 38 und Boecking N. D. I p. 177 f., der, 
finden sich ausser dem praefectus annonae in Rom noch zwei andere erwähnt:

1) Praefectus annonae Africae,

2) Praefectus annonae Alexandriae.

Der erstere hatte seinen sitz in Carthago (s. die stellen hei Gothofr. im Cod. Th. IV p. 569 anm. b) und es ist bemerkenswerth, dass er schon im j. 315, also funfzehn jahre vor der einweihung Constantinopels, erwähnt wird (Cod. Th. XI, 30, 4) ${ }^{113}$ ), nicht also erst, als Africa allein für Rom das getraide lieferte; doch hat dieses amt auch später noch bestanden, wie ein erlass ad Demetrianum pf. ann. Afric. im j. 369 (Cod. Th. 13, 5, 12) und die erwälınung in der Notitia dignitatum beweisen (s. auch Cod. Th. 13, 5, 36 : a. 412 und 38 : a. 414; tabularii desselben werden genannt im Cod. Th. $X I, 1,13$ : a. 366). Er stand übrigens nicht unter dem vicarius Africae, sondern direct unter dem praefectus praetorio Italiae, zu dessen diöcese bekanntlich Africa gehörte (Boecking N. D. II p. 11 und $150 \mathrm{f}$ ) ${ }^{144}$ ). Boecking a: o. nimmt an, dass dieses amt ,procul dubio" von Constantin eingesetzt sei; mir scheint das keineswegs zweifellos, da, wie wir gesehen haben, die einsetzung von der verlegung der residenz nach Coustantinopel unabhängig war; es ist vielmehr sehr möglich, dass schon im laufe des dritten jabrhunderts praefecti für die annona urbis Romae ausserhalb Italiens fungirt haben. Diese annahme scheint mir unterstïtzt zu werden durch die erwähnung des Maecius Brundisinus praefectus annonae Orientis in der Vit. Aurelian. c. 13; es ist der bericht über eine versammlung, die der kaiser Valerian im j. 258 n. Chr. in Byzanz abhielt; derselbe ist entnommen: ex libris Acholii, qui magister admissionum Valeriani principis fuit; libro actorum eius nono, kann also als durchaus officiell angesehen werden. Die stellung

wie ich glaube, mit vollem rechte annimmt (p. 174 f.), dass das blatt, das die Insignia Praefecti urbis $C p$. enthielt, aus dem archetypus ausgefallen ist.

143) In zwei anderen gesetzen (Cod. Th. XIII, 5, 2 und 3) heisst derselbe nur praefeclus annonae; wohl richtig bemerkt Gothofred $\mathrm{zu}$ Cod. Th. XIII, 5, 2: praefectus annonae scil. Africae, da dieses gesetz früher als das erste (Cod. Th. XI, 30,4) ist; dasselbe gilt wohl von Cod. Th. XIII, 5, 3, obgleich dasselbe vier jahre später erlassen ist und man daher ein avancement zur praefectura annonae in Rom annehmen könnte.

144) Eeber den praefectus annonae Africae vgl. Gothofr. zu Cod. Th. XI, $1,13$. 
des praefectus annonae Orientis war augenscheinlich sebr hoch, denn er wird unter den ersten würdenträgern des reiches genannt; seine aufgabe muss für sämmtliche orientalische provinzen, besonders für Aegypten, die erbebung und beförderung der naturallieferungen gewesen sein ${ }^{145}$ ); ob er in Byzanz selbst oder in Alexandria statiouirt war, ist fraglich. Nach der gründung von Constantinopel finden wir einen praefectus annonae Alexandriae im j. 349: Cod. Th. XII, 6, 3, der mit dem ägyptischen getraideexport nach Constantinopel betraut war $\left.{ }^{146}\right)$; in der Notitia dignitatum wird er nicht erwähnt und es ist möglich, dass das amt damals schor eingegangeu war; Boecking (N. D. II p. 150) nimmt an, dass er unter dem praefechus urbis $C p$. gestanden habe, und auf dem verlorenen blatte erwähnt gewesen sei; mir ist das unwahrscheinlich, da der praef. annonae Africae ebenfalls nicht unter dem praef. urbis Romae, sondern dem praefectus praetorio stand; ferner wird der praef. annonae Alexandriae schon im j. 349 erwähnt, während der erste praefectus urbis in Constantinopel erst im j. 359 eingesetzt wurde (Boecking N. D. I p. 175), - Ueber den praefectus annonae in Rom haben wir nur wenig hinzuzufuigen, da wir im laufe der abhandlung stets die späte zeit berïcksichtigt haben. Wenn man sich nicht durch die schwülstigen worte Cassiodor's blenden lässt, so sieht man aus der formula praefecti annonae (Variar. 6, 18), dass ihm im wesentlichen nichts geblieben war, als die beaufsichtigung der backer und der schweinehändler, und die leitung der brodvertheilungen ${ }^{14^{*}}$ ). Ausserdem war er verpflichtet, zuweilen nach Ostia resp. Portus sich zu begeben, um die zufuhr zu inspiciren (vgl. Cod. Th. 13, 5, 38. 14, 15, 2. Sidon. Apoll. epp. I,

145) Möglich ist freilich, dass unter annona hier nur die naturallieferungen zum unterhalte der beamten u. s. w. zu verstehen sind (vgl. Bethmann-Hollweg Civilprocess III p. 37 u. a.) und dieser praefectus in keiner beziehung zur annona urbis Romae gestanden habe.

146) Wahrscheinlich hatte er zugleich die aufsicht über die von Diocletian in Alexandria eingefuihrten getraidevertheilungen, über welche vgl. Gothofr. zu Cod. Th. XIV, 26, 2.

147) Folgende stelle ist besonders characteristisch: sed ut actionis ipsius in totum merita perscrutemur, triticeas quidem copias praefectura praetoriana procurat. Sed non minor laus est, dispensationem probabilem facere quam frumenta colligere: quando in quavis abundantia querela non tollitur, si panis elegantia nulla servetur. Ueber das urtheil des Boethius haben wir oben gesprochen, ebenso über den titel und die gerichtsbarkeit des praefectus annonae in später zeit vgl. Bethmann-Ilollweg Civilprocess III p. $64 \mathrm{f}$. 
10), auch dieses freilich unter zuziehung des praefectus urbis; wie in früheren zeiten standen unter seiner aufsicht die collegien der mensores, navicularii u. s. w. und er latte zu seiner disposition ein officium annonarium mit officiales und apparitores, wie alle höheren beamteu der nachdiocletianischen zeit (s. die stellen bei Gothofred. im index des Cod. Th. p. 14, ausserdem Cod. Theod. (ed. Haenel) I, 6, 7 und Cod. Iust. 12, 59: de apparitoribus praefecti annonae ${ }^{148}$ ). Aber durcli seine unterordnung unter den praefectus urbis in Rom und durch die überweisung der aufsicht über die getraidezufuhr an die praefecti praetorio (vgl. Symmachus Epp. X, 48. Cassiodor. Variar. VI, 18. Valesius zu Ammian. 28, 1. 18. Gothofred. zu Cod. Th. I, 2, 7) hatte der praefectus amnonae seine selbstständigkeit und den wichtigsten theil seiner functionen eingebüsst; trotzdem erhielt sich dieses amt äusserlich in wenig veränderter weise bis zum untergange des weströmischen reiches.

Es liegt ausserhalb unserer aufgabe, die nationalökonomische seite der getraidespenden hier ins auge zu fassen und naclizuweisen, wie sehr dieselben dazu beigetragen haben, den besitzlosen, aufrührerischen pöbel in. Rom zu vermehren, der in republikanischer, wie in kaiserlicher zeit eine so grosse und unheilvolle rolle spielte, bis der absolute militärdespotismus derselben ein ende machte. Wir wollen hier nur noch einmal darauf aufmerksam machen, dass die motive, die Gracchus und seine nachfolger zur einrichtung der frumentationen bewogen, weniger humaner, als politischer natur waren und dass, wenn in der kaiserzeit auch diese vertheilungen mehr den character einer armenverpflegung annehmen ${ }^{149}$ ), es doch ebenfalls, wenigstens zum theil, politische gründe waren, die Caesar und Augustus bestimmten, dieselben beizubehalten, freilich gründe sehr verschiedener art, die bedingt waren durch

148) Das verhältniss des praefectus annonae zum praefeclus urbis musste leicht zu streitigkeiten zwischen den officia dieser beiden beamten veranlassung geben; davon zeugt ein erlass an Volusianus praef. urb. aus dem j. 364 : cavens, ne urbaniciani officiales annonariis necessitatibus misceantur, omnia participe praefectura annonaria disponas.

149) Vgl. darüber die schönen worte Mommsen's (R. G. III p. 491): „zuerst Cäsar hat, was in der beschränkten enge des attischen lebens gemeindesache geblieben war, zu einer organischen staatsinstitution entwickelt und eine einrichtung, die für den staat eine last und eine schmach war, umgeschaffen in die erste jener heute so unzählbaren wie segensreichen anstalten, in denen das unendliche menschliche erbarmen mit dem unendlichen menschlichen elend ringt." 
die gänzlich umgestaltete lage des römischen volkes. Die republikanischen demagogen wollten durch diese gaben die s t i m in e in des volkes für ihre politischen reformen gewinnen, die kaiser gaben dem volke „brod und spiele", um es den verlust der freilheit vergessen zu machen, denn sie wussten wohl, dass hunger und langeweile mächtige triebfedern zu revolutionen sind ${ }^{150}$ ). Als die römische plebs allmählich ibre bedentung verlor, als dann durch verlegung der residenz nach Constantinopel Rom aufhörte, die erste und einzige stadt zu sein, da musste auch die sorge für den unterhalt der römischen bevölkerung in deu hintergrund treten, uı so mehr, als ganz ähnliche institutionen für die neue hauptstadt eingesetzt wurden und Aegypten seine schätze nicht mehr nach Rom, sondern dorthin sandte. Die gründung von Constantinopel war der todesstoss für Rom und die stadtrömischen beamten ${ }^{151}$ ), und in den letzten jahrhunderten des Römerreiches ist wenig mehr von dem glanze geblieben, der dieselben einst umgeben hatte. Die ersten zwei jahrhunderte des römischen kaiserreiches bieten auch für die hier besprochene verwaltung das grossartigste bild und, so zerstreut und lïckenhaft unsere nachrichten sind, so reichen sie doch hin, um uns eine anschaung, von der organisation und der bedeutung der institutionen zu geben, die bestimmt waren, e in e stadt, eine weltstadt freilich im vollsten sinne des wortes, vor mangel zu schützen.

\section{Anhang.}

1) Die bestimmungen betreffs der getraidevertheilungen in der Lex Iulia municipalis.

In dem eingange der tabula Heracleensis z. 1-19 findet

150) Hoeck R. G. ${ }^{2}$ p. 145 ; vgl. Epistula ad Caesarem senem do RP. 7 §. 2: igitur provideas oporlet ui pleps largitionibus et publico frumento corrupta habeat negolia sua, quibus ab malo publico detineatur, und die berühmten verse des Juvenal, Sat. $X, 77-81$ :

iam pridem, ex quo suffragia nulli

vendimus, effudit curas; nam qui dabat olim

imperium fasces legiones omnia, nunc se

continet atque duas tantum res anxius optat, panem et circenses;

ähnlich spricht sich Fronto (principia historiae p. 210 Naber.) aus.

151) Ausnehmen kann man höchstens den praefectus urbis, der gewissermassen als stellvertreter des kaisers angesehen wurde. 
sich bekanntlich die bestimmung, dass die namen derjenigen, welche nach diesem gesetz eine meldung (professio) an den consul, für den als stellvertreter der praetor urbanus, der praetor peregrinis und die volkstribunen genannt werden, zu machen hätten, in die tabulae publicae von dem betreffenden beamteu eingetragen werden sollen; ferner solle derselbe eademque omnia quae uteigne intabulas rettulerit ita intabulam in album reforunda [curato] idque aput forum et quom frumentum populo dabitur ibei ubei frumontum populo dabitur cottidie maiorem partem diei propositum habeto u(nde) d(e) p(lano) r(ecte) 1(egi) p(ossit) queiquomque frimentum populo dabunt (dab[i]t Momınsen) damdumve curabit neique (statt quoi) eormm quorum nomina $h(a c) \quad l(e g e)$ ad cos. pr. tr. pl. intabula in albo proposita erunt frumentum dato neve dare inbeto neve sinito: widrigenfalls er strafe zalilen soll.

Leider ist der anfang des gesetzes verloren gegangen und wir sind daher vollständig im unklaren darüber, was für eine professio eigentlich zu verstehen ist; es sind denn auch die verschiedensten erklärungen versucht worden, von denen wir die hauptsächlichsten hier anführen wollen :

Mazochi a. o.'p. 312 f. ist der ansicht, dass die meldung sich auf wohlhabende bürger, besonders grundbesitzer, beziehe, die von den getraidespenden auszuschliessen seien; während Marezoll (frgm. legis Romanae in aversa tabulae Heracleensis parte p. 89) vermuthet, dass sie auf die Italiker gebe, die in folge der Lex Iulia de civitate ihren wohnsitz nach Rom verlegt hätten. Diese ansichten sucht Dirksen (Civil. Abhdl. II p. 166 ff.) zụ widerlegen und nimmt zu der äusserst bedenklichen annahme seine zuflucht (p. 174): „es möge der nachlässige copist unserer tafel, bei der läufigen wiederkelır der negationen, das linter: in albo proposita nicht zu entbehrende non vergessen laben".

Nach der schönen entdeckung von Savigny ${ }^{152}$ ), dass dieses gesetz nichts anderes sei, als die Lex Iulia municipalis vom $\mathrm{j}$. 709 , ist die enge beziehung desselben auf die reform der frumentationen durch Caesar im j. 708 nicht zu verkennen (vgl. Savigny a. o. p. 375); über die professio hat Savigny jedoch keine neue

153) Vermischte schriften III p. 279-412: der römische volksschluss der tafel von Heraclea, mit zwei nachtragen. 
ansicht aufgestellt, sondern erklärt sie (p. 377) ähnlich wie Mazocbi: „von denjenigen aber, die nicht dürftig genug zum empfang befunden wurden, sollten listen aufgenommen und öffentlich ausgestellt werden".

Mommsen (Tribus p. 190 a. 40) erkennt dagegen darin die non recensi bei Sueton. Caesar c. 41: instituit quotannis in demortuorum locum ex iis, qui recensi non essent, subsortitio a practore fieret, $d$. $h$. die berechtigten expectanten; dieselbe ansicht hat er im Corpus inscr. Lat. I p. 124 wiederholt und Rein (in Pauly's R. E. IV p. 779), Nasse (a. o. p. 22) und Marquardt (a. o. p. 97 a. 458) haben ihm beigestimmt; dagegen hat sich Nipperdey (die Leges annales p. 20 a. 6) erklärt, der, wie Dirksen, annimmt, dass non ausgefallen sei ${ }^{153}$ ); er glaubt dieses und älınliche verselıen dadurch motivireu zu können, dass „wir es nur mit der sammlung eines privatmannes zu' thun haben".

Gegen alle hier aufgezählten erklärungsversuche sind, wie ich glaube mit recht, gewichtige bedenken geltend gemacht worden: vor allem wird man sich zu der annahme von Dirksen, dass gerade das wichtigste wort, non, ausgefallen sei, gewiss nur mit grossem widerstreben verstehen können; es kommt ferner dazu, dass die listen der getraideempfänger schon im j. 708 angefertigt und abgeschlossen waren und zwar nicht durch einzelne professionen bei einem magistrate, sondern durch einen vicatim abgehaltenen recensus: ein verfahren, das sich als practisch erwiesen haben muss, da es August im j. 752 ebenfalls einschlug. Gegen Mommsen's beziehung auf die expectantenliste scheint mir vorzüglich zu sprechen, dass die bestimmung: wer auf dieser liste stände, solle kein getraide empfangen, ganz unnöthig ist, da überhaupt nur diejenigen getraide empfangen konnten, die auf den im j. 708 augefertigten listen verzeichnet waren ${ }^{154}$ ). Es ist mir aber überhaupt wahrscheinlich, dass diese meldung sich nicht ausschliesslich auf die frumeutationen bezieht, wenn sie auch mit denselben im engsten causalen zusammenhange stehen muss; dafür sprechen folgende gründe :

1) Die professio richtet sich an den consul oder wenn dieser

153) Ebenso Goettling: 15 römische urkunden p. 62 ; s. dagegen Zumpt Comment. Epigr. I p. 85 anm.

154) Das hat schon Nipperdey a. o. hervorgehoben. 
abwesend ist, an die prätoren und volkstribunen; hätte dieselbe sich nur auf die berechtigung zu den getraidevertheilungen bezogen, so wäre es natürlicher und einfacher gewesen, sie direct dem magistrate, der die frumentationen leitete, zu machen.

2) Die meldung wird zuerst eingetragen in tabulas publicas (vgl. Dirksen a. o. p. 197) und daraus in tabulam in album, bebufs eines öffentlichen anschlages, und zwar soll dieses album auf dem forum und bei getraidevertheilungen an dem orte, wo dieselben stațtfinden, ausgeliängt werden. Es sind dies so umständliche maassregeln, besonders die doppelte ausstellung des album an verschiedenen orten, dass die gewölınliche annahme mir zur erklärung dieses verfalırens nicht auszureichen scheint.

3) Die meldungen geschehen auch von pupilli und pupillae; ist es nun auch denkbar, dass schon zu Caesar's zeit knaben zu den regelmässigen getraideempfängern gelıörten, obgleich wir diese ansicht nicht theileu (s. ob.), so kann dies von mädchen oder frauen gewiss nicht zugegeben sverden, da dieselben auch von den congiarien in der kaiserzeit ausgeschlossen waren (vgl. Dositheus Adriani sententiae n. 14); ja selbst zu den alimentationen in Rom, die ebenfalls in einer getraidevertheilung bestanden, liess noch Traian nur knaben zu (s. ob.).

-Wir werden demnach annelimen müssen, dass die in frage stehende professio allgemeinerer art war und nur als wichtigste consequenz die ausschliessung von den frumentationen bewirkte: es muss eine anzeige gewesen sein, welche zugleich manifestirte, dass der betreffende eins der erfordernisse nicht melır besass, die zu dem empfange des getraides obligatorisch waren. Es sind dies aber, wie wir oben hervorgehoben liaben, folgende:

1) besitz des vollen römischen bürgerrechtes;

2) ansässigkeit in Rom;

3) vielleicht die zugehörigkeit zur plebs d. h. der besitz eines vermögens unter $400,000 \mathrm{HS}$; obgleich es nicht zu erweisen ist, dass ritter und senatoren gesetzlich von den frumentationen ansgeschlossen waren.

Dass die professio, von der die Lex Inlia municipalis landelt, nicht den verlust des bürgerrechtes zum gegenstande haben konnte, bedarf wohl keines beweises; auch die bezielıng auf die erlan- 
gung des ritterlichen census ist schwerlich statthaft, da hierfür der consul bzw. prätoren und volkstribunen nicht die competente behörde waren, sondern damals noch die censur gesetzlich nicht aufgehoben war. Ich bin daher der überzeugung, dass die meldung auf diejenigen geht, welche ilır domicil von Rom nach einem anderen orte verlegten. Es ist sicher, dass jeder, der nach Rom zog, eine derartige anzeige machen musste ${ }^{155}$ ) und olne zweifel fand dasselbe statt, wenn jemand sein domicil in Rom aufgab: gerade zu Caesar's zeit, der so zalılreiche bürgerkolonieen ausfïhrte, war sine derartige controle doppelt nothwendig. Eine der wichtigsten folgen dieser aufgabe des domicil's war aber die ausschliessung von den öffentlichen spenden: den frumentationen und den congiarien ${ }^{150}$ ); nur durch die genaue verzeichnung der von Rom fortziehenden bürger konnte vermieden werden, dass diese etwa bei temporärem aufenthalte in Rom oder hauptsächlich durch dolose stellung von substituten fernerhin getraide empfingen und nur so konnte eine sofortige besetzung der vacanten platze ermöglicht werden.

Ist die von uns versuchte erklärung richtig, so wïrde dieselbe auch für die annahme sprechen, dass die tabula Heracleensis weder eine lex satura, noch eine gesetzsammlung enthält, sondern ein einziges auf die municipien sich beziehendes gesetz, „wenn auch manche bestimmungen desselben nicht die municipien ausschliesslich betreffen" (Puclita Institutionen I p. 396). Es gingen vielleicht in dem verlorenen anfange ausser anderen municipalen verordnungen (vgl. Mlommsen : C. I. L. I p. 124) die bestimmungen über die verlegung des domicils von den municipien nach Rom vorher, denen sich die uns erhaltenen anschliessen; es folgen polizeiverordnungen, gültig für Rom und vielleicht zugleich für die municipien (Puchta a: o.) und endlich die bestimmungen rein municipaler natur.- Jedoch kann

155) Cic. p. Arch. p. IV, 9: an domicilium Romae non habuit is, qui tot annis ante civitatem datam sedem omnium rerum ac fortunarum suarum Romae conlocavit? at $n$ on est professus. immo vero eis ta$b u l$ lis professus, quae solae ex illa professione conlegioque praelorum obtinent publicarum tabularum auctoritatem, vgl. ebend. c. IV, 8. $7-8$.

156) Ueber die nothwendigkeit des domicils zu diesen largitionen ist kein zweifel (vgl. Marquardt a. o. p. 98); noch Cassiodor (vgl. Contareni a. o. p. 55) sagt: neque enim fas est, ut qui urbis affectum domicilii indicio monstrare neglexerint, cius commodis perfruantur. 
man nicht leugnen, dass dieser complex verschiedenartiger verordnungen in einem gesetze immerlin selır eigenthümlich bleibt und olıne zweifel müssen es ausserordentliche umstände gewesen sein, die Caesar zu dieser art der abfassung bestimmt haben.

\section{2) Wann hat Seneca die schrift de brevitate vitae verfasst?}

Die schrift des Seneca de brevitate vitae ist an einen Paulinus gericlitet; genannt wird darin nur das cognomen, doch macht der umstand, dass die zweite frau des Seneca Pompeia Paulina liess (Tacit. A. 15, 60), also- sicherlich die tochter des Pompeius Paulinus war, es fast zweifellos, dass Pompeius Paulinus gemeint ist ${ }^{157}$ ) (vgl. Nipperdey zu Tacit. A. 13, 53). Derselbe war, wie Tacitus angiebt (A. 13, 53), im jalıre 58 mit $\mathrm{L}$. Vetus befehlshaber in Germanien und jedenfalls vor dem jalıre 62 consul (suffectus), denn zu diesem jalıre berichtet Tacitus (A. 15, 18): tris deinde consulares L. Pisonem, Ducenium Geminum, Pompeium Paulinum, vectigalibus publicis praeposuit. Nipperdey bezieht auf dieses amt, da „das wesentliclsste dieser abgaben die naturalabgaben von getraide waren", die anspielungen in der genannten schrift des Seneca, und glaubt daher, dass dieselbe im jalıre 62 oder einem der nächsten zwei jahre abgefasst sei. Dass die ansicht unrichtig ist, kann bei reiner genaueren prüfung der worte Seneca's nicht zweifellaft sein, denn alle die ausdrücke, die Seneca zur bezeichnung des von Paulinus bekleideten antes gebrauclit, passen auf kein anderes amt, als die praefectura annonae (s. ob.). Es kommt aber ausserdem ein sehr gewichtiger grund linzu, die schrift nicht in oder nach 62 zu setzen. Seneca sagt nämlich in dem merkwürdigen 13 ten capitel bei der verspottung antiquarischer grübeleien: hoc scire magis prodest, quam Aventinum montem extra pomerium esse, ut ille adfurmabat, propter alteram ex duabus causis, aut quod plebs eo secessisset, aut quod Remo auspicante illo loco aves non addixissent, Schon Nibby

157) Bekannt ist aus dieser zeit noch C. Suetonius Paulinus, consul 66 a. Chr. (Henzen 6767. Dio 63,.1. Tacit. A. 16, 14 und dazu Nipperdey); etwas später Valerius Paulinus procurator Galliae Narbonensis im j. 70 n. Chr. (Tacit. H. III, 42 f.), wahrscheinlich identisch mit Paulinus praefectus Aegypti im j. 72 (Joseph. B. J. VII, 10, 4); die uns bekannten Lollii Paulini fallen theils früher, theils später. 
(Roma antica I p. 100) hat daraus mit recht gefolgert, dass die schrift vor 50 n. Chr. abgefasst sein müsse, da Claudius in diesem jahre ${ }^{158}$ ) den Aventin in das pomeriuu aufgenommen habe (Tacit. A. 12, 23 vgl. Gellius 13, 14, 7). Erinnert man sich nun, dass Turranius noch im october des j. 48 praefectus annonae - (Tacit. A. XI, 31: Messalina . . . . adulto auctumno simulacrum vindemiac per domum celebrabat, mit anm. von Lipsius) war, so leuchtet ein, dass Paulinus sein unmittelbarer nacbfolger sein musste und es kann kein zweifel bleiben, dass der antsantritt des Paulinus ${ }^{159}$ ), wie die abfassung der schrift de brevitate vitae nach dem october 48 und vor den 24 . januar 50 fallt ${ }^{160}$ ). Dadurch bekommt die erwähnung des Turranius (praeterive quod milbi occurrit exemplum non possum: Turamius (s. ob.) fuit exactae diligentiae senex) erst die rechte bedeutung und die eigenthümliche bespreclung des pomerium und des Aventins wird leicht erklärlich, wenn die beabsichtigte aufnahme desselben in das pomerium so nahe bevorstand; ja man kann vielleicht geradezu annehmen, dass die ganze heftige und malitiöse invective gegen antiquarische spielereien auf den kaiser Claudius gemünzt ist, dem Seneca trotz seiner zurückberufung sein achtjähriges exil nie verziehen hat. Es ist fraglich, ob die schrift überhaupt zur sofortigen veröffentlichung bestimmt war; in jedem falle musste aber Seneca natürlich zu deutliche anspielungen vermeiden, um nicht den so schwer besänftigten groll des kaisers wieder zu erwecken.

158) Diese erweiterung des pomerium fallt vielmehr schon in das j. 49, zu dem Tacitus a. 0 . davon berichtet vgl. Orelli 710: Ti. Claudius . . . . trib. pol. $\overline{V I I I I}$. imp. $X \bar{V} I$. cos. $\overline{I I I}$. . . . pomerium ampliavit lerminatilq(ue); die neunte tribunicia potestas des Claudius dauerte aber vom 25. januar 49 bis zum 24. jannuar 50; auch Clinton setzt dies ereigniss richtig in das $j .49$.

159) Leute aus dem ritterstande wurden nach bekleidung procuratorischer ämter nicht selten zu senatorischen würden und zum consulate befördert; dass Pompeius Paulinus der sohn eines rồmischen ritters aus Arelate war, bezeugt übrigens ausdrücklich Plinius n. h. 33, 11,143 .

160) Auch Lehmann (Philologus VIII p. 315 und: Claudius und Nero p. 12) setzt die schrift in das j. $49 \mathrm{n}$. Chr., weil Seneca erst in diesem jahre aus Corsica zurückkehrte.

Göttingen.

Otto Hirschfeld. 